\title{
Air-Side Velocity Distribution in Finned-Tube Heat Exchangers
}

David A. Yashar

Hong Hyun Cho

U.S. DEPARTMENT OF COMMERCE National Institute of Standards and Technology Building Environment Division Building and Fire Research Laboratory Gaithersburg, Maryland 20899-8631

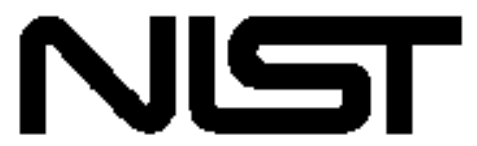

National Institute of Standards and Technology United States Department of Commerce 



\section{Air-Side Velocity Distribution in Finned-Tube Heat Exchangers}

David A. Yashar

Hong Hyun Cho

U.S. DEPARTMENT OF COMMERCE National Institute of Standards and Technology Building Environment Division Building and Fire Research Laboratory Gaithersburg, Maryland 20899-8631

December 2007

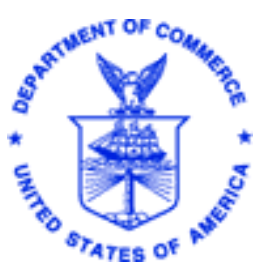

U.S. DEPARTMENT OF COMMERCE Carlos M. Gutierrez, Secretary National Institute of Standards and Technology James Turner, Acting Director 



\begin{abstract}
The performance of finned tube heat exchangers is greatly affected by the distribution of the air that passes through it. The air side velocity distribution for finned-tube heat exchangers in residential air conditioning installations is not very well documented today because it is difficult to measure accurately. In this study, we examined the air velocity distribution approaching finned-tube heat exchangers under three different common installation configurations. To this end we used a novel, laser based technique called Particle Image Velocimetry (PIV) to measure the velocity profile. The heat exchangers examined in this study were a vertically oriented single-slab coil, a single slab coil placed at an angle of $65^{\circ}$ to the duct wall, and a two slab AShaped coil with a $34^{\circ}$ apex angle.
\end{abstract}

The measurement results show that the velocity profile for any configuration is strongly influenced by the features within the duct and the orientation of the heat exchanger, and therefore each installation configuration has its own unique velocity distribution. The information presented here documents the magnitude and type of this mal-distribution realized in these systems, what features caused it, and which regions were most affected.

Computational Fluid Dynamics (CFD) simulations were carried out to simulate the air flow through the test subjects used for the PIV measurements. We employed momentum resistance models to simplify the computational domains and reduce computer time. Our simulation results showed good agreement with the measured velocity profiles in each case. This work suggests that CFD can be accurately applied as a tool to determine the velocity profile. CFD is preferred to laboratory experimentation because of its speed and simplicity.

Keywords: Air Conditioning, Air Velocity Profile, Computational Fluid Dynamics (CFD), finned-tube heat exchanger, Particle Image Velocimetry (PIV) 


\section{Acknowledgements}

Dr. Rodney Bryant of the Fire Research Laboratory provided vital input and equipment for the particle image velocimetry measurements taken in this study. Dr. Piotr Domanski and Dr. W. Vance Payne assisted with formulating the scope of this project and designing the test apparatus. Mr. John Wamsley assisted by building the test setup and constructing the ducted coil test sections. The authors would also like to thank Mr. Brian Dougherty of NIST and Mr. Dutch Uselton of Lennox Industries for reviewing the draft of this report. Finally the authors greatly appreciate the guidance and support provided by Michael Raymond of DOE’s Office of Building Technology, State and Community Programs. 


\section{Table of Contents}

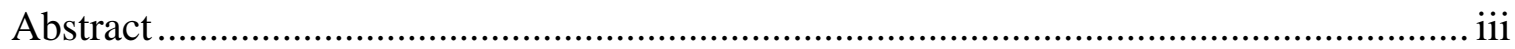

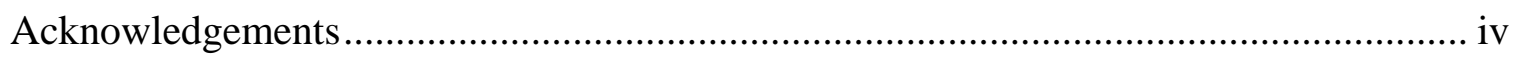

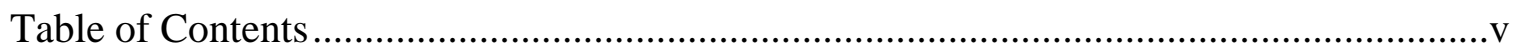

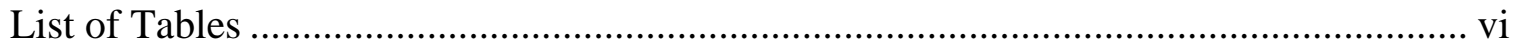

List of Figures ................................................................................................ vii

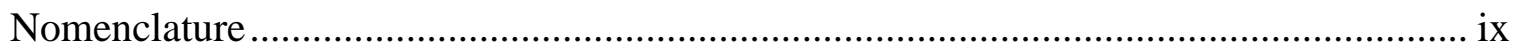

Nomenclature: Greek and other Symbols .................................................................

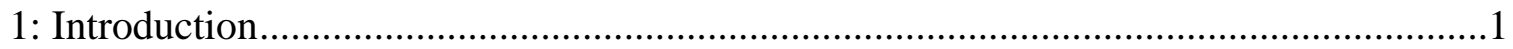

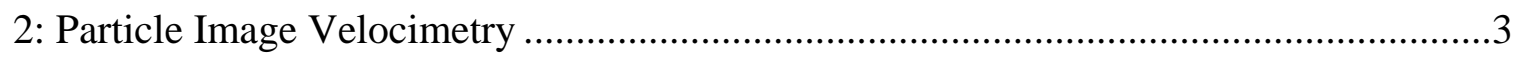

3: Experimental Air Flow Apparatus ..........................................................................6

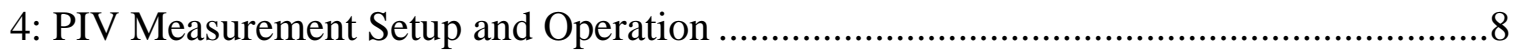

5: PIV Measurement Results and Discussion ..................................................................13

5.1 Single Slab Vertical Coil .................................................................................13

5.2 Slant Coil .......................................................................................................

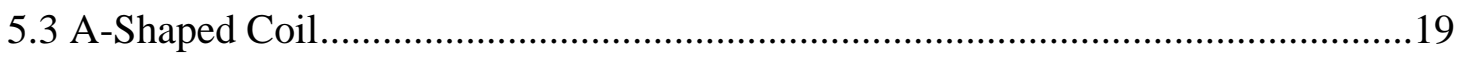

6: Computer Based Simulation Results and Discussion ...................................................26

6.1 Single Slab Vertical Coil ......................................................................................

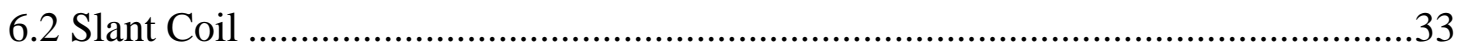

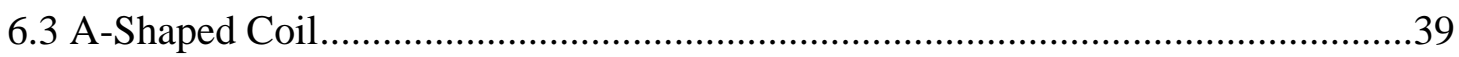

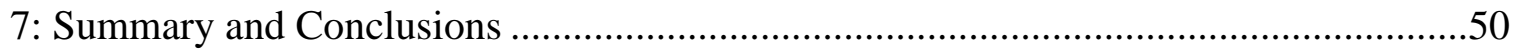

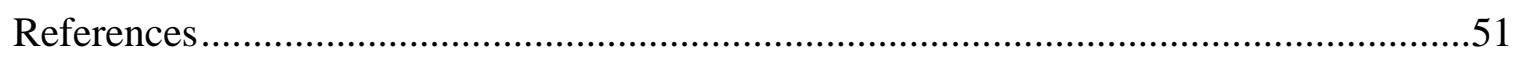

Appendix A: Pressure Drop Data for Flow Resistance Coefficients .................................52

Appendix B: Uncertainty Analysis .............................................................................54

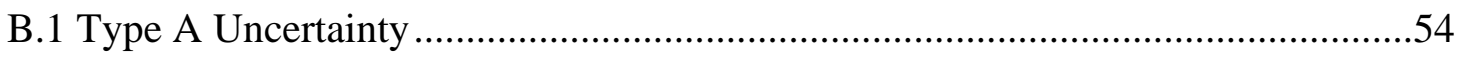

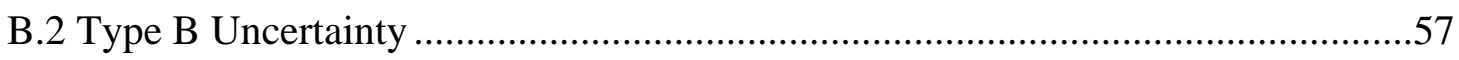




\section{List of Tables}

A.1 Data used to Determine Momentum Resistance Coefficients for Vertical Coil .........52

A.2 Data used to Determine Momentum Resistance Coefficients for Slant Coil..............52

A.3 Data used to Determine Momentum Resistance Coefficients for A-Shaped Coil ......53

B.1.1 Type A Uncertainty for Vertical Coil .............................................................55

B.1.2 Type A Uncertainty for Slant Coil .................................................................56

B.1.3 Type A Uncertainty for A-Shaped Coil ..........................................................56

B.2.1 Type B Uncertainty for Vertical Coil...............................................................57

B.2.2 Type B Uncertainty for Slant Coil ...............................................................58

B.2.3 Type B Uncertainty for A-Shaped Coil............................................................58 


\section{List of Figures}

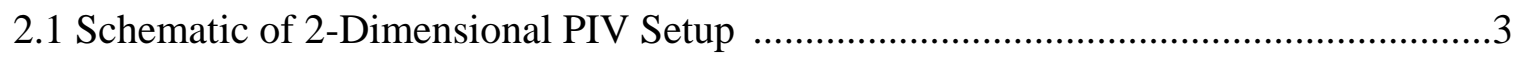

2.2 Cross Correlation Method for Evaluation of PIV Recordings ......................................5

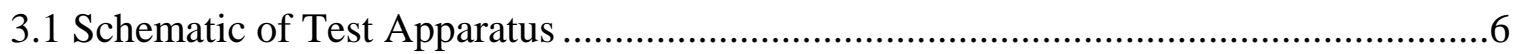

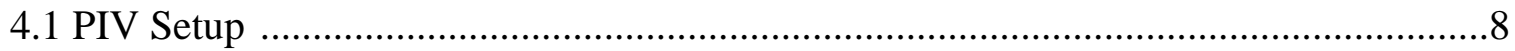

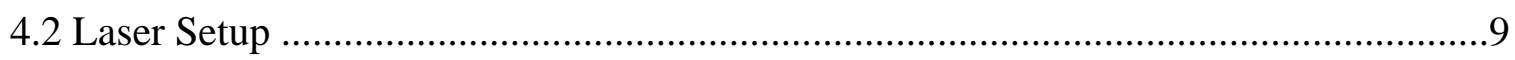

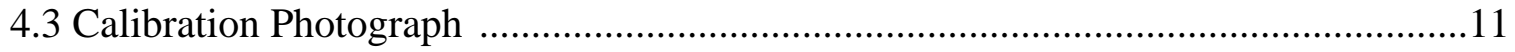

5.1.1 Measurement Location and Equipment Placement..............................................14

5.1.2 Piecewise Illustration of Measured Vector Fields for Vertical Coil .......................14

5.1.3 Two Dimensional Representation of Approach Velocity for Vertical Coil ............15

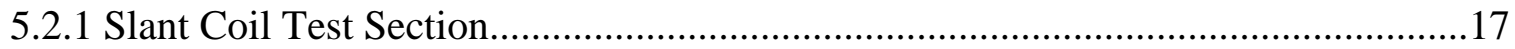

5.2.2 Velocity Profile at Midpoint for Slant Coil .......................................................18

5.2.3 Two Dimensional Representation of Approach Velocity for Slant Coil ................19

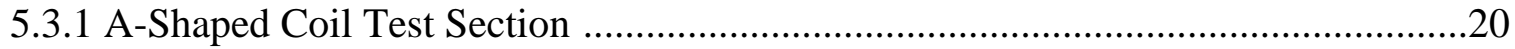

5.3.2 PIV Data Image File - A-Coil Entrance .......................................................22

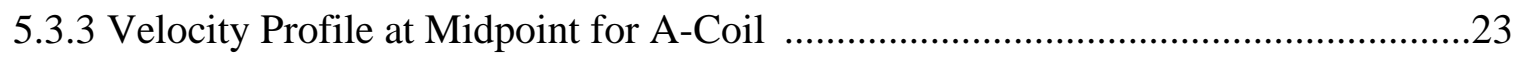

5.3.4 A-Coil Recirculation Zone...........................................................................24

5.3.5 Two Dimensional Representation of Approach Velocity for A-Shaped Coil .........24

6.1.1 Test Section Sketch with Computational Domain Outline ..................................27

6.1.2 Computational Domain for Vertical Coil ........................................................28

6.1.3 Stream-Wise Velocity Component for Simulation with Different

Number of Nodes per Line - Vertical Coil.........................................................31

6.1.4 Approach Velocity Profile for Vertical Coil .......................................................32

6.1.5 Pressure Profile in a Duct for Vertical Coil .........................................................32

6.1.6 Comparison of PIV and CFD Data for Vertical Coil...........................................33

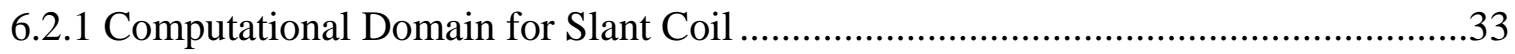

6.2.2 Stream-Wise Velocity Component for Simulation with Different

Number of Nodes per Line - Slant Coil ...........................................................37

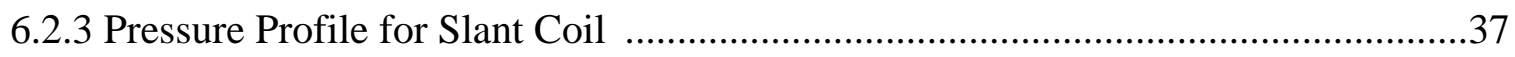

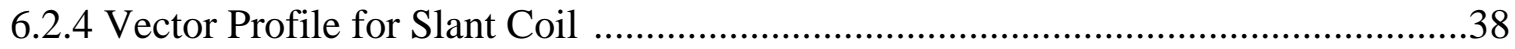

6.2.5 Comparison of PIV and CFD Data for Slant Coil .............................................39 
6.3.1 Computational Domain for A-Shaped Coil ..................................................................39

6.3.2 Blowup of Computational Domain for A-Shaped Coil .............................................40

6.3.3 Stream-Wise Velocity Component for Simulation with Different

Number of Nodes per Line - A-Shaped Coil............................................................43

6.3.4 Pressure Profile for A-Shaped Coil.............................................................................44

6.3.5 Vector Profile for A-Shaped Coil .......................................................................45

6.3.6 CFD Resolution of Recirculation Zone ................................................................46

6.3.7 Computational Domain Sections ...............................................................................46

6.3.8 CFD Velocity Profile at A-Shaped Coil Inlet ..........................................................47

6.3.9 Comparison of PIV Data with CFD Coil Inlet Data for A-Shaped Coil ...................48

6.3.10 Comparison of PIV Data with all Data from CFD

Computational Sub-Domain IV for A-Shaped Coil ..............................................49 


\section{Nomenclature}

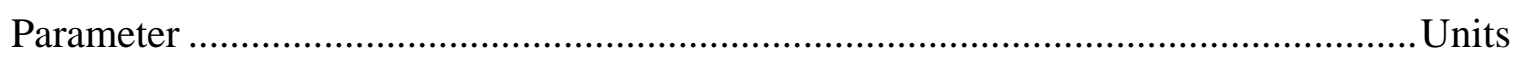

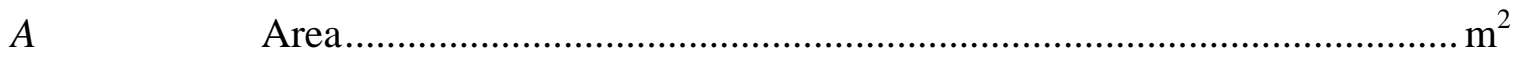

$C_{l} \quad$ Intermediate Linear Momentum Resistance Coefficient .................. kg $/ \mathrm{m}^{3} \mathrm{~s}$

$C_{q} \quad$ Intermediate Quadratic Momentum Resistance Coefficient................. kg $/ \mathrm{m}^{4}$

$D_{h} \quad$ Hydraulic Diameter........................................................................ $\mathrm{m}$

I Turbulence Intensity ...................................................................

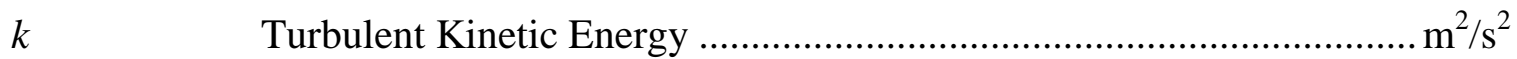

$K_{l} \quad$ Linear Momentum Resistance Coefficient ............................................1/s

$K_{q} \quad$ Quadratic Momentum Resistance Coefficient .................................... 1/m

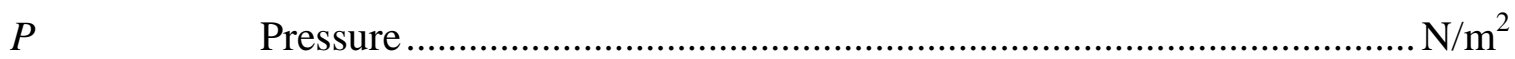

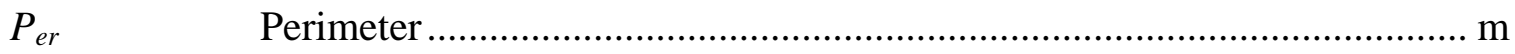

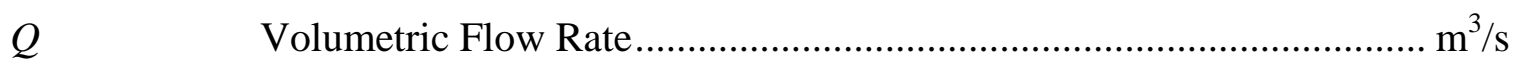

Re Reynolds Number ............................................................ dimensionless

$u \quad$ Component of velocity parallel to main flow direction .........................m/s

$v \quad$ Component of velocity perpendicular to main flow direction .................m/s

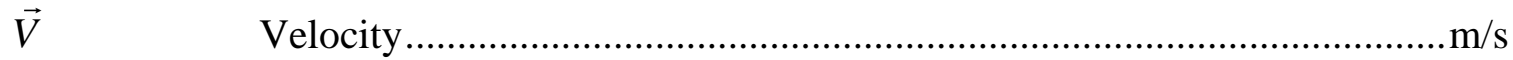




\section{Nomenclature: Greek Symbols}

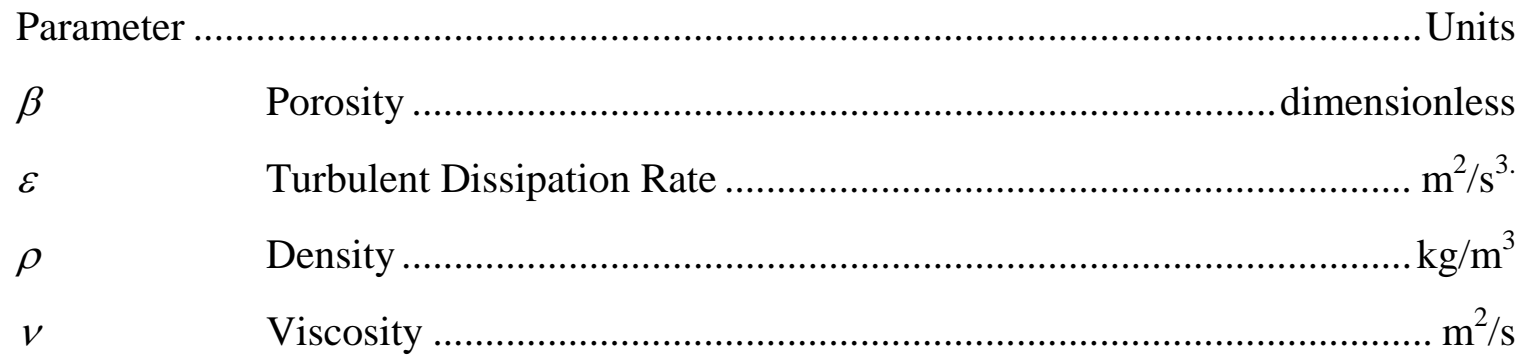




\section{1: Introduction}

Air-to-refrigerant finned-tube heat exchangers are the predominant type of heat exchangers used in comfort cooling and commercial refrigeration applications. An air-torefrigerant finned-tube heat exchanger is made up of a series of parallel, straight tubes that are connected to each other. Therefore, the refrigerant passing through the heat exchanger will flow back and forth through the tube bank, i.e. in one direction through one tube and return through another tube. Air flows through the heat exchanger in a direction perpendicular to the tubes in the bank. It passes through the heat exchanger by maneuvering through the spaces between adjacent tubes, and thereby exchanges thermal energy with the refrigerant in each of the tubes. In order to improve the heat transfer between the air and refrigerant, sheets of thermally conductive material, i.e. fins, are used to extend the tube surfaces. These fins are stacked along the length of the tubes, parallel to each other.

Designing a highly efficient refrigerant-to-air heat exchanger is a very difficult task. In essence, a finned-tube heat exchanger can be described as a number of single tube, air-torefrigerant, cross-flow heat exchangers. Each of these tubes, however, is connected to other tubes within the heat exchanger; therefore, the parameters associated with the heat transfer coefficient of refrigerant flowing in any tube are influenced by the occurrences in tubes that are connected upstream and downstream. To complicate the analysis, the tube banks are generally layered in multiple rows. Therefore, the air will pass around one tube and onto subsequent tubes in consecutive depth rows. The thermophysical properties of the air will therefore be different at each location because of the energy exchange with the previous tube. To complicate the analysis even further still, the velocity of the air approaching a heat exchanger can be vastly different between any two locations within the heat exchanger.

The heat exchange occurring at each tube changes the thermodynamic and transport properties of the refrigerant and the air; therefore, the performance of each tube is dependent on that of all of the other tubes in some way. Our ability to understand the performance of a finned-tube heat exchanger is therefore dependent on our ability to understand the performance of each tube. Since the problem is interconnected in this manner, it is somewhat difficult; but the thermodynamic and transport properties governing the heat exchanger performance can be calculated using computer simulations with a software tool such as EVAP-COND [Domanski, 2007]. The approach air velocity profile, however, is a very influential parameter which must be known prior to simulating the heat exchanger's performance. The influence of the velocity profile on a heat exchanger's performance can be quite large; one study showed that altering the velocity profile can reduce a heat exchanger's capacity by as much as $30 \%$ [Payne and Domanski, 2003]. Another related study [Domanski et. al., 2004] showed that nearly all of the capacity reduction due to non-uniformities in the velocity profile can be recuperated by simply redesigning the tube-to-tube connection sequence. To date, unfortunately, the air side velocity profile is largely left undetermined because it is difficult to measure accurately, and because the problem is so complex there is little understanding of the most effective way to use this information. The latter is rapidly becoming less of an issue through advancements in design software. 
In the late 1980's, researchers at the National Institute of Standards and Technology used smoke injection to qualitatively evaluate air flow fields in the vicinity of installed finnedtube heat exchangers [Chwalowski et. al., 1987]. They also measured air velocity using a traversing pitot tube and showed the air distribution to be highly non-uniform. Although those efforts laid the groundwork for the current study, the methods available at that time were rather crude compared to what is available today. The historically available measurement tools (pitot tubes, hot-wire anemometers, rotating vane anemometers, etc.) are all inadequate for this application because the device must be placed within, and properly oriented to, the locality of interest. Such placement is difficult if not impossible. Furthermore, the devices themselves interfere with the flow that is being measured.

Current measurement technology has brought about a number of highly accurate, laserbased, non-intrusive options to characterize the air velocity profile of a heat exchanger's approach flow field. In particular, Planar Laser Induced Fluorescence (PLIF), Laser Doppler Velocimetry (LDV) and Particle Image Velocimetry (PIV) all present possible options. Each of these methods is in some way based on laser interaction with some type of particle that is entrained in the flow, called seed particles. For PLIF, lasers are used to excite the seed particles, and flow velocity is inferred from the fluorescence captured by imaging cameras [Seitzman and Hanson, 1993]. Although this method is very accurate, it is relatively complicated and requires a substantial equipment investment. LDV infers velocity information based on the measured Doppler frequency shift; LDV is typically a single point measurement [Durst et. al., 1976]. The study presented in this report focuses on PIV, which uses a laser sheet to illuminate a single plane within the flow field, and a synchronized camera to track the motion of particles.

The ultimate goal of this study is to measure and characterize the velocity distribution of air approaching 3 typical finned-tube heat exchanger configurations. The information obtained in these measurements is used to develop Computational Fluid Dynamics (CFD) models of these installations. The goal is to provide design engineers with verified CFD models and methodologies that can be used to predict the flow fields associated with similar situations. More efficient finned-tube heat exchangers can therefore be designed by incorporating features that capitalize on the specific air flow distribution. 


\section{2: Particle Image Velocimetry}

PIV is an optically based measurement technique used to obtain flow distributions across entire flow fields. A good overview of the technique is presented in [Adrian, 1991]. It is very attractive for the application at hand because it is not intrusive and provides very accurate measurements. The drawbacks of this technique are the cost of equipment and the safety hazards resulting from working with lasers. The simplest method of 2Dimensional PIV was used in this study, and therefore the discussion is limited to this application. Figure 2.1 shows a schematic of the basic 2D PIV setup.

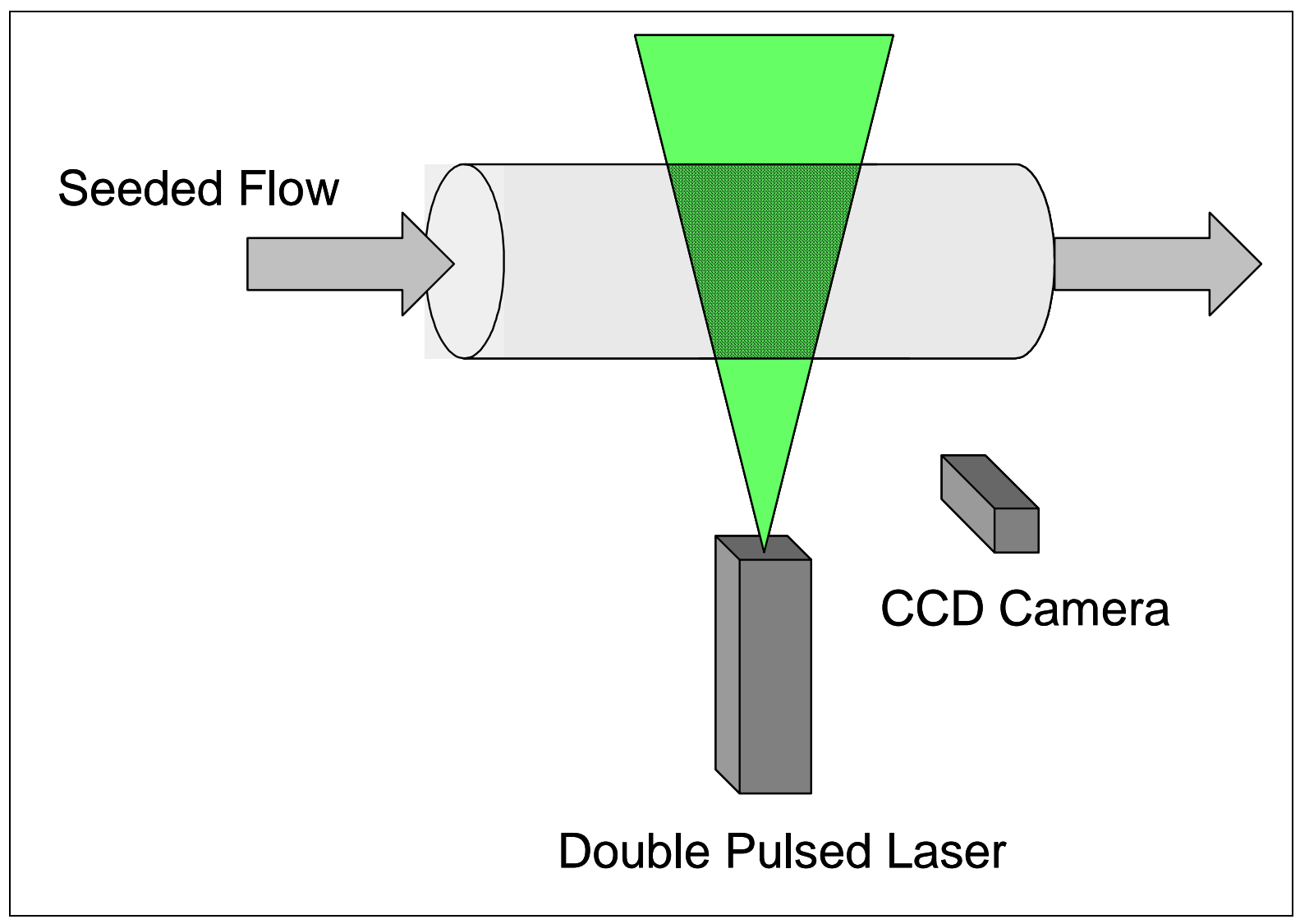

Figure 2.1 Schematic of 2-Dimensional PIV Setup

PIV works on the basis of tracking the motion of particles entrained in the flow field. In order for PIV to work particles must be dispersed into the flow. These particles, called seed particles or tracer particles, provide markers within the flow field whose displacement can be mapped between two points in time. As the seed particles move through the test section they are illuminated by a series of laser light sheets. These laser sheets are generated by spreading laser light beams through a divergence optical lens. The laser sheets are oriented in such a manner that the illuminated plane is aligned to the main flow direction within the test section. A Charge Coupled Device (CCD) camera is used to capture images within the illuminated plane and therefore records the location of the seed particles. Velocity information is calculated from the displacement of particles between consecutive images. 
For this setup, two lasers are required to properly fire the laser sheets with the appropriate temporal spacing. These lasers are mounted together, with the beams emitted from each passing through the same optical lens. This lens distorts the laser beams and spreads them into sheets. In this manner, a set of two identical light sheets can be produced in rapid succession with very accurate timing. Also, the camera used to capture images is a double framed camera. During the acquisition of a data point, the camera captures two image frames coincident with the firing of the lasers. The lasers and camera are all triggered by a Programmable Timing Unit (PTU) through a personal computer.

It is necessary to disperse a well mixed and appropriate quantity of seed particles in the flow. A number of trade-offs exist regarding the selection and disbursement of seed particles. Ideally, these particles should have the same density as the media in which they are entrained. Particles should be selected such that their terminal velocity and response time should be very small compared to the velocity magnitudes expected and the time scales of the flow. The seed particles must be small enough to respond quickly to abrupt changes in the flow, but at the same time they must be large enough to be adequately captured and mapped by the imaging camera. Furthermore, determining the optimal quantity of particles is a bit of an art form. If too many particles are entrained in the flow it becomes difficult to determine the position of individual particles; if not enough particles are present, the results computed from the images become heavily affected by noise. See [Bryant, 2005] for a comprehensive discussion on particle selection.

As mentioned earlier, each image capture is synchronized with a laser sheet pulse and the images are captured in pairs. Therefore, the particle positions that correspond to laser pulse \#1 are recorded in camera frame \#1 and the particle positions that correspond to laser pulse \#2 are recorded in camera frame \#2. These image pairs are transferred to the computer for data storage and processing. Data reduction is a very computationally intensive process.

During the data reduction process, each frame is divided into a number of small square regions, called interrogation windows. It is assumed that all particles within a given interrogation window have moved in the same direction and the same distance between image frames. The data reduction software maps the light intensity over each interrogation window from the first frame and compares these maps to those from the corresponding interrogation windows from the second frame; this method is called crosscorrelation. From this analysis, it probabilistically determines the distance traveled by each particle within the interrogation window. A velocity vector for each interrogation window is then calculated by dividing the average distance by the time delay between the two frames. The velocity vector field is then constructed from the vectors assigned to the interrogation windows. This process is depicted in Figure 2.2. 


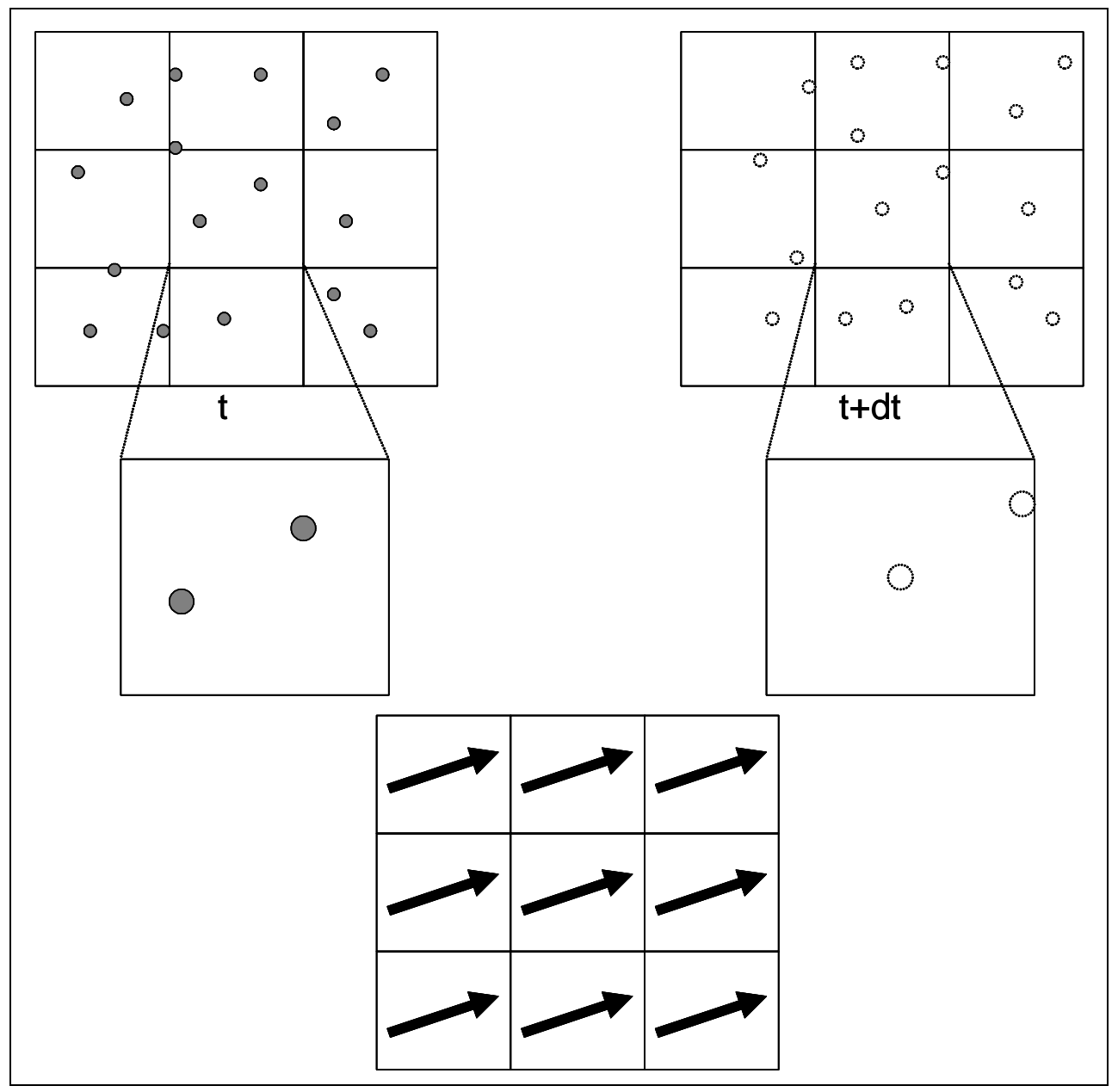

Figure 2.2 Cross Correlation Method for Evaluation of PIV Recordings. 


\section{3: Experimental Air Flow Apparatus}

The objective of this study was to measure the approach air velocity profile of finnedtube heat exchangers under adiabatic conditions. A test apparatus that was capable of delivering a specified air flow rate through a ducted heat exchanger was constructed for this study, Figure 3.1.

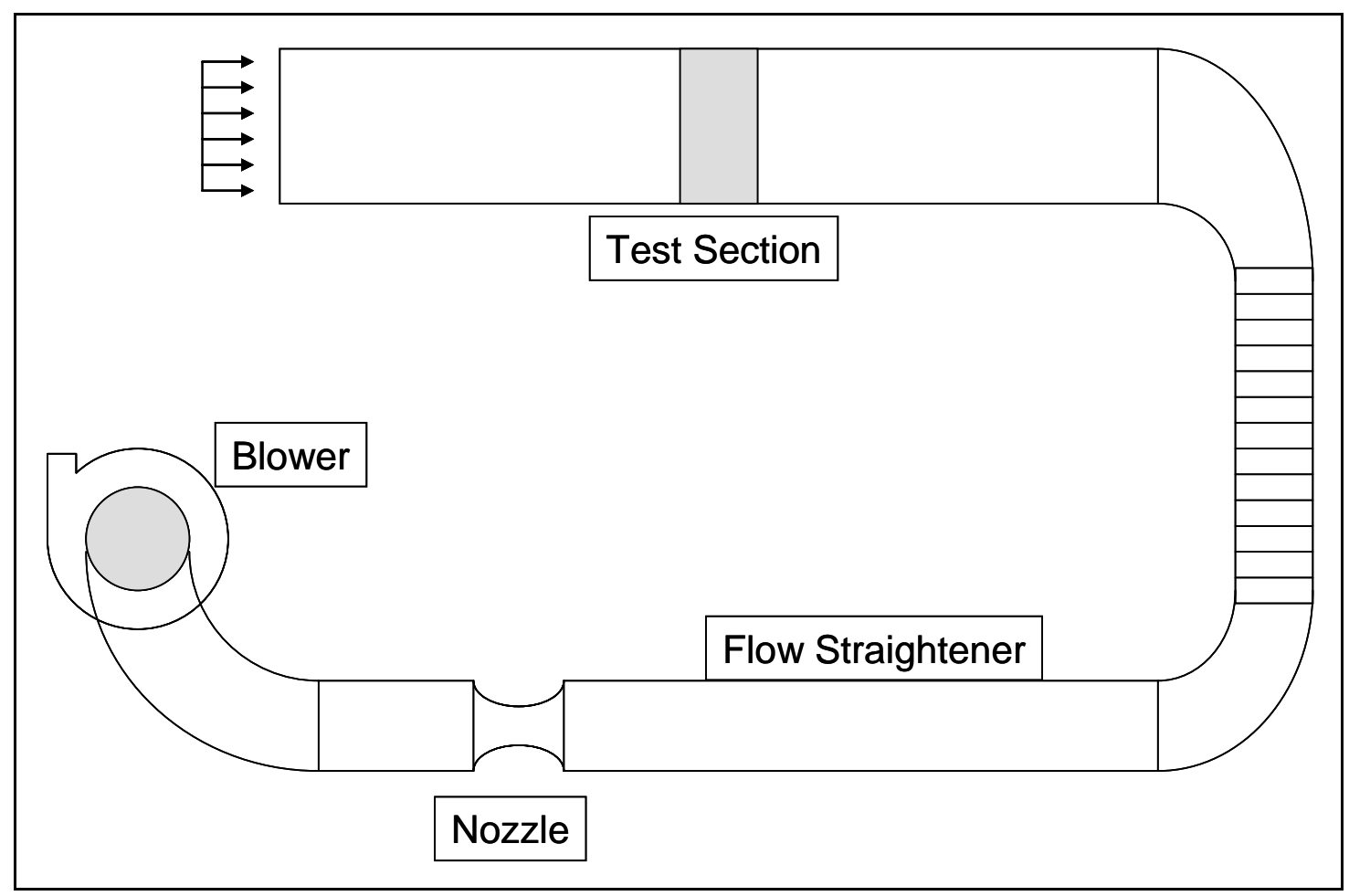

Figure 3.1 Schematic of Test Apparatus

In the test apparatus, air is pulled into the straight duct test section as depicted in the upper left portion of Figure 3.1, and continues clockwise through the apparatus. The view shown is from the top looking downward. There is negligible change in height through the apparatus. The air temperature and dew point are measured using a T-type thermocouple, calibrated to $+/-0.2^{\circ} \mathrm{C}\left(0.36^{\circ} \mathrm{F}\right)$, and chilled mirror hygrometer, calibrated to $+/-1.0^{\circ} \mathrm{C}\left(1.8^{\circ} \mathrm{F}\right)$, positioned near the inlet of the test section. The air then passes through the finned-tube heat exchanger in the test section; the air pressure drop is measured across the heat exchanger using a differential pressure sensor calibrated to $+/$ $0.5 \mathrm{~Pa}$ over the range of ( 0 to 125$) \mathrm{Pa}\left(0.5{ }^{\prime \prime} \mathrm{H}_{2} \mathrm{O}\right)$. After the air exits the test section, it is ducted to a flow straightener and through a venture nozzle where the volumetric flow rate is measured using a differential pressure transducer calibrated to $+/-1 \mathrm{~Pa}$ over the range of (0 to 620) $\mathrm{Pa}\left(2.5 ” \mathrm{H}_{2} \mathrm{O}\right)$. After exiting the nozzle, the air is then drawn through a blower module which is controlled by a variable speed drive, and discharged to the laboratory environment.

The inlet air temperature and the dew point measured at the inlet to the apparatus were used, along with the atmospheric pressure, to calculate the density of the air entering the 
duct. The air density was used along with the pressure difference between the venturi inlet and throat to calculate the volumetric flow rate.

The ducting configuration conformed to ANSI/ASHRAE Standard 37 [1998], with the exception that no refrigerant line connections were made to the heat exchanger since we are only examining the adiabatic case. The test section was made out of clear plexiglass to allow visual communication between the heat exchanger and the PIV measurement equipment. 


\section{4: PIV Measurement Setup and Operation}

The PIV measurement system was installed around the air flow test apparatus. It consists of four components: a particle generator, a pair of lasers, a double framed CCD camera, and a computer. The layout of these components is depicted in Figure 4.1.

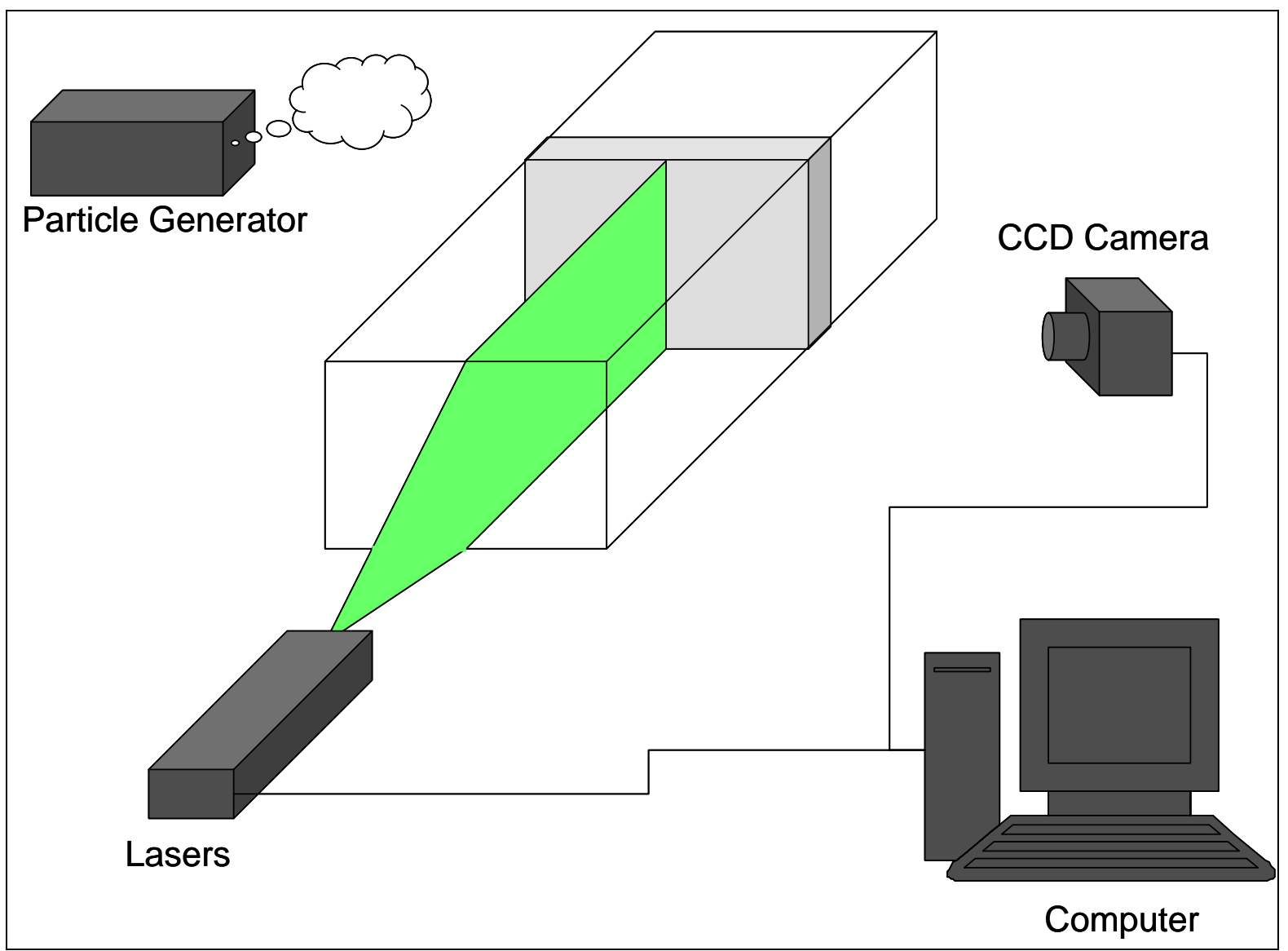

Figure 4.1 PIV Setup

To generate seed particles for the flow measurements, we used a theater style fog generating machine. The entire laboratory environment was filled with non-hazardous particles and the test apparatus drew air from and discharged air to the room. This method generated the particles and allowed them to be well dispersed and mixed with the air flowing through the test section. It is very important to ensure that the fog particles are well mixed with the air so that the dispersion is uniform; poorly dispersed particles result in photographs that are difficult to resolve into vector fields.

The illumination source was the most substantial piece of equipment; we used a pair of solid state lasers (Nd: YAG) for this setup. Using two laser heads allows the lasers to fire a pair of pulses at maximum output energy per pulse within a single flashlamp cycle. The lasers were mounted on top of an electronically controlled positioner, which was itself mounted onto an industrial strength tripod. The lasers were located in front of the test section inlet, oriented such that the lasers were aimed downstream into the test section, aligned with the main air flow direction. The laser beams were passed through 
beam combining optics, which received light from both laser sources and discharged them to a single location and direction. The beams then passed through a divergence lens to form them into sheets. These sheets formed planes of light that were oriented vertically. A photograph of the assembly consisting of the laser pair, beam combining optics, and sheet forming optics is shown in Figure 4.2.

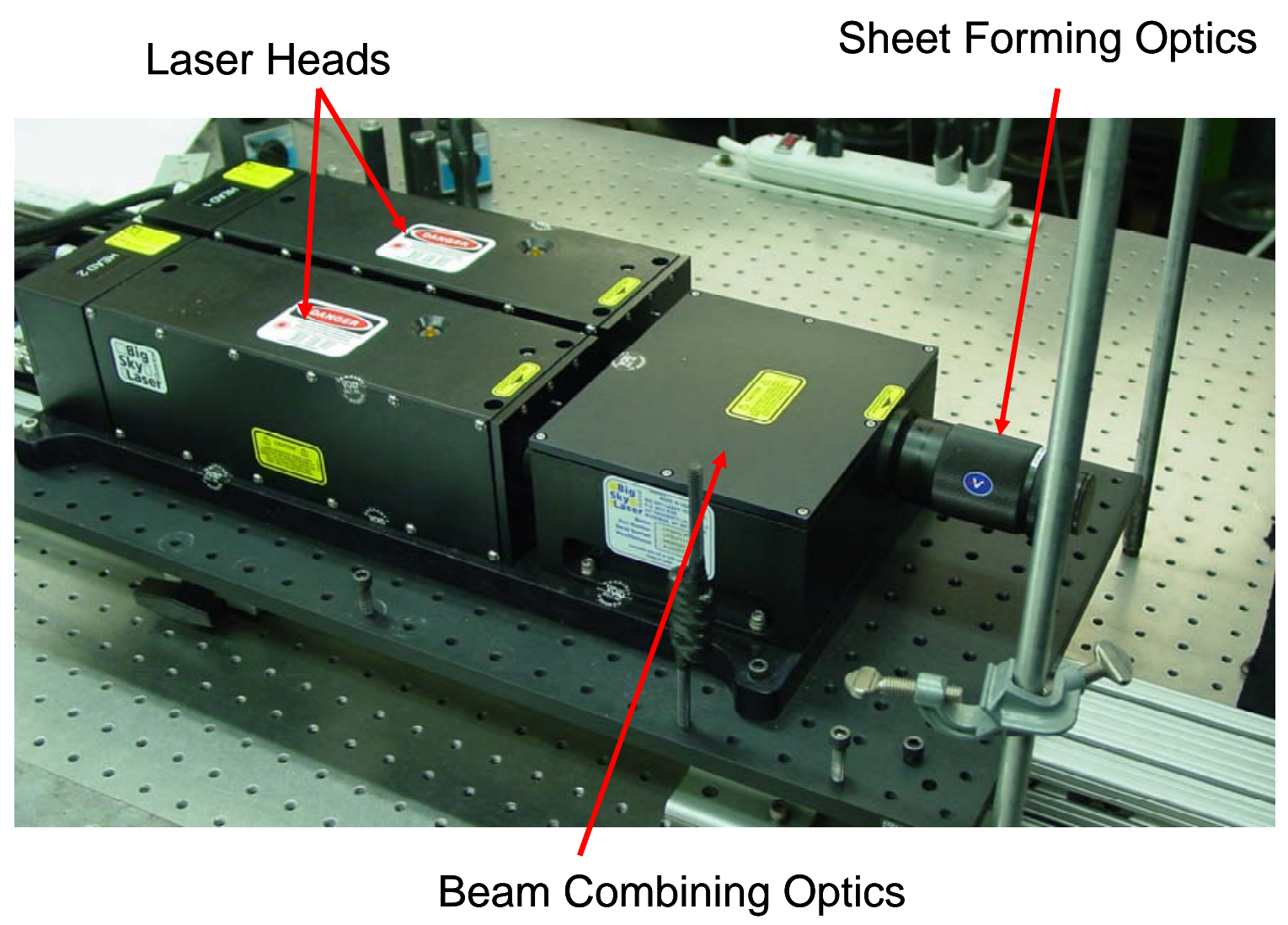

Figure 4.2 Laser Setup

Expanding a laser beam into a sheet over a large area reduces the intensity of the light; therefore this setup required relatively high pulse energy laser beams. We used lasers with pulse energy of $200 \mathrm{~mJ}$, which renders them Class IV lasers under the international laser safety standard, IEC 60825 [2007]. Class IV lasers present safety risks for eye and skin damage as well as being a fire hazard. For this reason the entire test section was covered in heavy black felt to collect all of the laser light, with the exception of a small viewing window used by the CCD camera.

Since PIV requires a pair of images taken in very rapid succession, the camera used in this system had a specialized feature in that it could operate in a double shuttered mode. A CCD camera converts photons to electric charge based on the photoelectric effect. The solid state sensor consists of an array of pixels where electrons are accumulated during exposure. In double shuttered mode, a part of each pixel is masked off and can not be exposed by incident light. When recording a pair of PIV images, the optically sensitive area of each pixel is exposed and the accumulated charge is quickly shifted to the masked area so that the second image can be exposed onto the optically sensitive area. The 
camera that we used for this apparatus can complete this process in 110 ns with pixel resolution of 2 megapixels (1600 X 1200), and has the ability to repeat this process at a rate of $30 \mathrm{~Hz}$.

The camera was mounted onto a tripod located alongside the test section, just upstream of the heat exchanger. The camera was oriented so that it faced a direction normal to the laser sheets generated by the lasers, and perpendicular to the main direction of the air flow. It is important to realize that any light reflections that are recorded by the camera will severely distort the data; therefore, the camera was positioned such that the fins on the heat exchanger were not visible by the camera. Also, objects on the opposite side of the plexiglass duct from the camera were either masked off with black material or painted black to minimize the amount reflected light from these surfaces.

The camera and the lasers were both controlled and synchronized by a Programmable Timing Unit (PTU) installed in a dedicated server operating with two $3.8 \mathrm{GHz}$ processors and 3 GB of random access memory. Although this level of computing power may seem rather excessive to control a data acquisition system by modern standards, it is necessary to operate the PIV system. The PTU requires higher bandwidth PCI busses than can be supported by a standard desktop PC, and the processing power is necessary to handle the very intensive computations involved with the data reduction.

The measurement technique for this setup involved four steps: alignment, calibration, measurement, and processing. The goal for the alignment step is to position the plane of illumination so that it follows the main flow direction at a predetermined location. This was done by aligning the laser planes to markings within the test section. Since a plane is determined by three points, we used three independent markings to orient our illumination plane. During the construction phase of each test section, we placed metrically delimitated ruler tapes along the top of the heat exchanger, the bottom of the heat exchanger, and along the bottom of the duct inlet. For each measurement, we aligned the laser plane to the same tick mark on each ruler so that the light plane was aligned with the duct's sidewalls and was perpendicular to the duct's upper and lower walls.

The calibration for 2-Dimensional PIV is a relatively simple and straightforward process. For this test setup, however, the PIV apparatus must be calibrated prior to acquiring each data point, which is time consuming. Furthermore, the entire system must be recalibrated if any piece of equipment is moved. The calibration process begins by placing a ruler within the test section such that it is aligned to the heat exchanger and lies entirely within the plane illuminated by the laser sheets. We used a small tripod to hold the ruler in place during the calibration process. Next, the CCD camera is focused on the ruler and a photograph is taken. The data acquisition computer examines the photograph in 'calibration mode' where the user is allowed to fix markers to pixels on the photograph, see Figure 4.3. The calibration process is completed by marking the crosshairs on the ruler and entering the true lineal distance between the markers; the computer scales all subsequent work from this calibration data. 


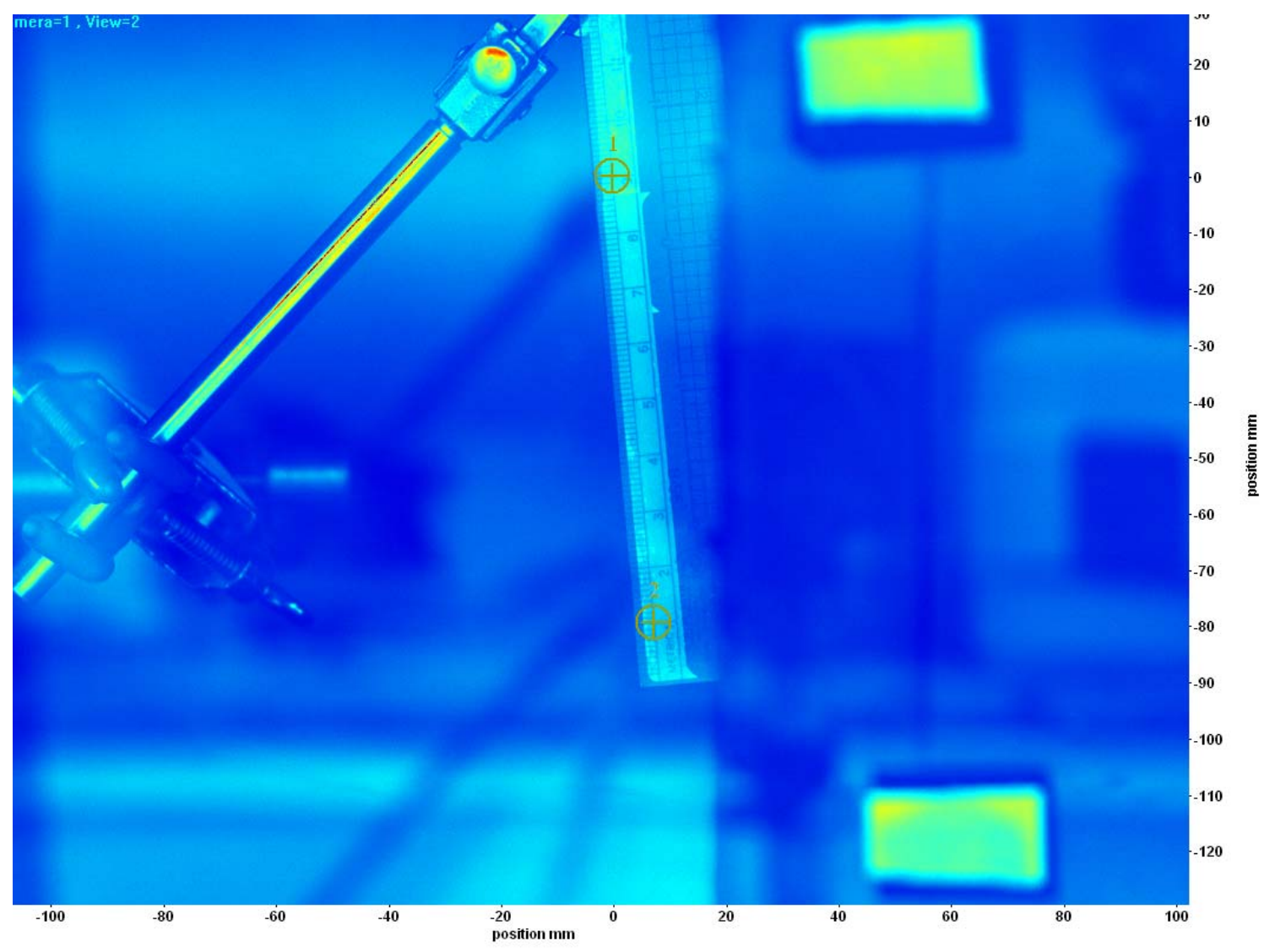

Figure 4.3 Calibration Photograph

Data could be taken once the system was calibrated. First, the correct air flow rate was established using the variable-speed drive for the blower module. Once the flow rate was set, it was kept constant throughout the data acquisition. Next, the particle generator was switched on to fill the laboratory with fog and seed the flow with tracer particles. For the next step, the lasers and camera were switched on. The PTU controlled and synchronized these components. To reiterate, there are two lasers and each fires one pulse per cycle coincident with an image capture from the double pulsed camera. The time delay between these two snapshots is set within the controls of the PTU. It is recommended for optimal computational results that the time delay should result in image pairs where most particles travel approximately one fourth of the interrogation window size between image captures. Therefore, the time delay is a function of particle velocity, camera resolution, detail preferences, and the scaling magnification determined during calibration. It is possible to analytically determine what to use as a time delay; however, it is substantially faster and simpler to examine an image pair on high magnification and adjust the time delay accordingly until a good value is located.

Once these parameters were set, a program was run to record data. Since air flow through the duct is inherently turbulent, there were a lot of unsteady components captured using this instant snapshot type of data collection method. Therefore, in order to acquire data representative of steady state flow pattern, data collection was performed by 
capturing many of these snapshots and averaging the results. In this study, we acquired 100 image pairs for each data point.

Data reduction was carried out on the server controlling the PIV apparatus. It was not performed after each data collection, but rather at the end of each day and after all of the data collection was completed because of the excessive amount of computational time and power required. During the data reduction, each (1648 X 1214) pixel image is divided into a number of interrogation windows. The software allows the user to input the interrogation window size ranging from (4 X 4) pixels to (1024 X 1024) pixels. We used interrogation windows ranging from (16 X 16) pixels to (64 X 64) pixels (depending on the specifications of each measurement) and used a $50 \%$ overlap of the interrogation areas; therefore each image was divided into somewhere between (200 X 150) windows to $(50 \mathrm{X} 38)$ windows. The image pairs were reduced to vector fields and these vector fields were averaged to produce the final data. The entire process typically takes about 3 hours to reduce each set of 100 image pairs and return the resultant average vector field. 


\section{5: PIV Measurement Results and Discussion}

In this study, we examined three different finned-tube heat exchanger configurations: a vertically oriented single-slab coil, a single-slab coil oriented at an angle, and a two-slab A-shaped coil.

\subsection{Single Slab Vertical Coil}

A single slab heat exchanger consisting of 72 tubes (4 depth rows of 18 tubes) with louvered fins was examined in the test apparatus. The dimensions of this heat exchanger were $455 \mathrm{~mm}$ (18”) tall X $455 \mathrm{~mm}$ (18”) wide X $63.5 \mathrm{~mm}$ (2.5”) thick. The mounting brackets for this heat exchanger position it such that its' air side inlet and exit surfaces are perpendicular to the main flow direction within the duct.

Each data point was taken with a specific laser illumination plane and camera position. The laser illumination plane was aimed at the heat exchanger in 5 separate locations, creating 5 separate vertical slices of the flow picture. The locations used for this heat exchanger were $230 \mathrm{~mm}$ from the side wall (midpoint), $300 \mathrm{~mm}, 360 \mathrm{~mm}, 405 \mathrm{~mm}$, and $450 \mathrm{~mm}$ (near the wall).

When determining the best position for the camera relative to the illumination plane in the test section, we must note that there is a trade off between the resolution and the field of view. If the camera is placed close to the illumination plane, the resolution of the images is very good, but the field of view is small. To achieve a good balance, we positioned the camera as close as possible to the test apparatus and divided the heat exchanger surface into 4 horizontally stacked overlapping segments; therefore we measured the data on each segment separately. The CCD camera was positioned in locations that encompassed the following range of distances from the bottom edge of the heat exchanger: (0 to 125$) \mathrm{mm}$; (110 to 240 ) $\mathrm{mm}$; (225 to 355) $\mathrm{mm}$; and (330 to 455) mm. We measured the air velocity at a total of 20 different stations on the inlet surface of the heat exchanger. A photograph of the heat exchanger and camera position is shown in Figure 5.1.1, a representative measurement plane is provided in the figure to illustrate the measurement technique. Figure 5.1.2 shows a piecewise illustration of the measured vector fields from this coil at the manufacturers' air flow rate of $0.30 \mathrm{~m}^{3} / \mathrm{s}\left(635 \mathrm{ft}^{3} / \mathrm{min}\right)$. 


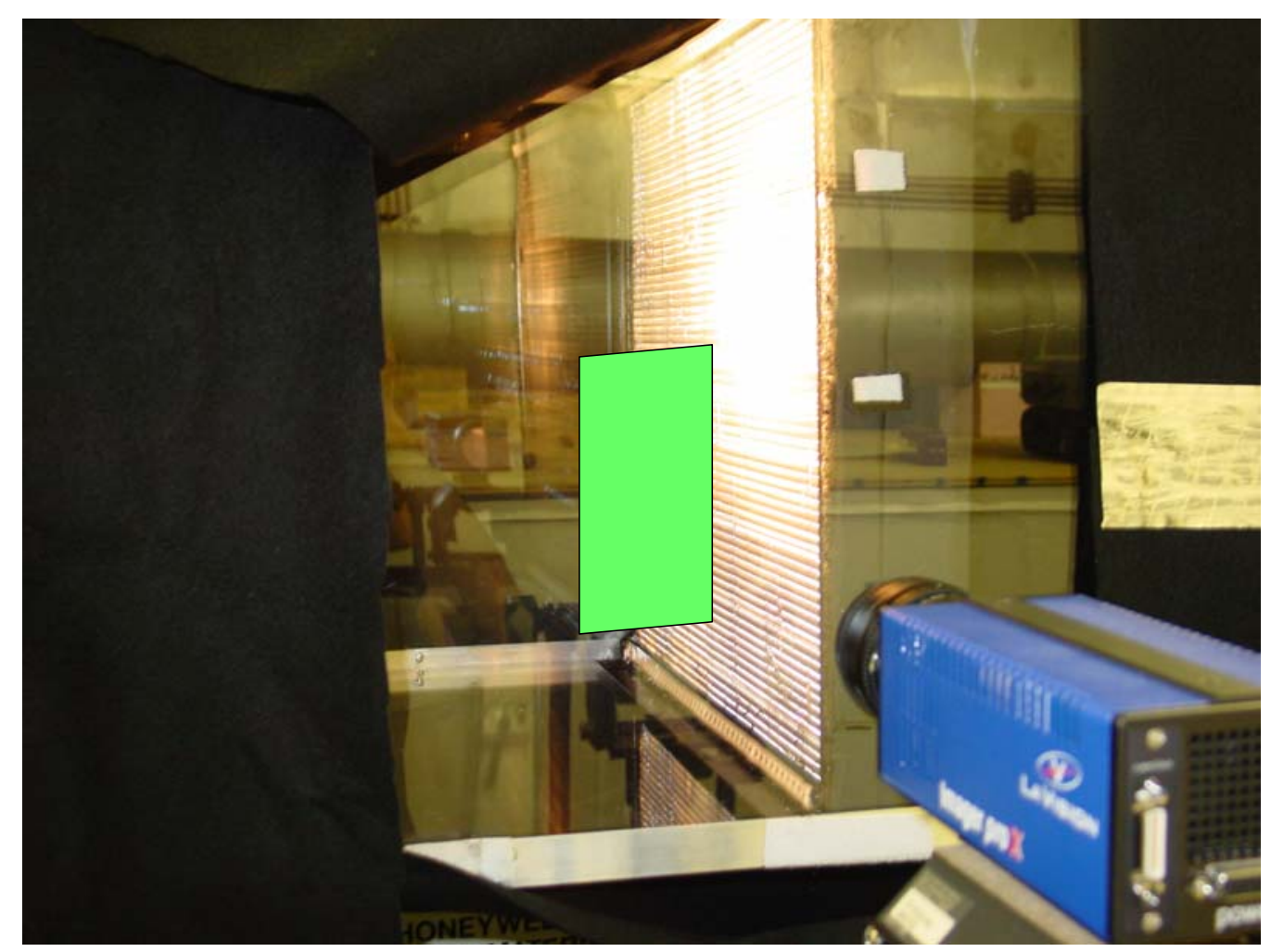

Figure 5.1.1 Measurement Location and Equipment Placement

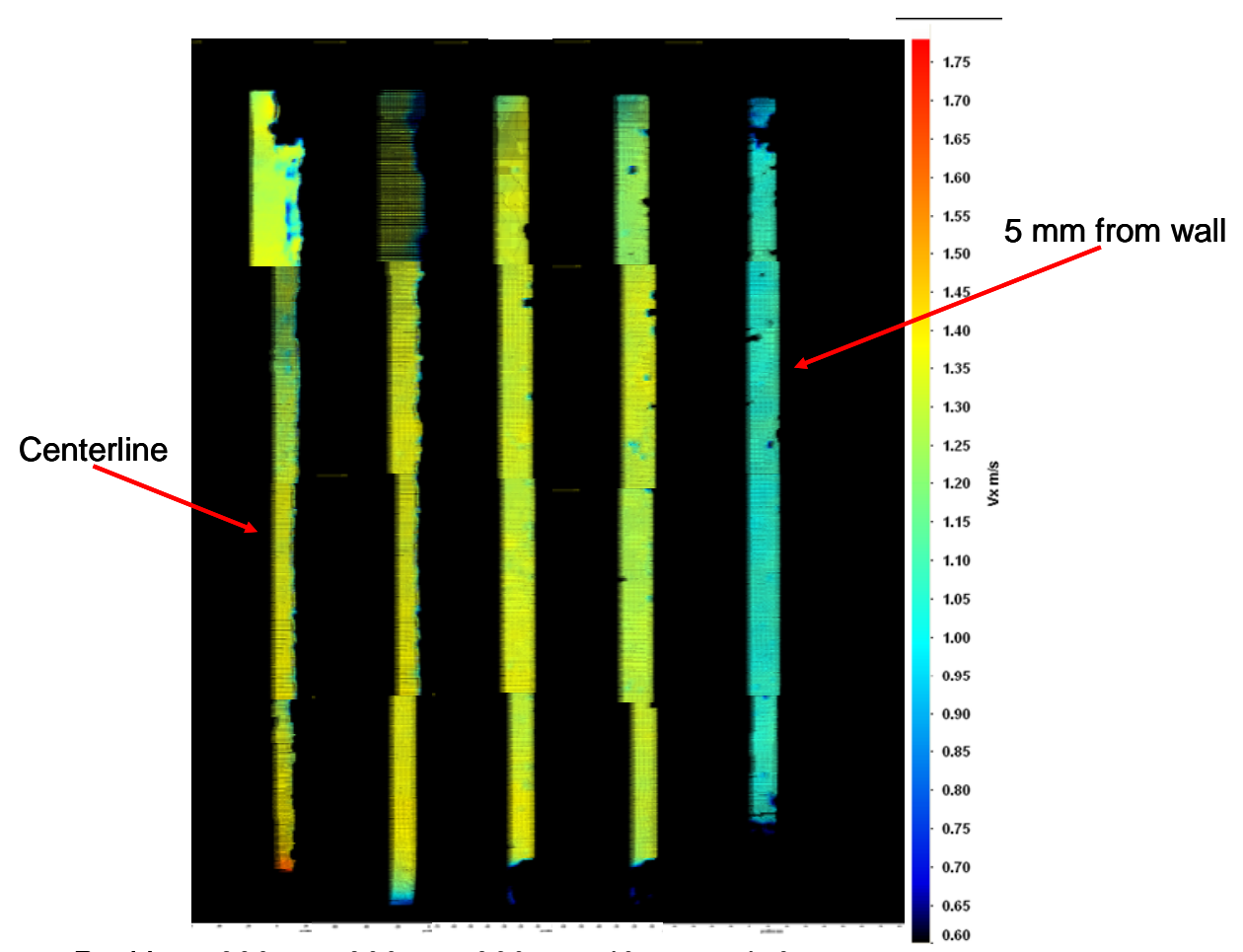

Position: $230 \mathrm{~mm} 300 \mathrm{~mm} 360 \mathrm{~mm} 405 \mathrm{~mm} 450 \mathrm{~mm}$

Figure 5.1.2 Piecewise Illustration of Measured Vector Fields for Vertical Coil 
Figure 5.1.3 shows a 2-dimensional representation of the component of the velocity perpendicular to the heat exchanger acquired during the measurements; data for this figure was taken from the measured velocity vectors closest to the heat exchanger surface. Each data set shown represents the velocity profile along a vertical slice upstream of the heat exchanger. The ordinate axis in this figure corresponds to the vertical distance from the bottom of the heat exchanger. We can see that the air approach velocity is fairly uniform (approximately $1.3 \mathrm{~m} / \mathrm{s}$ ) with the exception of the areas near the top and bottom edges. The velocity profile measured $5 \mathrm{~mm}$ from the duct wall shows a distribution that is similar the other slices, but is about $20 \%$ slower due to interactions imposed by the boundary.

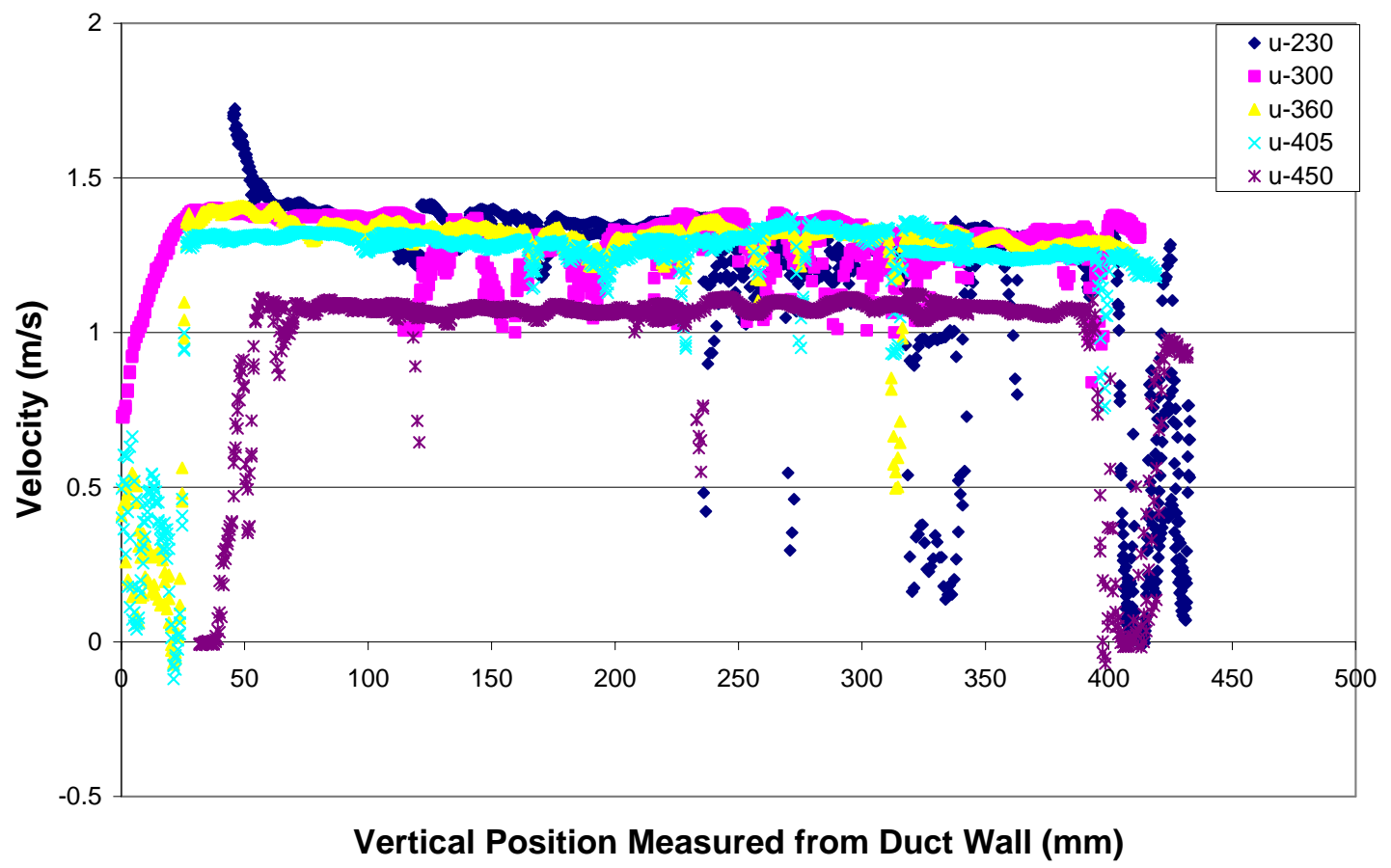

Figure 5.1.3 Two-Dimensional Representation of Approach Velocity for Vertical Coil

There are a few other items seen in this figure which are worthy of discussion. First of all, there are a few data points that show local velocity to be lower than that of the neighboring points. This is not actually occurring but rather it is a problem due to image distortion. Each data point shown was produced by analyzing a data set consisting of 100 image pairs. A vector field was calculated for each image pair by tracking the motion of the particles between the images. Once the vector fields were calculated for each image pair, the vector at each location was averaged with all of the other vectors in the same location in the other 99 calculated vector fields. By reducing a large number of image pairs into vector fields and then averaging these vector fields, we are able to dampen out unsteady components picked up by the instantaneous measurements of turbulent flow; therefore we expect the end result to be a fairly smooth curve. The outlying points shown here are caused by either light reflection or dirt particles stuck to the plexiglass duct wall. These features are captured in each frame of the camera and therefore are picked up by 
the data processing software as stationary particles. If a dust particle, for example, is stuck to the duct wall and is captured by the camera, the data reduction software will map its (lack of) movement along with the particles in the flow and therefore determine a velocity value that is slower than the true value. This effect is not very large, since the duct was cleaned between most tests and great care was taken to minimize any light reflections; but there are a few outlying points in the data due to this, most notably at the lateral midpoint (position $230 \mathrm{~mm}$ ).

The data corresponding to the flow at $\mathrm{x}=300 \mathrm{~mm}$ in Figure 5.1.3 displays another interesting feature. A periodic pattern of high and low velocity covers most of the measurements at $300 \mathrm{~mm}$. These particular data files were obtained with the optimal camera position that allowed images to be captured right against the heat exchanger surface without realizing any reflections from the metallic fins. Every attempt was made to place the camera in this position for each measurement set. The periodic pattern seen here corresponds to the absence or presence of tubes within the first depth row of the heat exchanger. Air approaching the heat exchanger at a location corresponding to a tube will move towards a location that corresponds to a position between adjacent tubes; therefore the high velocity points seen in the figure are located between tubes and the low velocity points are located directly upstream of the tubes.

\subsection{Slant Coil}

The slant coil was a single slab coil positioned at an angle of $65^{\circ}$ to the duct wall. It has 72 tubes (4 depth rows of 18 tubes) with louvered fins. The dimensions of this heat exchanger are $455 \mathrm{~mm}$ (18”) tall X $430 \mathrm{~mm}$ (17”) wide X 65 mm (2.5”) deep. There was a plastic mounting bracket fastened to the lower portion of this heat exchanger that maintains the angle between the heat exchanger and the lower wall of the duct. A short metal sheet was attached to the upper edge of the heat exchanger and was used to fasten the top of the heat exchanger to the upper wall of the duct. Figure 5.2.1 shows the position of the slant coil within the test section. 


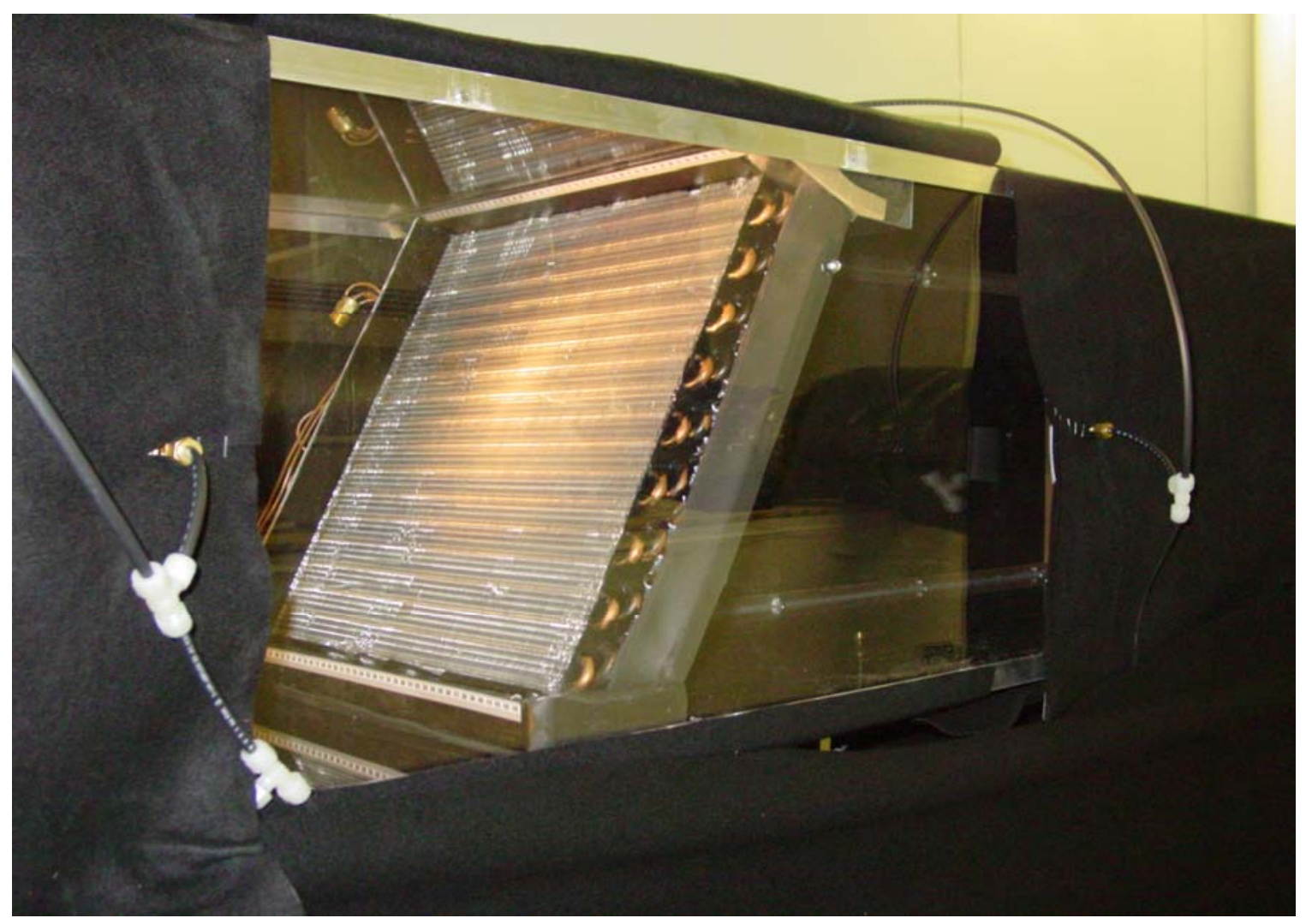

Figure 5.2.1 Slant Coil Test Section

The lasers were aimed to capture 5 vertical slices of the flow profile at locations corresponding to $215 \mathrm{~mm}$ (midpoint), $280 \mathrm{~mm}, 340 \mathrm{~mm}, 380 \mathrm{~mm}$, and $420 \mathrm{~mm}$ (near the outer edge of the heat exchanger). The profile of the heat exchanger was again divided into 4 segments. The segments corresponded to positions $60 \mathrm{~mm}$ to $180 \mathrm{~mm}$ from the bottom of the duct (the heat exchanger bottom is elevated off of the duct because of the mounting bracket as seen in Figure 5.2.1), $150 \mathrm{~mm}$ to $280 \mathrm{~mm}, 250 \mathrm{~mm}$ to $370 \mathrm{~mm}$, and $350 \mathrm{~mm}$ to $480 \mathrm{~mm}$. The measurements were all taken at the manufacturer's rated air flow rate of $0.35 \mathrm{~m}^{3} / \mathrm{s}\left(750 \mathrm{ft}^{3} / \mathrm{min}\right)$. 


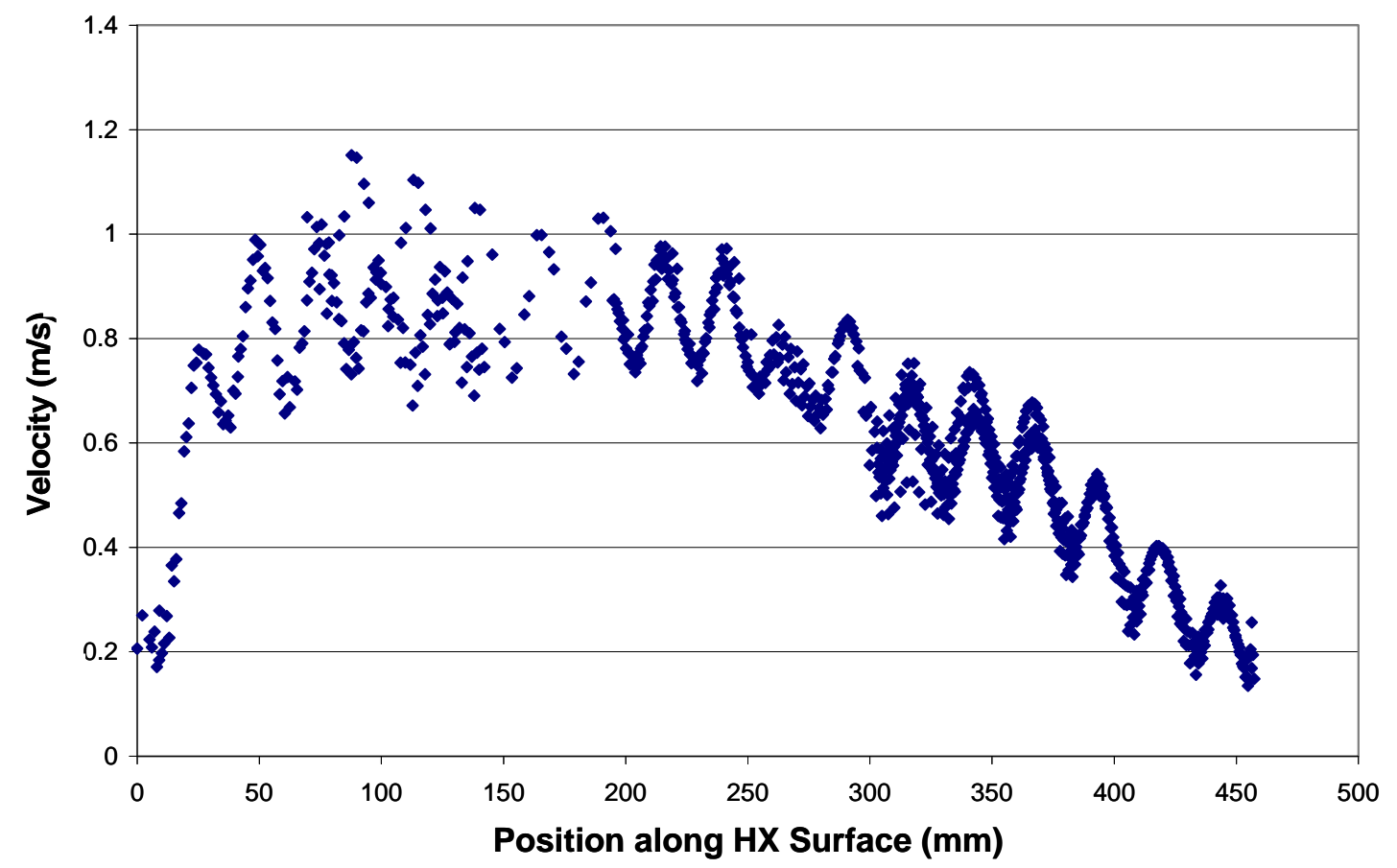

Figure 5.2.2 Velocity Profile at Midpoint for Slant Coil

Figure 5.2.2 shows the component of the air velocity profile perpendicular to the coil surface measured at the heat exchanger's midpoint. Similar to that seen in Figure 5.1.3, we see the sinusoidal velocity pattern indicating the location of the tubes within the heat exchanger. What is much more interesting, however, is that the flow appears to have three distinctly separate regions, which illustrates the magnitude of the non-uniformity with which air flows through this heat exchanger. In the lower portion of the coil, corresponding approximately to the region between $0 \mathrm{~mm}$ and $50 \mathrm{~mm}$ from the bottom, the air flow is very slow near the bottom edge of the heat exchanger and it rapidly increases in locations towards the mid section of the coil. In area between $50 \mathrm{~mm}$ and $250 \mathrm{~mm}$ from the bottom of the coil, the flow rate is relatively constant. In the upper portion of the heat exchanger, from $250 \mathrm{~mm}$ to $455 \mathrm{~mm}$ from the bottom, the figure shows a long gradual taper of the air flow rate caused by the diminishing duct area.

It is interesting to examine the location of the maximum air velocity for this coil. As air approaches the heat exchanger near the bottom of the duct, it encounters the lower mounting bracket, which turns the flow upwards. The air in this region must then accelerate around the bracket, which causes the local maximum near the bottom of the coil. It is also interesting to see the decrease in the flow velocity near the top of the heat exchanger.

This figure illustrates the importance of measuring the air flow distribution by presenting the magnitude of the variation of the flow pattern. The amount of air available for heat exchange with each tube in strongly related to the tube's position. There are 18 tubes per 
depth row in this heat exchanger; the position of each tube is identifiable by a local minimum in the velocity seen in Figure 5.2.2. The first tube near the bottom of the heat exchanger (and those occupying the same position within subsequent depth rows) receives very little air flow at all. Starting from approximately $25 \mathrm{~mm}$ from the bottom through the $250 \mathrm{~mm}$ from the bottom of the heat exchanger, the air velocity is relatively constant. In the region between $250 \mathrm{~mm}$ and $455 \mathrm{~mm}$ from the bottom of the heat exchanger, the amount of air flow approaching each tube is a strong linear function of its position; the tube nearest the top of the heat exchanger receives less than one third of air flow that a tube positioned in the middle receives.

Figure 5.2.3 shows the air flow distribution measured along each vertical slice examined in this study. Here we see that the variation between the profiles at different slices is small. Overall, the general pattern of air flow velocity seems to be relatively insensitive to the location of the image plane, indicating that the wall effects are not very important here.

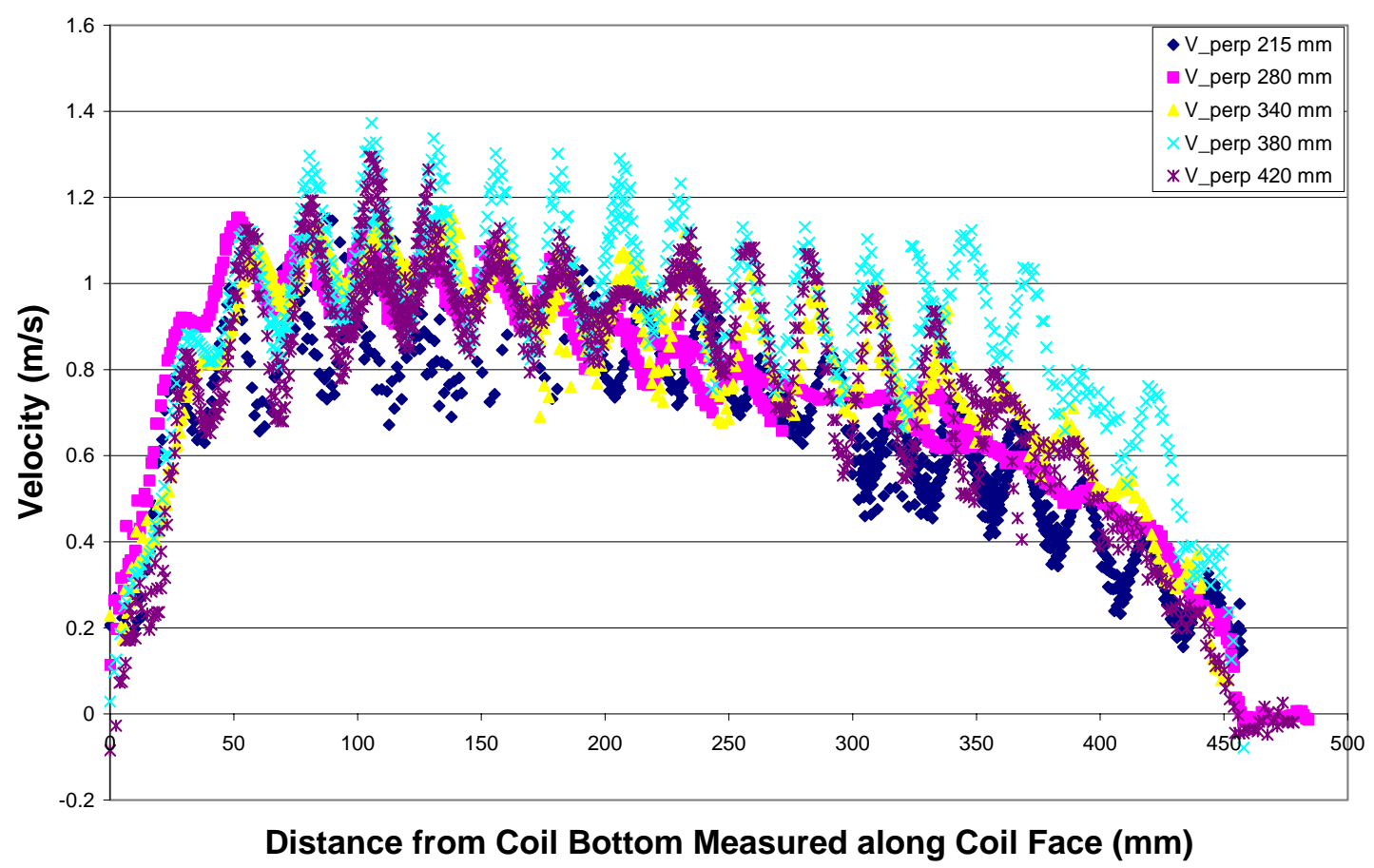

Figure 5.2.3 Two Dimensional Representation of Approach Velocity for Slant Coil

\subsection{A-Shaped Coil}

The last heat exchanger tested in this study is described as a two-slab heat exchanger, with the slabs assembled in such a way that it resembles the letter ' $\mathrm{A}$ '. A photograph of this coil mounted in the test section is shown in Figure 5.3.1. 


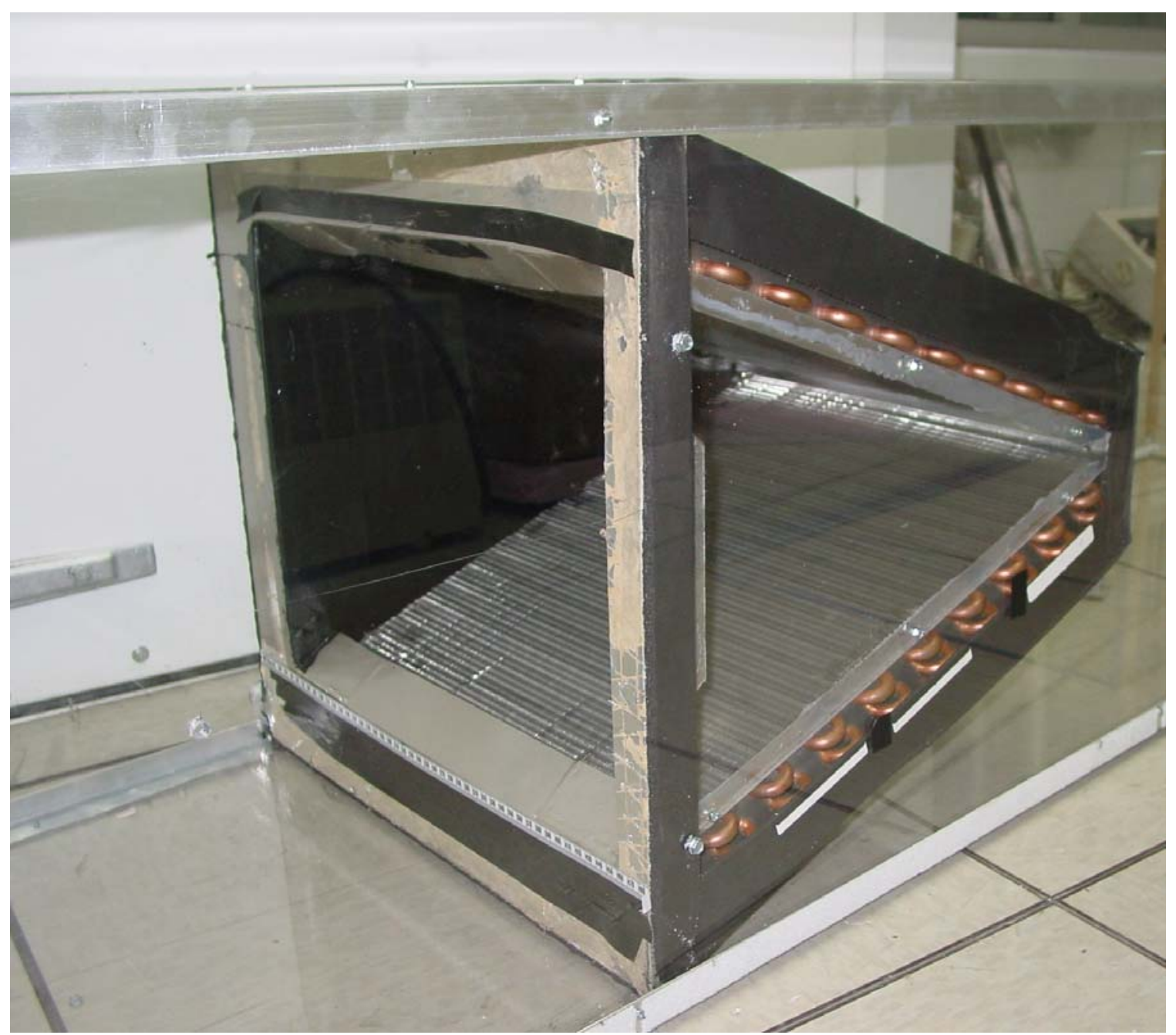

Figure 5.3.1 A-Shaped Coil Test Section

This heat exchanger represents a very typical configuration found in residential air conditioning systems. Note that there is a condensate pan attached to the left side of the coil in the figure. In field use, this heat exchanger would be positioned such that the condensate pan would be on the bottom of the assembly and the air flow would be upwards. Since this study examined only the adiabatic cases, there was no moisture removal from the air. Because there is no moisture removal, it was unnecessary (and would provide a substantial laboratory burden) to position the heat exchanger vertically; therefore measurements were performed on this heat exchanger in the sideways position as shown in Figure 5.3.1.

Each coil in the assembly had 60 tubes (3 depth rows of 20 tubes) with louvered fins; giving a total of 120 tubes in the dual slab A-Shaped coil. The dimensions of each coil were $520 \mathrm{~mm}$ in height, $400 \mathrm{~mm}$ in width, and $65 \mathrm{~mm}$ in thickness. The condensate pan fully occluded the plexiglass duct and had outer dimensions of $511 \mathrm{~mm}$ X $495 \mathrm{~mm}$. The coils were attached together with an apex with an angle of $34^{\circ}$ between them, and the opposite side of each coil was attached to the condensate pan. 
PIV measurements were taken along 4 vertical slices corresponding to positions of $270 \mathrm{~mm}$ (the midpoint), $340 \mathrm{~mm}, 400 \mathrm{~mm}$, and $420 \mathrm{~mm}$ (35 mm from the edge of the heat exchanger) from the duct wall. Each data set was measured in three segments. Since these heat exchangers were positioned at such a small angle ( $17^{\circ}$ to the duct wall) the camera field of view was limited by the horizontal distance and therefore the measurement segments were divided along the horizontal. The segments corresponded to horizontal positions of $0 \mathrm{~mm}$ to $75 \mathrm{~mm}, 165 \mathrm{~mm}$ to $340 \mathrm{~mm}$, and $330 \mathrm{~mm}$ to $480 \mathrm{~mm}$. The measurements were all taken at the manufacturers rated air flow rate of $0.65 \mathrm{~m}^{3} / \mathrm{s}\left(1380 \mathrm{ft}^{3} / \mathrm{min}\right)$.

Figure 5.3.2 shows a picture of tracer particles in the illumination plane near the entrance of this heat exchanger. The main flow direction in this picture is left to right, and the air entering the heat exchanger in this portion would turn downwards to flow through the lower coil (the lower coils' return bends can be seen along the bottom of this picture). When the illumination source lit up the imaging plane, it was obstructed by the metal condensate pan and illuminated the coil surface beginning from approximately the $6^{\text {th }}$ tube in the coil. A secondary illumination plane caused by the diffracting light is also seen in this figure, which illuminated the coil surface from approximately the $4^{\text {th }}$ tube in the coil. Unfortunately, since we could not bend the light around or transmit it through the condensate pan, we could not illuminate the bottom most 3 tubes in the coil and therefore could not measure the flow in this region at the coil surface. We may also note that this image shows some distortion near the edge of the heat exchanger between the $8^{\text {th }}$ and $9^{\text {th }}$ tubes, this is caused by light scattering within the silicone based sealant used to join the plexiglass duct to the heat exchanger; the data from these distorted pixels were removed from the data set.

What is most interesting about this configuration is that the condensate pan causes a recirculation zone, which effectively blocks the air flow to a substantial portion of the coil. As air flows over the pan's edge, it turns downward towards the coil and continues to circulate between the coil and the pan. Figure 5.3.3 shows the profile of the perpendicular component of velocity measured along the midline of the heat exchanger, close examination of the data points near the entrance of the heat exchanger shows that there is a very steep velocity gradient in this region. Here, each data point represents a single interrogation window used in the PIV data reduction algorithm. The locus of data points corresponding to the edge of the diffracted illumination plane closest to the coil surface is the set that shows negative velocity in Figure 5.3.3; the first set above this corresponds to the set of interrogation windows just above the illumination plane's edge, etc. These large velocity gradients are the two dimensional representation of the recirculation zone. Upon examining the velocity in this area, the steepest gradients occur in the vicinity of the $3^{\text {rd }}$ tube from the bottom of the coil, with flow away from the coil at the nearest measured point. 


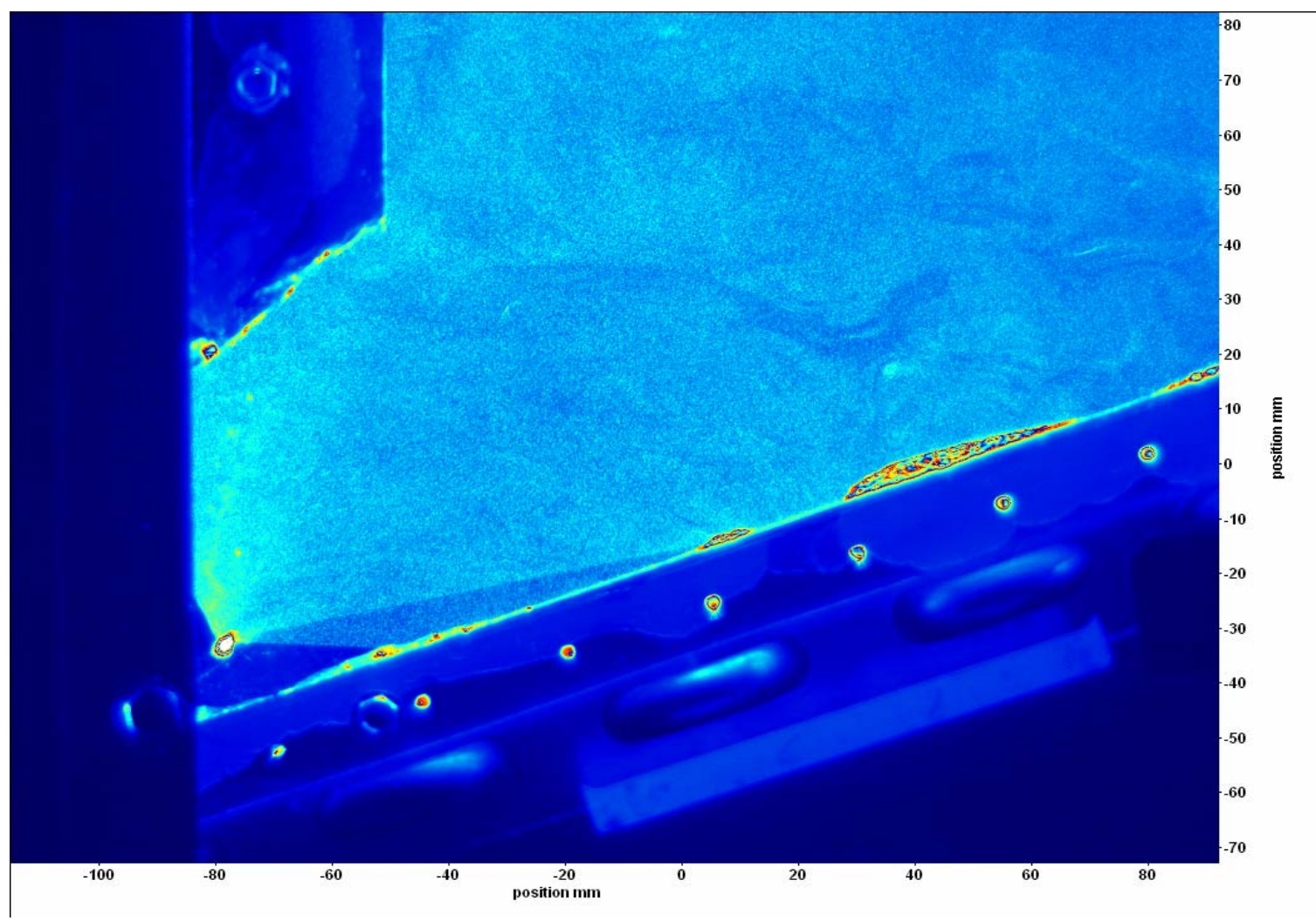

Figure 5.3.2 PIV Data Image File - A-Coil Entrance

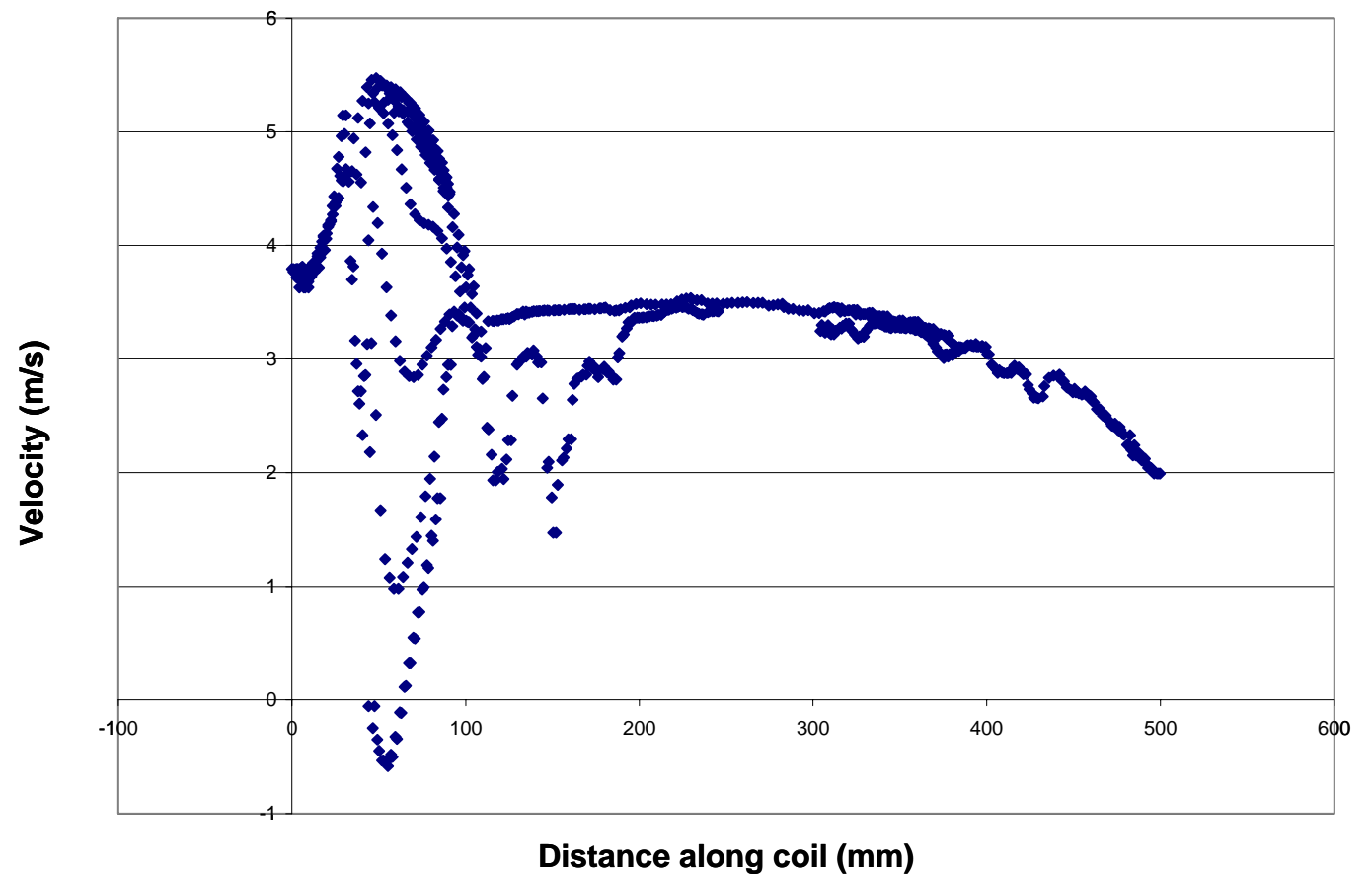

Figure 5.3.3 Velocity Profile at Midpoint for A-Coil 
Figure 5.3.4 is a better illustration of the recirculation zone. This figure shows the computed vector field from the diffracted laser light portion of the PIV measurements; the triangular region between the edge of the condensate pan and the $4^{\text {th }}$ and $6^{\text {th }}$ heat exchanger tubes. The most interesting thing about these pictures is that they illustrate that the first 3 or 4 tubes in each coil do not receive a significant amount of air flow. These tubes, therefore, can not provide much (if any) heat transfer because the condensate pan prevents air from flowing to these tubes.
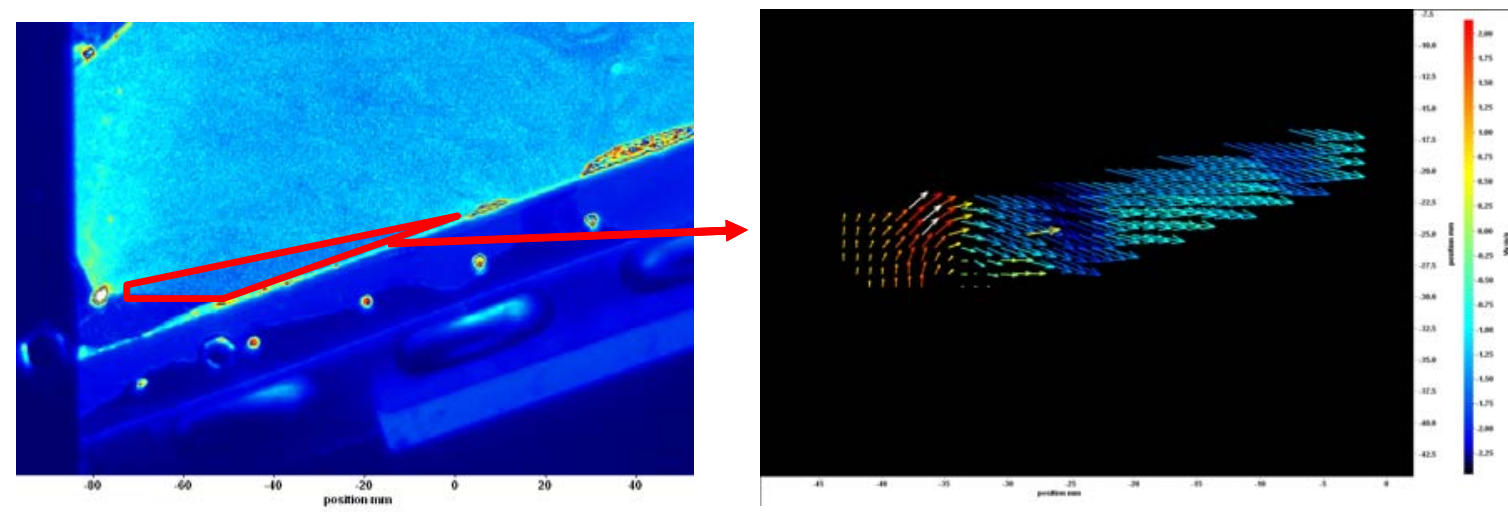

Figure 5.3.4 A-Coil Recirculation Zone

This large inefficient portion of the heat exchanger illustrates the importance of knowing the air flow distribution prior to manufacturing heat exchangers. In this case, approximately $20 \%$ of the entire heat exchanger provides little or no functionality to this product. Had this air flow distribution pattern been known during the design phase of this heat exchanger, the manufacturer could have designed around this flow distribution pattern by either saving costs through elimination of tubes that receive no air flow, by reducing the penalty by providing a spacer for the recirculation zone between the condensate pan and the heat exchanger so that the heat exchanger is separated from this region, or by other means.

Figure 5.3.5 shows the measurement results from each slice of data from this heat exchanger. Here, again we see that the distance from the wall does not significantly impact the velocity distribution. 


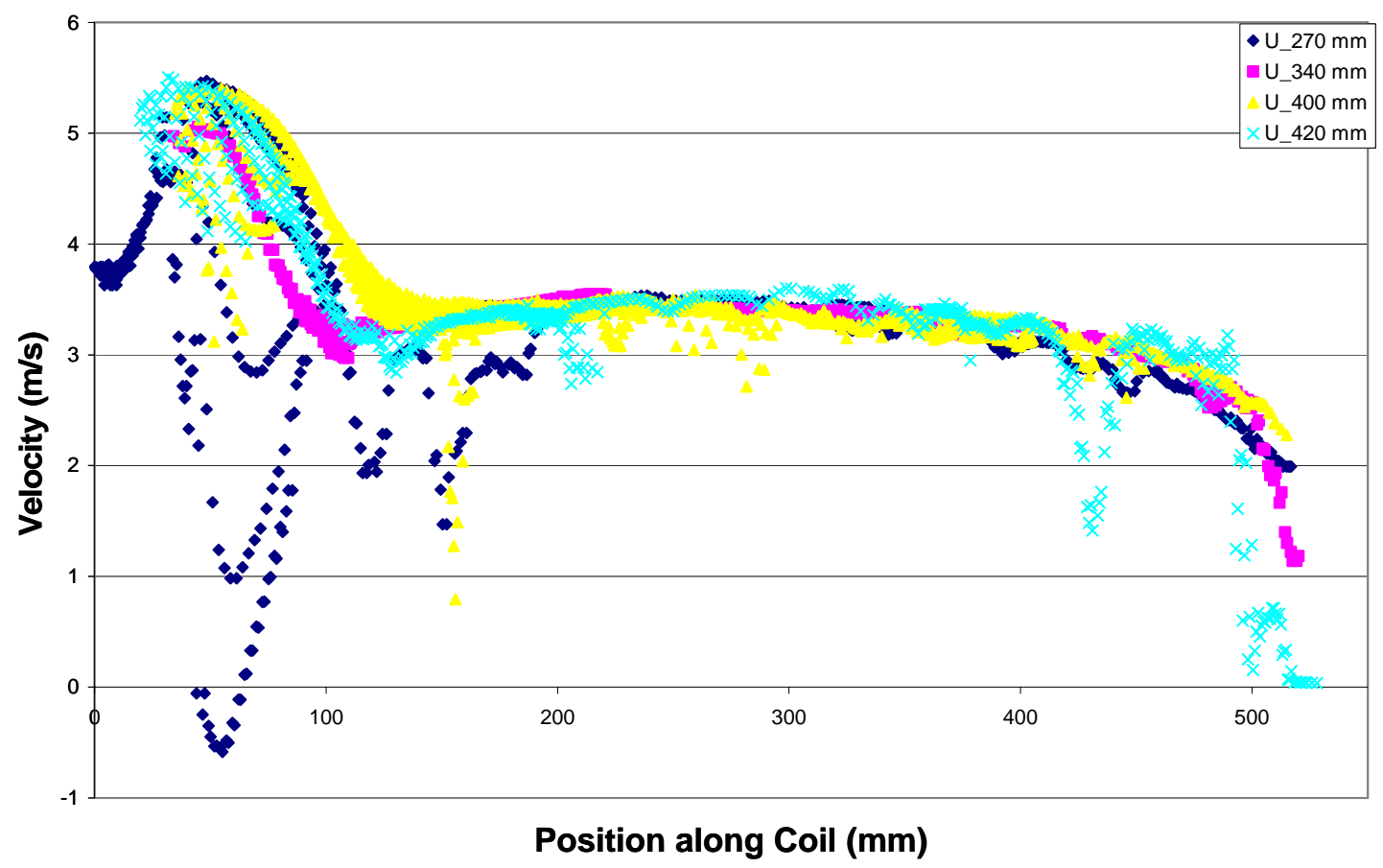

Figure 5.3.5 Two Dimensional Representation of Approach Velocity for A-Shaped Coil

We have seen a few consistencies throughout the PIV measurements of all three tested heat exchangers. The most important point is that the air flow, in general, is not uniform. The fins and tubes of the heat exchanger provide resistance to the air flow, which in general has the affect of evening out the distribution; however, it seems that other factors are more influential on the air flow distribution. The presence of any irregularities in the duct boundaries or heat exchanger mounting has a much more profound impact. These discontinuities locally alter the air flow and change its direction.

With the first single slab heat exchanger, the test section was relatively free from any boundary discontinuities. The heat exchanger had mounting brackets which effectively reduced the ducts' cross sectional area right at the heat exchanger interface; but this reduction was very small and occurred right at the point of transition to the introduction of the flow resistance and therefore this did not largely impact the air flow. Since the heat exchanger itself was uniformly distributed throughout the ducts' cross section, the measurements showed that the air flow distribution through this heat exchanger was fairly constant at any location.

The slanted single slab heat exchanger showed a very different air flow distribution pattern because the heat exchanger was positioned at an angle and abrupt area changes were introduced by the mounting brackets. The measurements for this test subject showed that there was a high flow region caused by the acceleration of the air flow around the lower mounting bracket. Also, the measurements showed that positioning the 
coil at an angle caused about half of the coil to be subject to a somewhat linearly declining air velocity profile.

For the A-shaped coil, the velocity profile had a lot of similarities to that of the slanted coil. The A-shaped coil showed a relatively linearly declining air velocity profile as we moved closer towards the apex, although not as pronounced as seen on the slanted coil. More importantly, though, the condensate pan attached to this coil was an obstructive feature, much more so than the ones attached to the slanted coil, and therefore its effects were more pronounced. The metal plated used to catch the condensate running off the coil acted as an airfoil and caused the presence of a recirculation zone between it and the coil. This severely reduced the air supply to approximately $1 / 5$ of the entire heat exchanger.

Another observation that was common to each test specimen is that the velocity profile did not change significantly as the image plane is traversed within the duct. All of these heat exchangers effectively had 2-dimensional geometry; the geometry of the duct and heat exchanger changed dramatically in the downstream and vertical directions, but not in the lateral direction. Also, since air has a low viscosity, the effects of the boundaries did not seem to be very influential. Together, these aspects resulted in flow maps that were 2-dimensional and image planes captured at different lateral locations showed the same flow pattern. This is a very important point because ultimately we would like to have the ability to predict the air flow distribution using computer generated algorithms, and 2dimensional solutions offer much faster, less complicated calculations than 3-dimensional simulations. This point, however, may not hold for all possible heat exchanger installation configurations. In many typical household installations, the blower module is attached directly to the coil assembly, which would likely cause three dimensional velocity variation. These effects were removed from this study because the blower module was located very far downstream from the test section, with two $90^{\circ}$ bends and a venturi flow meter between them. The present study provides a very good starting point but future work is necessary to examine this issue in more detail. 


\section{6: Computer Based Simulation Results and Discussion}

In this section our goal was to use computer simulations to numerically replicate the velocity distribution of the heat exchangers that we examined with the PIV system. For this task, we employed a commercially available Computational Fluid Dynamics (CFD) software package to model the flow field. Successful replication of the measured data with computer simulations demonstrates that we can use CFD to predict the air flow distribution of similar heat exchanger/duct configurations. Once verified, we can use computer simulations as the preferred method to predict the air velocity distribution, since it is far less expensive, time consuming, and cumbersome than laboratory PIV measurements.

In order to achieve a reasonable computational model of the flow, we first graphically replicated the flow domain. This is generally accomplished by modeling each and every boundary that interacts with the flow, and using these boundaries and the space between them to create a network of nodes at which the conservation equations can be numerically solved. However, this approach is not possible with the current state of the art computing power, nor is it a very efficient way of modeling the flow field at hand. Since every tube and fin on the heat exchanger is an individual boundary, any given flow passage would consist of the small gap between adjacent fins bounded by adjacent tubes. Therefore, using a conventional approach, the number of nodes required would be astronomical. We sought a much simpler approach through momentum resistance modeling [ESI Group, 2005].

Momentum resistance models are used to model flow domains that include obstructions or elements which are smaller than the desired grid resolution. This approach is based on the idea that we can model the momentum resistance imparted to the flow by these elements by characterizing the pressure drop using lumped parameters called momentum resistance coefficients and assigning them to nodes that reside within the resistive domain. To employ this method, we first characterized the resistive domain by relating the pressure gradient to the velocity through the following relationship:

$$
\nabla P=\rho\left(\frac{\left[K_{l}\right]}{2 \beta}+|\vec{V}| \frac{\left[K_{q}\right]}{2 \beta^{2}}\right) \cdot \vec{V}
$$

Where $P$ is the pressure, $\rho$ is the air density, $K_{l}$ and $K_{q}$ are linear and quadratic momentum resistance coefficient matricies, $\beta$ is the porosity factor (flow volume/total volume), and $\vec{V}$ is the velocity. We determined the values of the momentum resistance coefficients specific to our test subjects through laboratory measurement, since the test burden was minimal due to the already constructed test apparatus. Alternatively, we could have determined these coefficients through numerical simulation. Prior to each set of PIV measurements we measured the volumetric flow rate and the differential pressure through each heat exchanger test section. This data was used to determine the coefficients for the momentum resistance models used in each of the simulations. 


\subsection{Single Slab Vertical Coil}

We began the CFD simulation of the single slab vertical coil by constructing a geometrical representation of the heat exchanger and the attached ducting. Since all of the measurement data showed that the flow through each heat exchanger was 2dimensional, it is unnecessary to perform a much more involved 3-dimensional CFD simulation. Three dimensional simulations were explored at the onset of this work; however, their results did not provide any additional information and the simulations proved to be far more computationally demanding.

The first step was to characterize the domain over which we solved the flow field. For this coil we used a 2-dimensional slice, in the same orientation as the laser light pulses. We took advantage of the symmetrical line that divides the plane in half vertically. Figure 6.1.1 shows a sketch of the geometrical domain that was used to compute the flow domain for the single slab vertical coil; here the domain is represented by the area within the red lines.

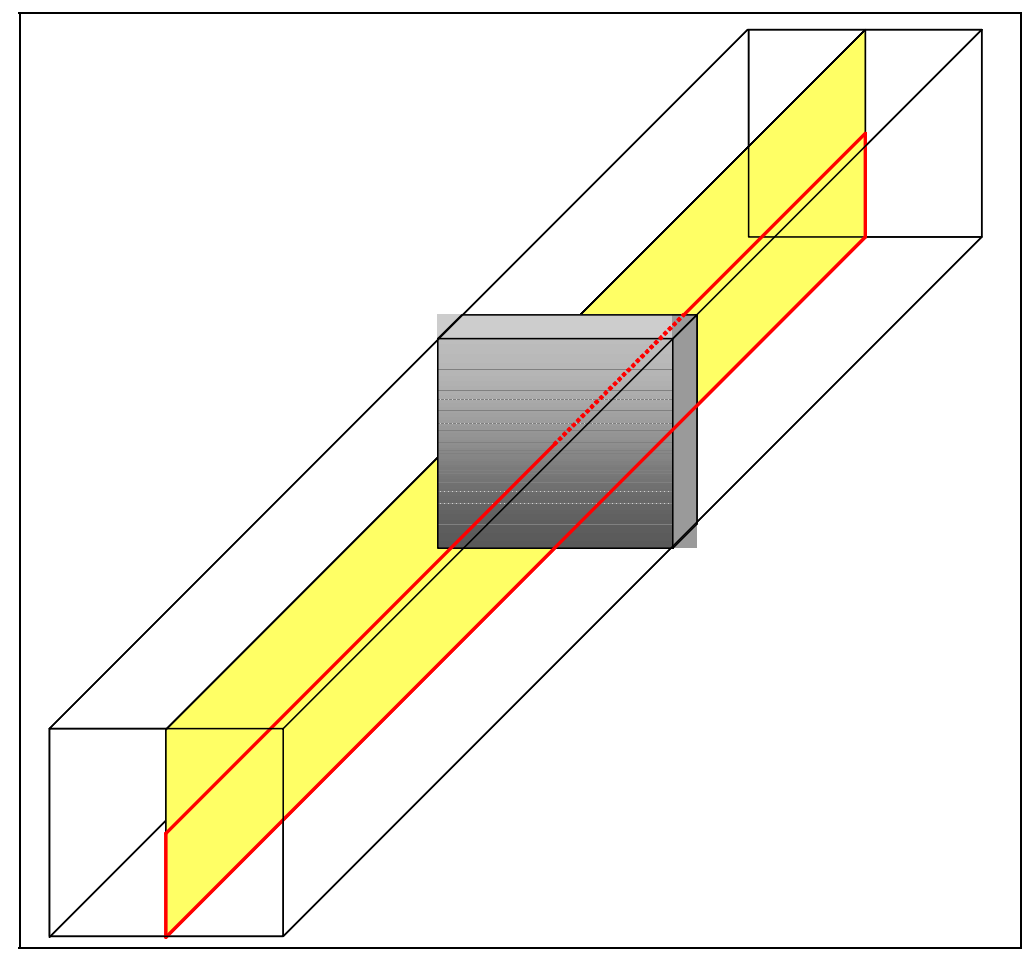

Figure 6.1.1 Test Section Sketch with Computational Domain Outline

Figure 6.1.2 shows the domain as constructed with the CFD software package. The domain was comprised of six separate sub-domains; two that represented the flow field upstream of the heat exchanger, two that represented the flow through the heat exchanger, and two that represented the flow field downstream of the heat exchanger. The boundary at the lower edge of the domain represented the wall of the duct, the upper line represented the symmetry line, the duct inlet was on the left side, and the duct outlet was on the right side (air flow is left to right). Each portion of the domain (e.g. upstream) was represented by two sub-domains because the heat exchanger's mounting bracket 
obstructs the air flow to the lowest $25.4 \mathrm{~mm}$ (1 inch) of the duct, and modeling this required a break in the associated entities.

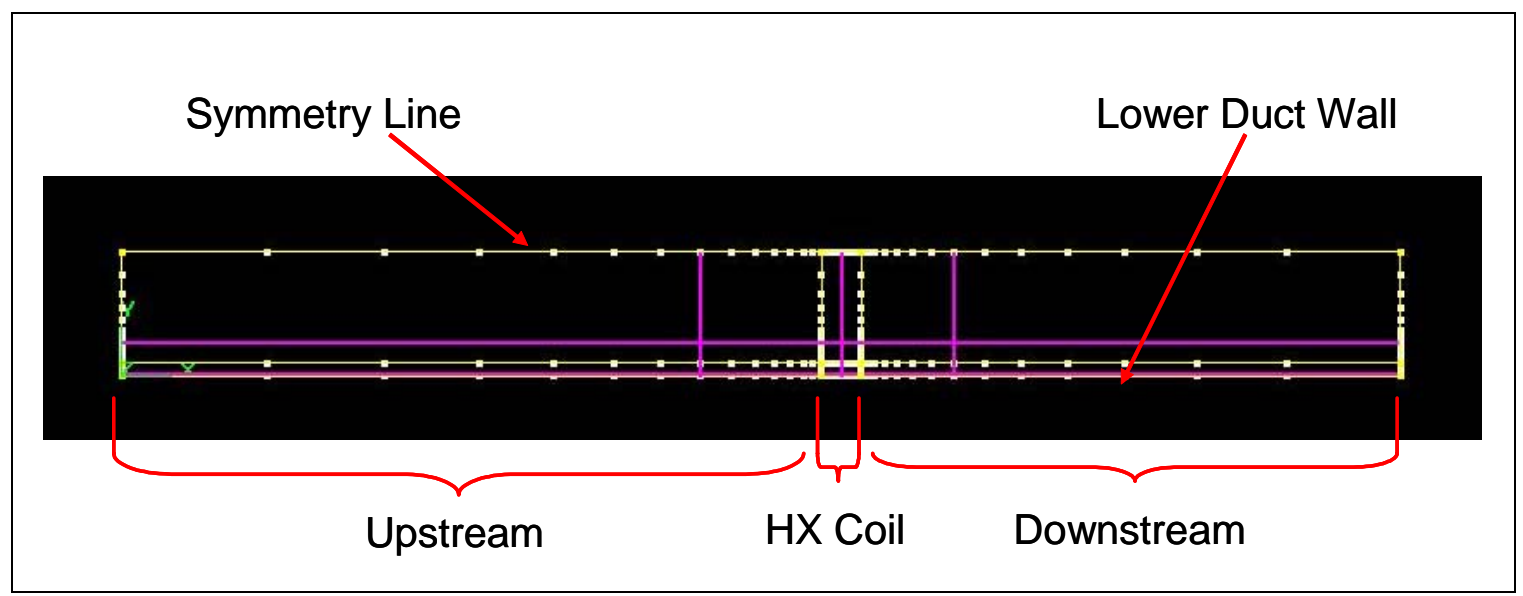

Figure 6.1.2 Computational Domain for Vertical Coil

Each line was divided into a number of sections by overlaying them with a specified number of nodes. We determined the number of nodes required to accurately solve this flowfield by iteratively performing the simulation, adding nodes and re-simulating, and comparing the results. Through this process, we consistently used a geometric spacing pattern for the nodes with a geometric transition factor of 1.25; the finer nodal spacing was located closest to the heat exchanger for the upstream and downstream portions, closest to the wall for the vertical boundaries, and we used a double sided geometric pattern for the entities within the heat exchanger section (as shows in Figure 6.1.2).

This computational domain was imported into the CFD solver software environment. We performed our simulations using the flow, turbulence, and momentum resistance models. Boundary conditions were set for each lined edge of each sub-domain. The boundaries at the top edge of the domain represented a symmetry line; therefore all gradients were set to zero along these boundaries. The boundaries on the far left side represented the domain's inlet; here we used a constant inlet velocity and pressure boundary conditions. At the far right side of the domain was the outlet; here we used a constant farfield velocity and pressure. The boundaries along the bottom of the domain represented the duct wall; here we enforced a no-slip boundary condition $(u=v=0)$. The vertical lines at the interfaces between the open duct and the heat exchanger nearest to the duct wall represented the heat exchanger's mounting bracket. This element was modeled as a thin wall, we set $u=v=0$ along its surface. Finally, all other boundaries were interfaces between adjacent sub-domains, and they were unbounded.

Our next step was to calculate the Reynolds number to determine the parameters necessary for the $k-\varepsilon$ turbulence model. During our PIV measurements, we used a constant flow rate of $0.30 \mathrm{~m}^{3} / \mathrm{s}$, which divided by the upstream duct cross sectional area of $0.470 \mathrm{~m} \times 0.508 \mathrm{~m}=0.239 \mathrm{~m}^{2}$, gives an average upstream velocity of $1.255 \mathrm{~m} / \mathrm{s}$.

The hydraulic diameter based on the duct dimensions is: 
$D_{h}=\frac{4 A}{P_{e r}}=\frac{4\left(0.239 \mathrm{~m}^{2}\right)}{2(0.470 \mathrm{~m}+0.508 \mathrm{~m})}=0.488 \mathrm{~m}$

We used the constant values for thermophysical properties for air at $25^{\circ} \mathrm{C}$ and $101.325 \mathrm{kPa}$ [Lemmon et. al. 2007]:

$$
\begin{aligned}
& \rho=1.184 \frac{\mathrm{kg}}{\mathrm{m}^{3}} \\
& v=1.562 \cdot 10^{-5} \frac{\mathrm{m}^{2}}{\mathrm{~s}}
\end{aligned}
$$

Therefore, the Reynolds number for this case is:

$$
\operatorname{Re}=\frac{U D_{h}}{v}=\frac{\left(1.255 \frac{\mathrm{m}}{\mathrm{s}}\right)(0.488 \mathrm{~m})}{1.562 \cdot 10^{-5} \frac{\mathrm{m}^{2}}{\mathrm{~s}}}=39,200
$$

The turbulence intensity, I, was calculated from this Reynolds number:

$$
I=0.16 \operatorname{Re}^{-1 / 8}=0.0427
$$

The turbulent kinetic energy, $k$, is therefore:

$$
k=1.5 U^{2} I^{2}=1.5\left(1.255 \frac{\mathrm{m}}{\mathrm{s}}\right)^{2}(0.0427)^{2}=0.00431 \frac{\mathrm{m}^{2}}{\mathrm{~s}^{2}}
$$

And the dissipation rate, $\varepsilon$, is:

$$
\varepsilon=\frac{0.01643 \cdot k^{3 / 2}}{0.07 D_{h}}=\frac{0.01643\left(0.00431 \frac{\mathrm{m}^{2}}{\mathrm{~s}^{2}}\right)^{3 / 2}}{0.07(0.488 \mathrm{~m})}=0.000136 \frac{\mathrm{m}^{2}}{\mathrm{~s}^{3}}
$$

These values of $k$ and $\varepsilon$ were used as input to the CFD $k-\varepsilon$ turbulence model [ESI Group, 2007].

Lastly, we needed to characterize the pressure drop through the heat exchanger to implement the momentum resistance model. For the single slab flat coil, we measured 10 points with the laboratory apparatus, varying the flow rate between $0.165 \mathrm{~m}^{3} / \mathrm{s}$ $\left(350 \mathrm{ft}^{3} / \mathrm{min}\right)$ and $0.467 \mathrm{~m}^{3} / \mathrm{s}\left(990 \mathrm{ft}^{3} / \mathrm{min}\right)$. Pressure taps were located $150 \mathrm{~mm}$ upstream and downstream of the heat exchanger, and the flow rate was measured using the venturi tube located between the test section and the blower module as shown in Figure 3.1. 
Assuming that the entire pressure drop was realized linearly through the coil, we declared that the pressure gradient is equal to the pressure difference divided by the coil thickness.

$\frac{\partial P}{\partial x}=\frac{\Delta P}{\Delta x}$

Next, we approximated the average air flow velocity through the heat exchanger as the volumetric flow rate divided by the cross sectional area. Then we fit a curve to the measured data with the functional form:

$\frac{\partial P}{\partial x}=C_{q}[u]^{2}+C_{l}[u]$

And determined the values of $C_{q}$ and $C_{l}$ using the least squares method. The measurement data and reduction is shown in Appendix A.

$C_{q}=123.23 \frac{\mathrm{kg}}{\mathrm{m}^{4}}$

$C_{l}=226.19 \frac{\mathrm{kg}}{\mathrm{s} \cdot \mathrm{m}^{3}}$

$R^{2}=0.9975$

$C_{q}$ and $C_{l}$ were then used with the heat exchangers' porosity, $\beta$, and the air density, $\rho$, to calculate the momentum resistance coefficients $K_{q}$ and $K_{l}$ through the following relationships:

$$
\begin{gathered}
K_{q}=\frac{2 \beta^{2} C_{q}}{\rho}=\frac{2 \cdot\left(123.23 \frac{\mathrm{kg}}{\mathrm{m}^{4}}\right)}{1.184 \frac{\mathrm{kg}}{\mathrm{m}^{3}}}=212.15 \frac{1}{\mathrm{~m}} \\
K_{l}=\frac{2 \beta C_{l}}{\rho}=\frac{2 \cdot\left(226.19 \frac{\mathrm{kg}}{\mathrm{s} \cdot \mathrm{m}^{3}}\right)}{1.184 \frac{\mathrm{kg}}{\mathrm{m}^{3}}}=389.41 \frac{1}{\mathrm{~s}}
\end{gathered}
$$

Note that here we used a value of $\beta=1$ rather than the actual value of the porosity of this heat exchanger. In effect, by doing this we are simplifying the problem by incorporating the porosity directly into the momentum resistance coefficients; therefore, these values for $K_{q}$ and $K_{l}$ are valid for simulation purposes as long as the porosity used in the simulation is also set to unity.

All of the above values were used as input to the CFD solver and the flow simulation converged to a solution. As mentioned earlier, we examined the solutions that were calculated when each entity was divided into $(10,15$, and 20$)$ nodes. Visual inspection of the charted results showed that the solution found with 15 nodes per entity was similar to the solution found with 20 nodes per entity indicating that 15 nodes were sufficient for 
this simulation. We compared these results by using the results of the 20 point solution to calculate the vectors at nodal locations for the 15 point solution. These solutions differed by $0.15 \%$. Figure 6.1 .3 shows the results of these three simulations, the stream wise velocity component is shown for each picture.

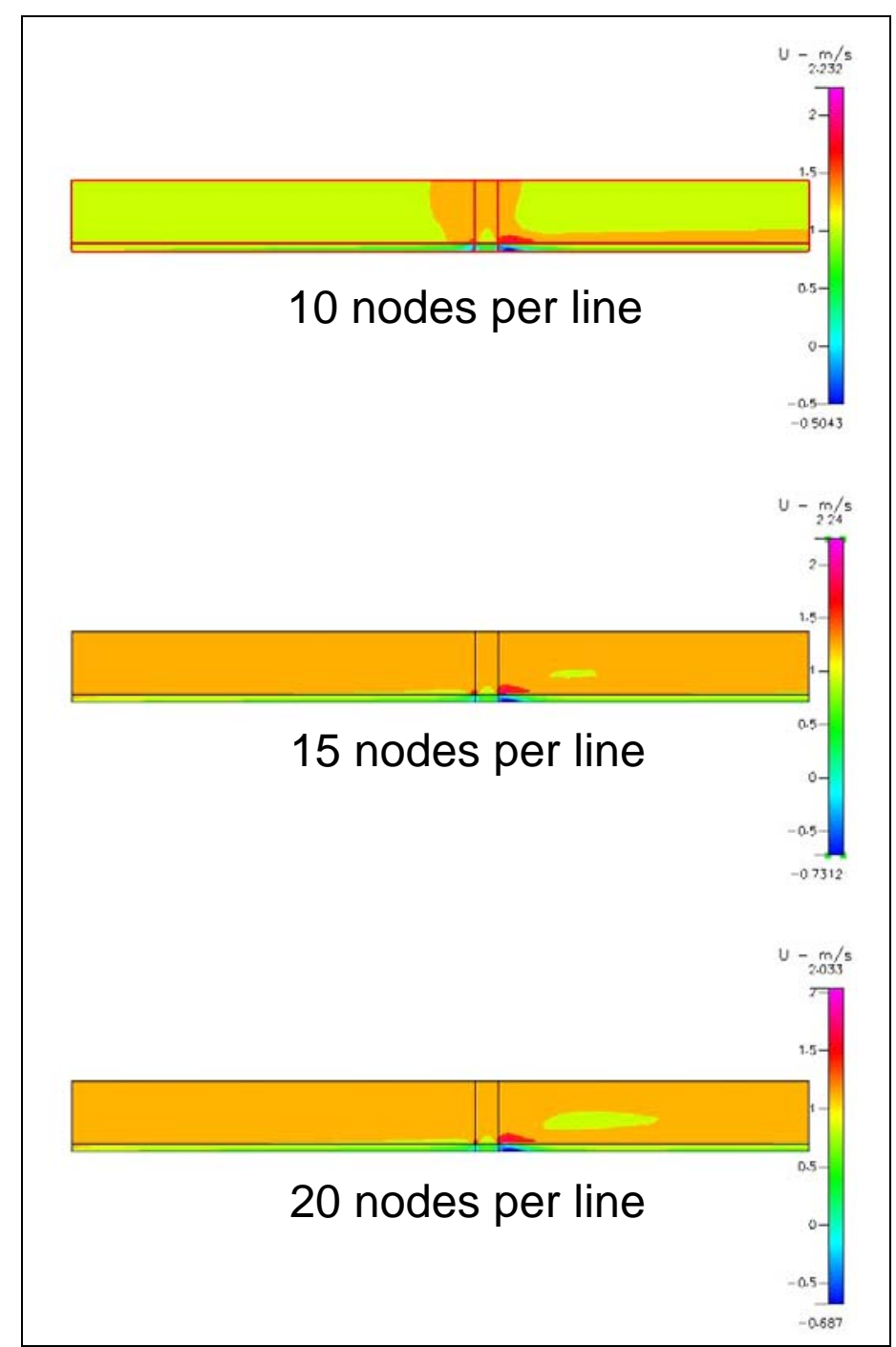

Figure 6.1.3 Stream-Wise Velocity Component for Simulation with Different Number of Nodes per Line - Vertical Coil

Figure 6.1.4 shows the velocity distribution upon approach to the heat exchanger. This figure shows that the velocity profile is altered by the presence of the mounting bracket in the lower portion of the domain. The profile changes with the distance to the coil surface. At $50 \mathrm{~mm}$ upstream, the velocity profile resembles that of free stream turbulent flow; at $25 \mathrm{~mm}$ upstream, the simulation shows that the air must begin to accelerate to navigate around the bracket, which causes a small region near the bottom of the coil to receive a slightly higher flow rate of air than the rest of the coil. At $1 \mathrm{~mm}$ upstream, the peak velocity is realized in the vicinity of the mounting bracket. 


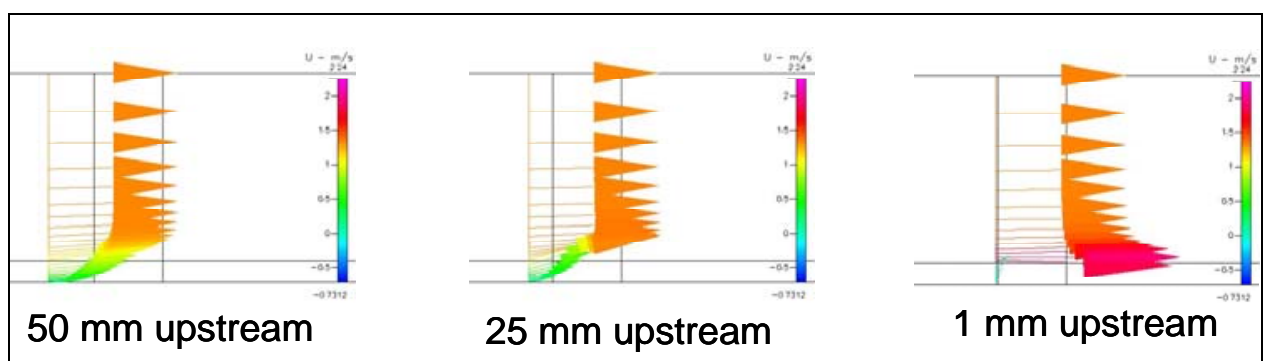

Figure 6.1.4 Approach Velocity Profile for Vertical Coil

Figure 6.1.5 shows the pressure distribution throughout the flow domain. Here we can see that the entire pressure drop occurs as a result of the flow resistance encountered as the air passes through the coil.

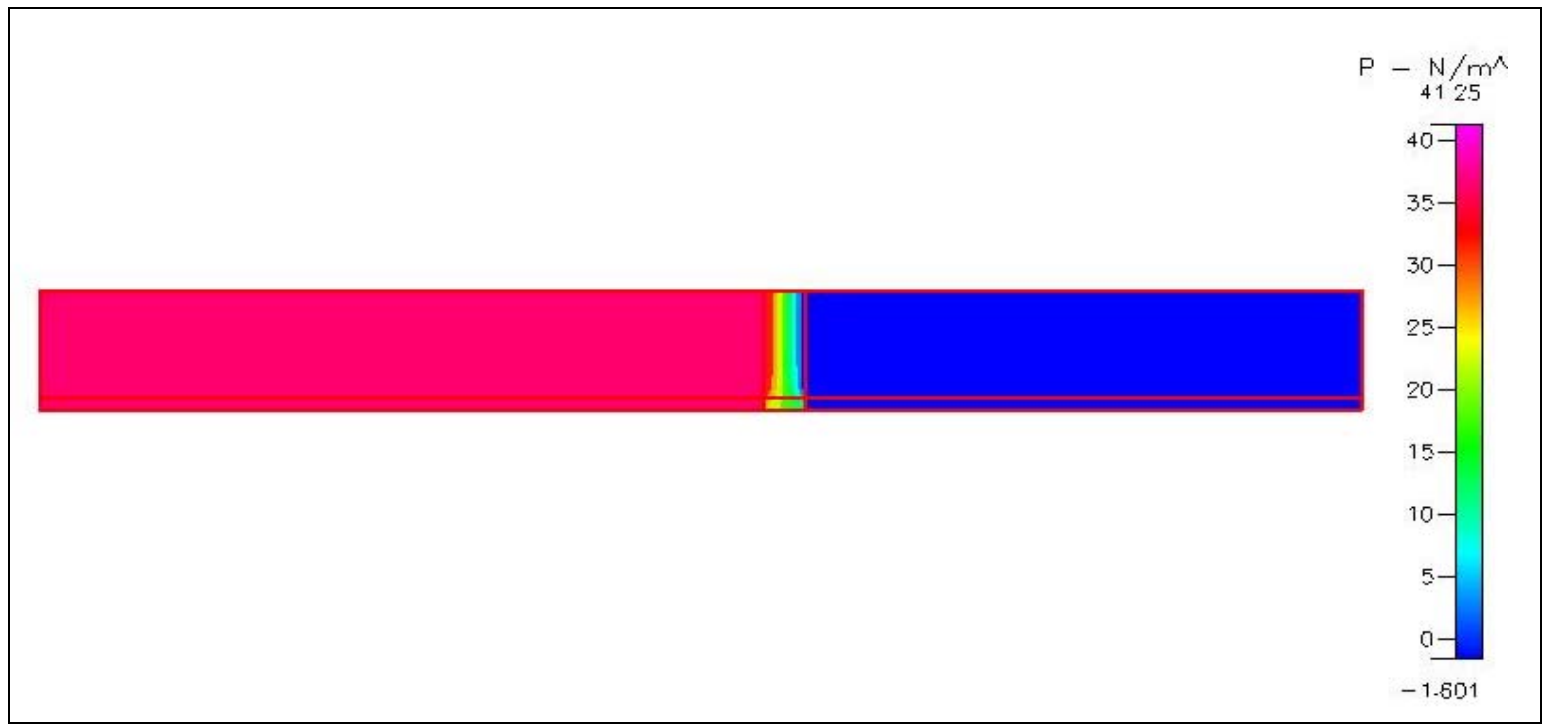

Figure 6.1.5 Pressure Profile in a Duct for the Vertical Coil

The CFD simulations show that the velocity profile changes with distance to the coil surface for the $20 \mathrm{~mm}$ upstream of the mounting bracket, as the air redistributes to navigate around the bracket. All of the simulation data shows a fairly constant velocity of $1.35 \mathrm{~m} / \mathrm{s}$ for locations further than $20 \mathrm{~mm}$ upstream of the mounting bracket, which agrees very well with the measured data. Since the camera was positioned manually for the PIV data acquisition, the data taken from these images were all measured with slightly different locations upstream of the coil surface, but were between $10 \mathrm{~mm}$ and $16 \mathrm{~mm}$. The only set of PIV data to capture this accelerated zone near the bottom of the coil was the set taken at the center of the coil, which was measured at $10 \mathrm{~mm}$ from the surface. Figure 6.1.6 shows this set of PIV data compared to the simulation data at locations $2 \mathrm{~mm}, 5 \mathrm{~mm}, 7 \mathrm{~mm}, 9 \mathrm{~mm}$, and $12 \mathrm{~mm}$ upstream of the coil surface. This figure shows that the measured PIV data is bounded by the simulated data in the $2 \mathrm{~mm}$ to $12 \mathrm{~mm}$ range. 


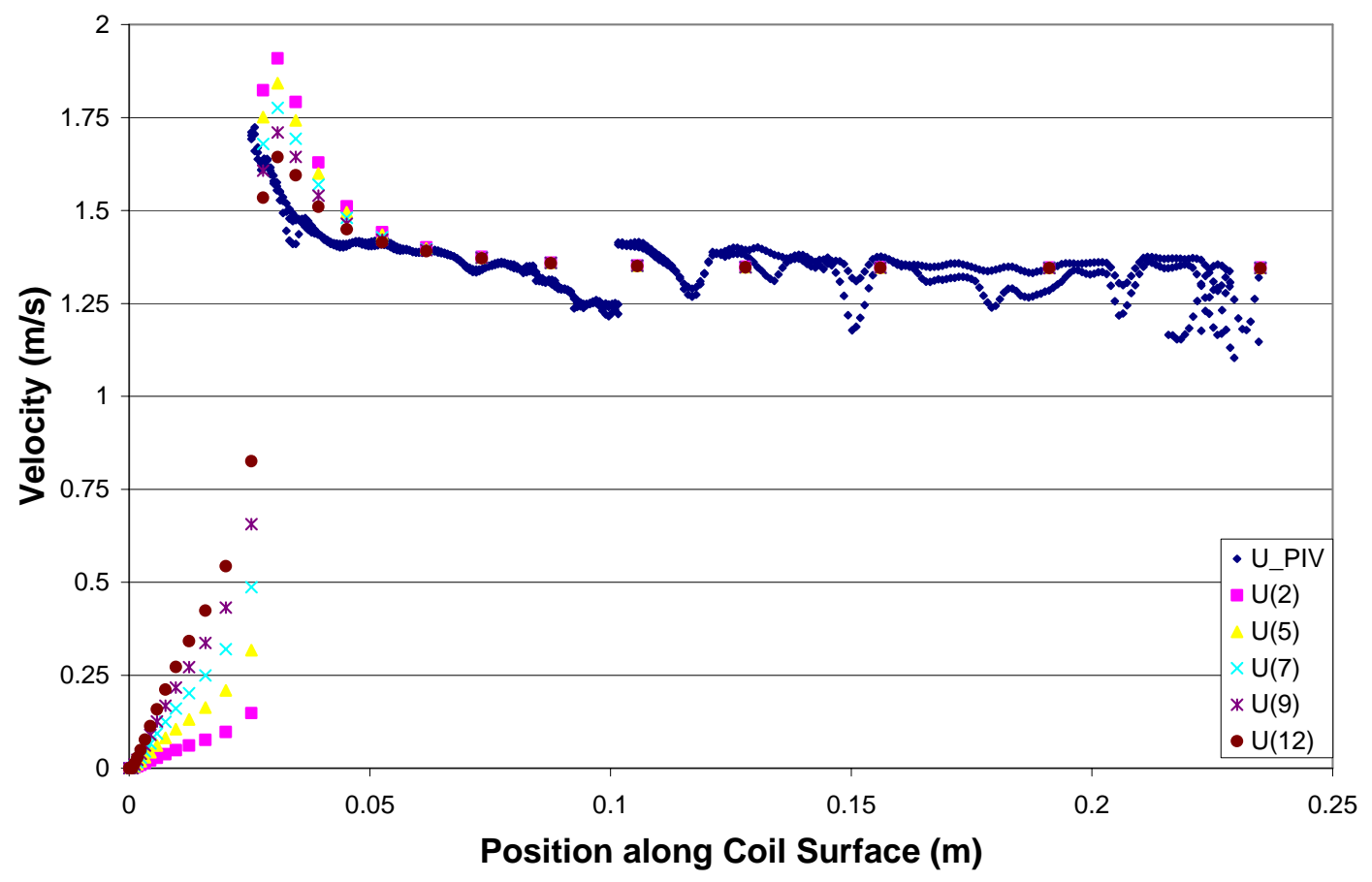

Figure 6.1.6 Comparison of PIV and CFD Data for Vertical Coil

\subsection{Slant Coil}

The CFD simulations for the slant coil were much more involved than those for the vertical coil because of the more complicated coil and duct geometry. In order to prepare a two-dimensional computational domain representative of the slant coil's flow field, the domain was divided into three regions with a total of seven sub-domains, and there were no available symmetry planes to simplify the domain. Figure 6.2.1 shows the wire mesh representation of the flow domain, with each region outlined in red and each sub-domain labeled with roman numerals I through VII. The flow through the domain is left to right.

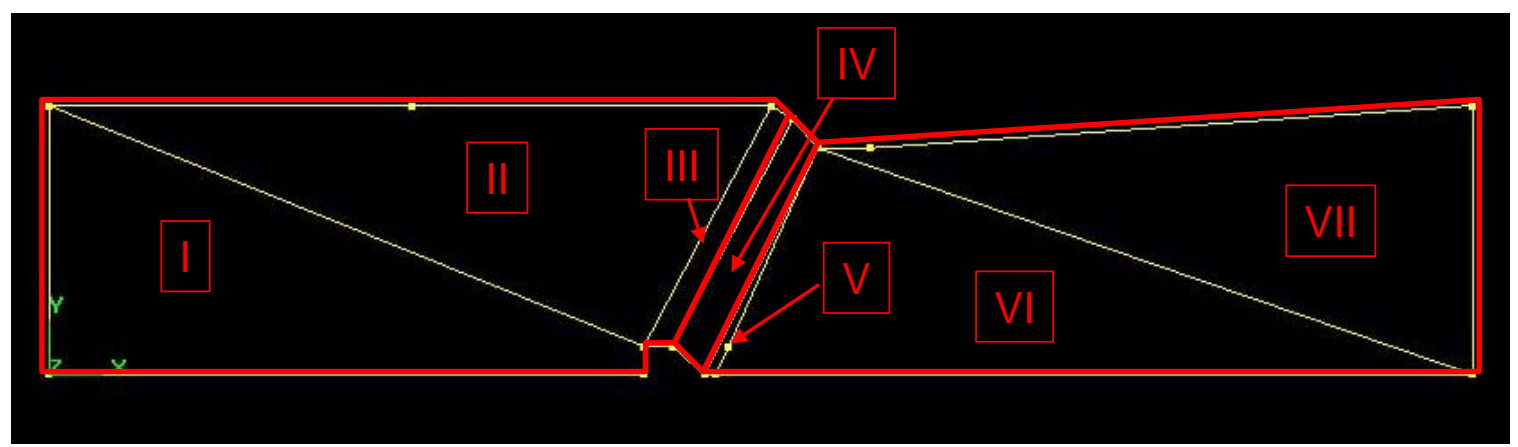

Figure 6.2.1 Computational Domain for Slant Coil

The first region, comprised of sub-domains I, II, and III, represent the duct inlet and the flow area upstream of the heat exchanger. Here, the flow inlet is located at the left-most boundary, the upper and lower boundaries represent the duct walls, and the right-most 
boundary represents the inlet surface of the heat exchanger. As the flow approaches the heat exchanger, it encounters some changes in the top and bottom boundaries. At the lower boundary, the flow approaches a step, which is representative of the heat exchanger's lower mounting bracket. At the top boundary, the flow encounters the upper mounting bracket, which angles downward.

The second region is entirely comprised of sub-domain IV. This region represents the heat exchanger, positioned at an angle to the duct. This region is where the flow will encounter all of the momentum resistance assigned by the momentum resistance CFD model.

The third region represents the computational domain downstream of the heat exchanger and is comprised of sub-domains V, VI, and VII. The air flow enters this region through sub-domain V on the left side, and exits through sub-domain VII on the right side. Note that sub-domain $\mathrm{V}$ is a very thin portion of the region. The reason for this sub-domain is that there exists a short plate attached to the lower portion heat exchanger, which acts to collect and direct water that condenses during operation. This plate is located at the back side of the heat exchanger, at a distance of $19 \mathrm{~mm}$ downstream, and follows the heat exchanger to a height of $51 \mathrm{~mm}$ above the lower duct wall.

Once the domain was constructed with the CFD software package, we used this domain for all of the CFD simulations for the slant coil. Again, we applied the same technique to determine the grid resolution; that of iteratively solving the flowfield within the computation domain, reducing the grid spacing, solving the flowfield again, and repeating until the solution matches that of the previous simulation. We consistently used a geometric spacing pattern throughout the simulations. We used a double sided spacing pattern for the inlet plane and all boundaries in sub-domains III, IV, and V; nodes were spaced along all other boundaries with a single sided geometric spacing pattern, with finer nodal spacing located in the areas with the largest expected velocity gradients. All of the nodes were dispersed along the boundaries with a geometric transition factor of 1.1, with the exception of the exit plane, which required a larger transition factor (varying between 1.2 and 1.25) to ensure a proper grid.

Constant velocity and pressure boundary conditions were set along the domain inlet, and constant farfield velocity and pressure boundary conditions were set along the domain outlet. The top and bottom of the flow domain represented the duct walls and therefore were set with no-slip boundary conditions. The short plate downstream of the heat exchanger, near the bottom of the duct, was modeled as a thin wall obstruction therefore no-slip boundary conditions were also set here. Lastly, all of the remaining boundaries were modeled as unbounded interfaces, which served to connect adjacent sub-domains.

The next step was to determine the kinetic energy and dissipation rate for the turbulence model. We started by calculating the Reynolds number from the measured data. During our PIV measurements, we used a constant flow rate of $0.355 \mathrm{~m}^{3} / \mathrm{s}$, which divided by the upstream duct cross sectional area of $0.470 \mathrm{~m} \times 0.533 \mathrm{~m}=0.251 \mathrm{~m}^{2}$, gives an average velocity of $1.416 \mathrm{~m} / \mathrm{s}$. 
The hydraulic diameter based on the duct dimensions is then:

$$
D_{h}=\frac{4 A}{P_{e r}}=\frac{4\left(0.251 \mathrm{~m}^{2}\right)}{2(0.470 \mathrm{~m}+0.533 \mathrm{~m})}=0.500 \mathrm{~m}
$$

We again used the same constant values for the density and viscosity of air as were used with the previous simulation; therefore, the Reynolds number is:

$$
\operatorname{Re}=\frac{U D_{h}}{v}=\frac{\left(1.416 \frac{\mathrm{m}}{\mathrm{s}}\right)(0.500 \mathrm{~m})}{1.562 \cdot 10^{-5} \frac{\mathrm{m}^{2}}{\mathrm{~s}}}=45,300
$$

The turbulence intensity, $I$, was calculated from this Reynolds number:

$$
I=0.16 \operatorname{Re}^{-1 / 8}=0.0419
$$

The turbulent kinetic energy, $k$, is therefore:

$$
k=1.5 U^{2} I^{2}=1.5\left(1.416 \frac{\mathrm{m}}{\mathrm{s}}\right)^{2}(0.0419)^{2}=0.00528 \frac{\mathrm{m}^{2}}{\mathrm{~s}^{2}}
$$

And the dissipation rate, $\varepsilon$, is:

$$
\varepsilon=\frac{0.1643 \cdot k^{3 / 2}}{0.07 D_{h}}=\frac{0.1643 \cdot\left(0.00528 \frac{\mathrm{m}^{2}}{\mathrm{~s}^{2}}\right)^{3 / 2}}{0.07(0.500 \mathrm{~m})}=0.001801 \frac{\mathrm{m}^{2}}{\mathrm{~s}^{3}}
$$

These values of $k$ and $\varepsilon$ were imposed along the inlet and exit planes of the simulation domain and were also used as an initial guess for the simulations. The next step was to calculate the momentum resistance coefficients based on the measured data from the laboratory measurements of the pressure drop through the slant coil. The momentum resistance coefficients were again based on 10 measured data points of the air volumetric flow rate and pressure drop through the coil; a table containing the data is included in Appendix A. We again curve fit this data with a least squares quadratic best fit to obtain the coefficients that relate the pressure gradient with the average velocity.

We made some assumptions to account for the momentum resistance model's applicability within this test section geometry. The measured data shows the pressure difference between points upstream and downstream of the heat exchanger, which includes portions of the flow domain that may impart some pressure drop to the flow, specifically the obstructive mounting bracket. Also, we know that the flow must turn to 
pass through the heat exchanger, which may induce further pressure losses. However, the momentum resistance model that we used for this simulation is based on the assumptions that the entire measured pressure drop through the test section occurs within the heat exchanger, and that any other losses will be negligible.

Our momentum resistance model is based on the average velocity through the heat exchanger; therefore the velocity used in the calculations is based on the measured volumetric flow rate divided by the face area of the heat exchanger. Through this analysis, we assigned a quadratic curve fit to the data and obtained the following coefficients for pressure gradient vs. velocity relationship:

$$
\begin{aligned}
& C_{q}=134.8 \frac{\mathrm{kg}}{\mathrm{m}^{4}} \\
& C_{l}=212.33 \frac{\mathrm{kg}}{\mathrm{s} \cdot \mathrm{m}^{3}} \\
& R^{2}=0.9963
\end{aligned}
$$

$C_{q}$ and $C_{l}$ were then used to calculate the momentum resistance coefficients $K_{q}$ and $K_{l}$ through the following relationships, again using the simplifying value of unity for the heat exchanger's porosity:

$$
\begin{gathered}
K_{q}=\frac{2 \beta^{2} C_{q}}{\rho}=\frac{2 \cdot\left(134.8 \frac{\mathrm{kg}}{\mathrm{m}^{4}}\right)}{1.184 \frac{\mathrm{kg}}{\mathrm{m}^{3}}}=227.71 \frac{1}{\mathrm{~m}} \\
K_{l}=\frac{2 \beta C_{l}}{\rho}=\frac{2 \cdot\left(212.33 \frac{\mathrm{kg}}{\mathrm{s} \cdot \mathrm{m}^{3}}\right)}{1.184 \frac{\mathrm{kg}}{\mathrm{m}^{3}}}=358.67 \frac{1}{\mathrm{~s}}
\end{gathered}
$$

We performed simulations using these values to solve the flow field within the computational domain with four different mesh resolutions. We began with 15 nodes dispersed across each entity, as described in the previous section, and increased the number of nodes to 20, 25, and 30. Visual inspection of the charted results showed that the solution found with 25 nodes per entity was similar to the solution found with 30 nodes per entity indicating that 25 nodes were sufficient for this simulation. We compared these results by using the results of the 30 point solution to calculate the vectors at nodal locations for the 25 point solution. These solutions differed by $0.7 \%$. Figure 6.2.2 shows the maps depicting the downstream component of velocity for each of the simulations. 

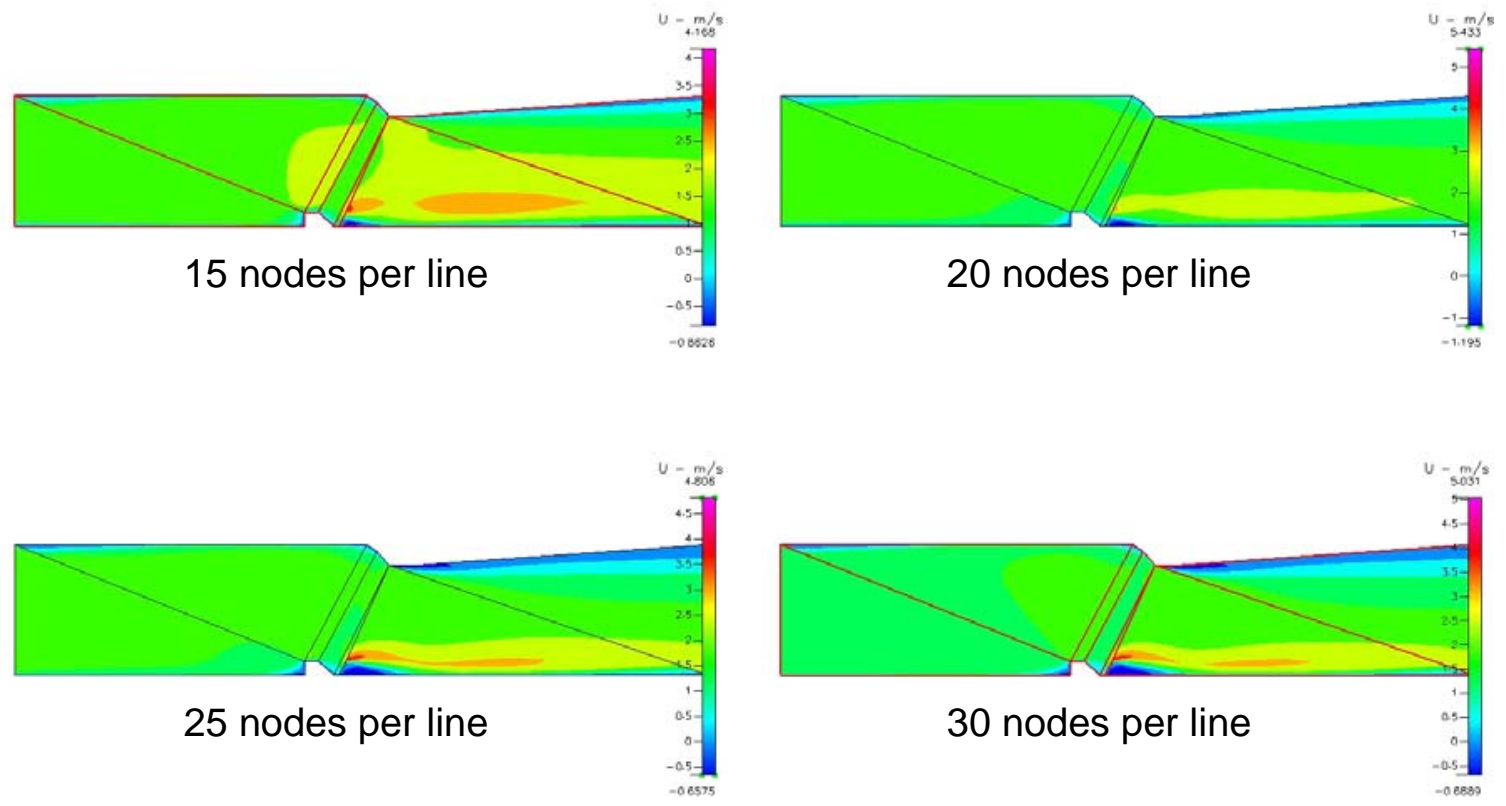

Figure 6.2.2 Stream-Wise Velocity Component for Simulation with Different Number of Nodes per Line - Slant Coil

Figure 6.2.3 shows the pressure distribution over the computational domain. Here we can see that the majority of the drop in pressure occurs within the sub-domain representative of the heat exchanger slab; however, there exists some pressure drop occurring outside of the momentum resistance domain.

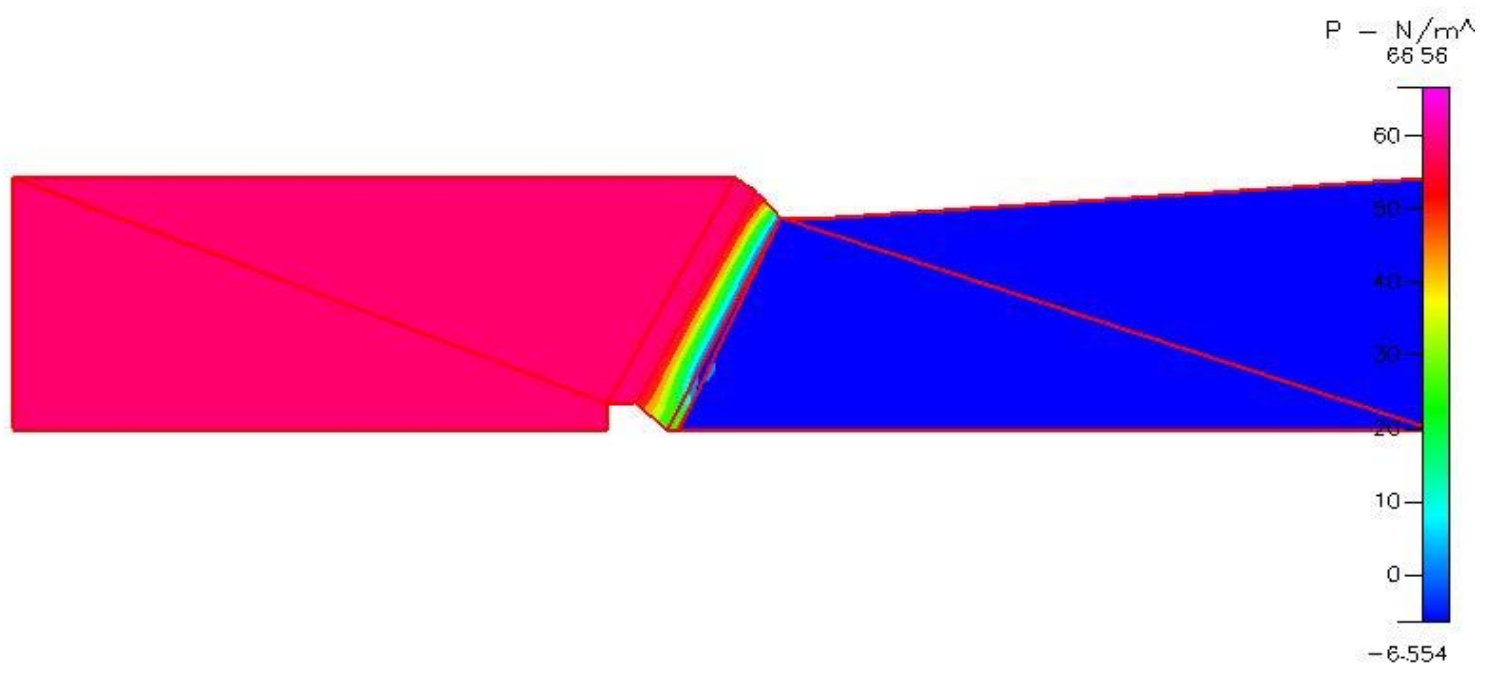

Figure 6.2.3 Pressure Profile for Slant Coil

Figure 6.2.4 shows the velocity vector field upon approach to the vector field at various locations measured from the duct inlet. The first two pictures in this sequence show image planes that are entirely upstream of the heat exchanger, the third picture (location $1118 \mathrm{~mm}$ ) shows the point where the bottom of the image plane first touches the inlet 
surface of the heat exchanger, and the last two pictures show the plane passing through a portion of the heat exchanger. In this sequence, we can see that the flow reacts to the mounting bracket by accelerating around it causing an increase in the local flow rate near the lower portion of the heat exchanger.

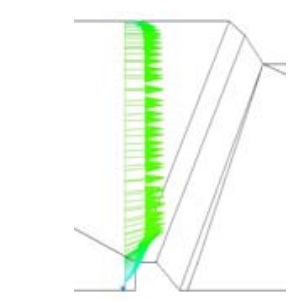

Location:1042mm

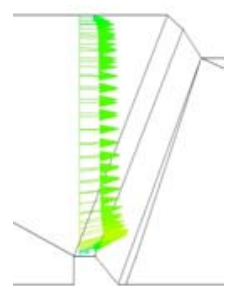

$1080 \mathrm{~mm}$

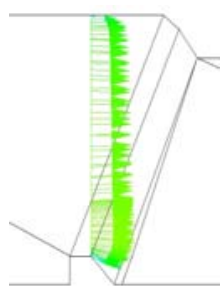

$1118 \mathrm{~mm}$

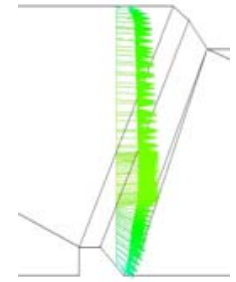

$1156 \mathrm{~mm}$

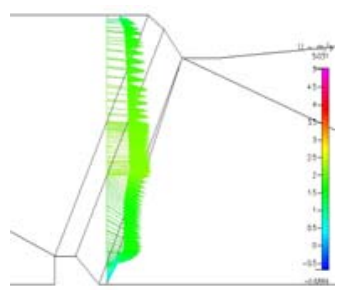

$1195 \mathrm{~mm}$

Figure 6.2.4 Vector Profile for Slant Coil

Figure 6.2.5 shows the comparison of the CFD simulations with the measured PIV data. Here, the perpendicular component of velocity is plotted against the position along the coil. We can see that there is very good agreement between the predicted data and the measured data. 


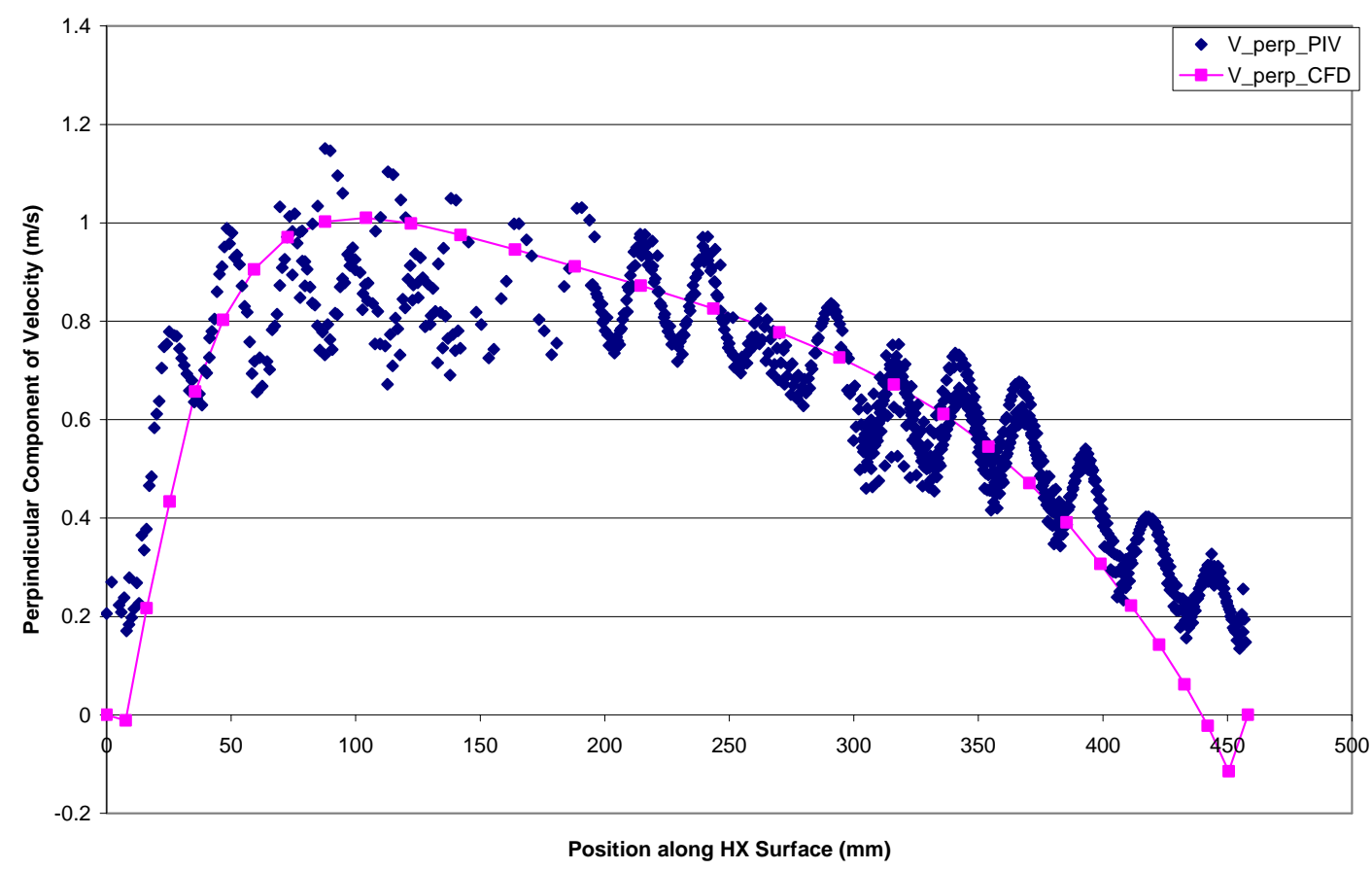

Figure 6.2.5 Comparison of PIV and CFD Data for Slant Coil

\subsection{A-Shaped Coil}

The CFD simulations for the A-shaped coil were the most complicated of those examined in this study due to the complexity of the geometry. We began by preparing the geometrical domain for the solver in the same manner as the other two heat exchangers, two dimensional and in alignment with the PIV measurement slices. The A-shaped coil did provide an opportunity for a simplification in the domain due to symmetry; therefore, only one slab of the heat exchanger is modeled in this domain. The computational domain used for these simulations is shown below in Figure 6.3.1.

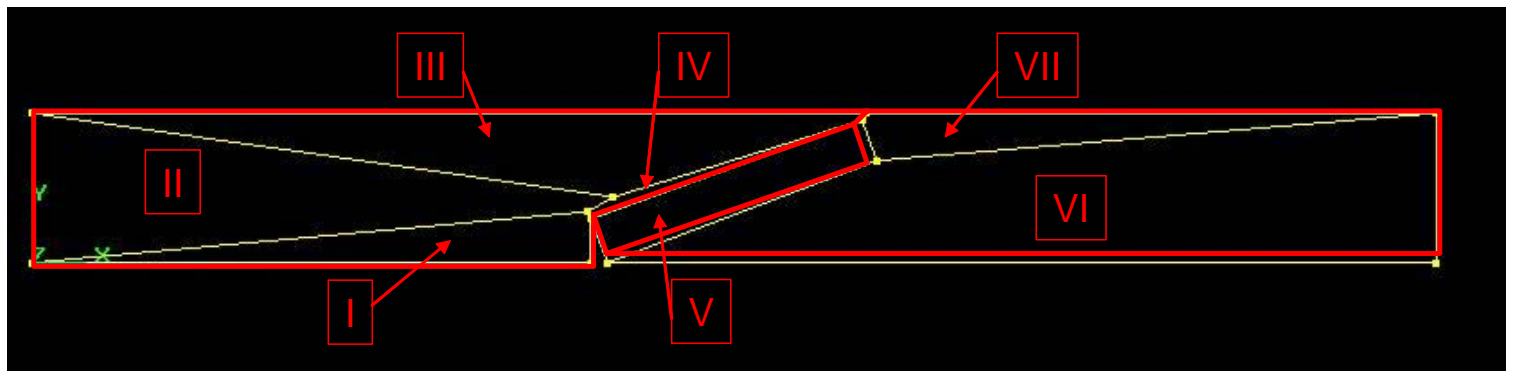

Figure 6.3.1 Computational Domain for A-Shaped Coil

We divided the computational domain into three regions with a total of seven subdomains as shown. Sub-domains I through IV are upstream of the heat exchanger slab, sub-domain V represents the heat exchanger itself, and sub-domains VI and VII represent the flow domain downstream of the heat exchanger. The inlet is the left-most entity 
located in sub-domain II, and the exit is the right-most entity located in sub-domain VI. The entities that span the top portion of this figure represent the symmetry line that we used to simplify the computational domain. The lines along the lower portion of the figure represent the duct walls and the rigid obstructions connected to the heat exchanger slab. The lines partitioning sub-domains I from II; II from III; III from IV; and VI from VII merely serve to divide the sub-domains and are not physical boundaries. Figure 6.3.2 shows an enlarged portion taken from Figure 6.3.1, as this section requires a more detailed explanation.

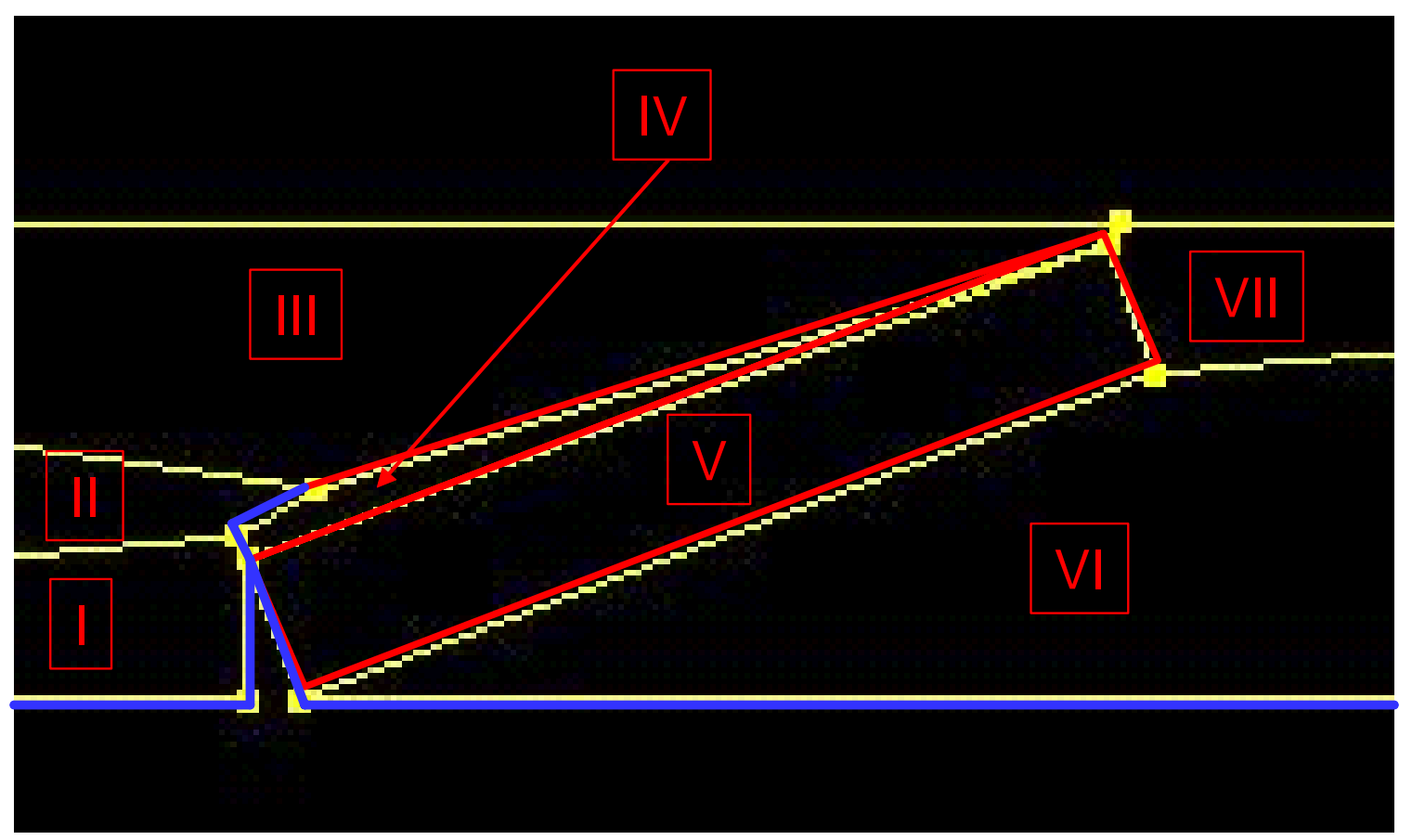

Figure 6.3.2 Blowup of Computational Domain for A-Shaped Coil

In this figure, rigid boundaries (specifically the duct wall and the condensate drain pan) are represented by the blue lines. These are fixed boundaries; therefore air cannot pass though them. Here we can see that the flow coming from sub-domains I and II must accelerate around the edge of the condensate pan and approach the heat exchanger through sub-domain III. All flow into the heat exchanger must, therefore, pass through sub-domain III then through sub-domain IV before entering sub-domain V.

Once we completed the wire grid domain, we again applied the iterative simulate/tighten mesh/re-simulate technique until the solution matched the previous simulation. We consistently used geometric nodal spacing with a transition factor of 1.2 throughout the simulations. Single sided geometric spacing was applied for entities that approached the symmetry plane, the domain inlet, and the domain exit, with the finer nodal spacing nearest the wall or the center of the domain. Double sided geometric nodal spacing was applied to all other entities. We again imposed the inlet boundary conditions of constant velocity and pressure, and the exit boundary conditions of constant farfield velocity and pressure. 
Next we determined the parameters for use in the CFD solver's $k$ - $\varepsilon$ turbulence model in the same manner as with the other simulated cases. First the duct's cross sectional area and the hydraulic diameter:

$$
\begin{aligned}
& A=(0.511 \mathrm{~m})(0.495 \mathrm{~m})=0.253 \mathrm{~m}^{2} \\
& D_{h}=\frac{4 A}{P_{e r}}=\frac{4\left(0.253 \mathrm{~m}^{2}\right)}{2(0.511 \mathrm{~m}+0.495 \mathrm{~m})}=0.503 \mathrm{~m}
\end{aligned}
$$

And therefore the average velocity based on the tested flow rate is:

$\bar{V}=\frac{Q}{A}=\frac{0.651 \frac{\mathrm{m}^{3}}{\mathrm{~s}}}{0.253 \mathrm{~m}^{2}}=2.574 \frac{\mathrm{m}}{\mathrm{s}}$

We again used the same constant values for the density and viscosity of air as were used with the previous simulation; therefore, the Reynolds number is:

$$
\operatorname{Re}=\frac{U D_{h}}{v}=\frac{\left(2.574 \frac{\mathrm{m}}{\mathrm{s}}\right)(0.503 \mathrm{~m})}{1.562 \cdot 10^{-5} \frac{\mathrm{m}^{2}}{\mathrm{~s}}}=82,900
$$

The turbulence intensity, $I$, is calculated from this Reynolds number:

$$
I=0.16 \operatorname{Re}^{-1 / 8}=0.03884
$$

The turbulent kinetic energy, $k$, is therefore:

$$
k=1.5 U^{2} I^{2}=1.5\left(2.574 \frac{\mathrm{m}}{\mathrm{s}}\right)^{2}(0.03884)^{2}=0.01499 \frac{\mathrm{m}^{2}}{\mathrm{~s}^{2}}
$$

And the dissipation rate, $\varepsilon$, is:

$$
\varepsilon=\frac{0.1643 \cdot k^{3 / 2}}{0.07 D_{h}}=\frac{0.1643\left(0.01499 \frac{\mathrm{m}^{2}}{\mathrm{~s}^{2}}\right)^{3 / 2}}{0.07(0.503 \mathrm{~m})}=0.00856 \frac{\mathrm{m}^{2}}{\mathrm{~s}^{3}}
$$

Lastly, we again determined the momentum resistance coefficients for this configuration. Using the laboratory apparatus, we measured 10 points relating the flow rate to the pressure drop through the heat exchanger. Data was taken over a range of flow rates 
between $0.151 \mathrm{~m}^{3} / \mathrm{s}\left(319 \mathrm{ft}^{3} / \mathrm{min}\right)$ and $0.661 \mathrm{~m}^{3} / \mathrm{s}\left(1400 \mathrm{ft}^{3} / \mathrm{min}\right)$; the measurement data are shown in Appendix A. As we did with the slant coil, we assumed that the entire measured pressure drop occurs within the heat exchanger slab, thereby allowing us to assign momentum resistance coefficients solely to the heat exchanger. We determined the average velocity through the heat exchanger by dividing the flow rate by the sum of the surface areas of both slabs of the A-Shaped coil. We then used the least squares method to determine the coefficients of the curve fit of the model's functional form:

$$
\begin{aligned}
C_{q} & =258.11 \frac{\mathrm{kg}}{\mathrm{m}^{4}} \\
C_{l} & =56.49 \frac{\mathrm{kg}}{\mathrm{s} \cdot \mathrm{m}^{3}} \\
R^{2} & =0.999
\end{aligned}
$$

And then used these intermediate coefficients to determine the momentum resistance model coefficients as was done in the previous cases with the porosity equal to unity:

$$
\begin{gathered}
K_{q}=\frac{2 \beta^{2} C_{q}}{\rho}=\frac{2 \cdot\left(258.11 \frac{\mathrm{kg}}{\mathrm{m}^{4}}\right)}{1.184 \frac{\mathrm{kg}}{\mathrm{m}^{3}}}=435.99 \frac{1}{\mathrm{~m}} \\
K_{l}=\frac{2 \beta C_{l}}{\rho}=\frac{2 \cdot\left(56.49 \frac{\mathrm{kg}}{\mathrm{s} \cdot \mathrm{m}^{3}}\right)}{1.184 \frac{\mathrm{kg}}{\mathrm{m}^{3}}}=95.416 \frac{1}{\mathrm{~s}}
\end{gathered}
$$

Once we had determined all of the relevant parameters, we began the computational simulations to determine the required mesh resolution for this flow domain. We began our simulations with a resolution of 15 nodes spaced over each entity and added 5 nodes per entity until we reached a solution that coincided with the previous simulation. In this case, we repeated this iterative process with 20, 25, 30, 35 and 40 nodes per entity. Visual inspection of the charted results showed that the solution found with 40 nodes per entity was similar to the solution found with 35 nodes per entity indicating that 35 nodes were sufficient for this simulation. We compared these results by using the results of the 40 point solution to calculate the vectors at nodal locations for the 35 point solution. These solutions differed by $3 \%$. The results of these simulations is shown in Figure 6.3.3, both the plots depicting the $u$ and $v$ components of velocity are shown, since these results involve substantial contributions from each. 

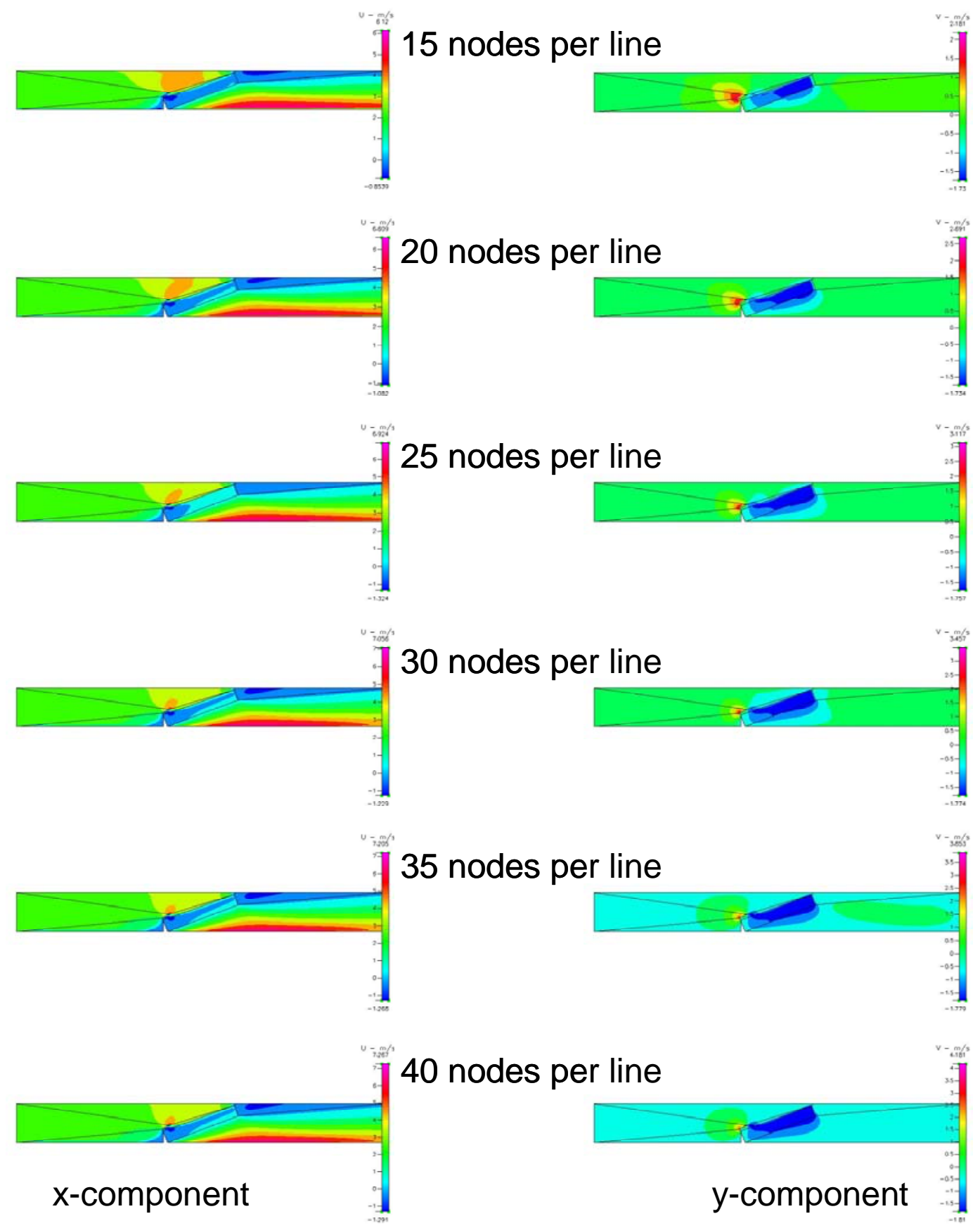

Figure 6.3.3 Stream-Wise Velocity Component for Simulation with Different Number of Nodes per Line - A-Shaped Coil

At the onset of this simulation, we made an assumption for our momentum resistance model that the entire measured pressure drop occurred within the heat exchanger slab. Our simulation results do not agree very well with this assumption, as shown in Figure 6.3.4. 


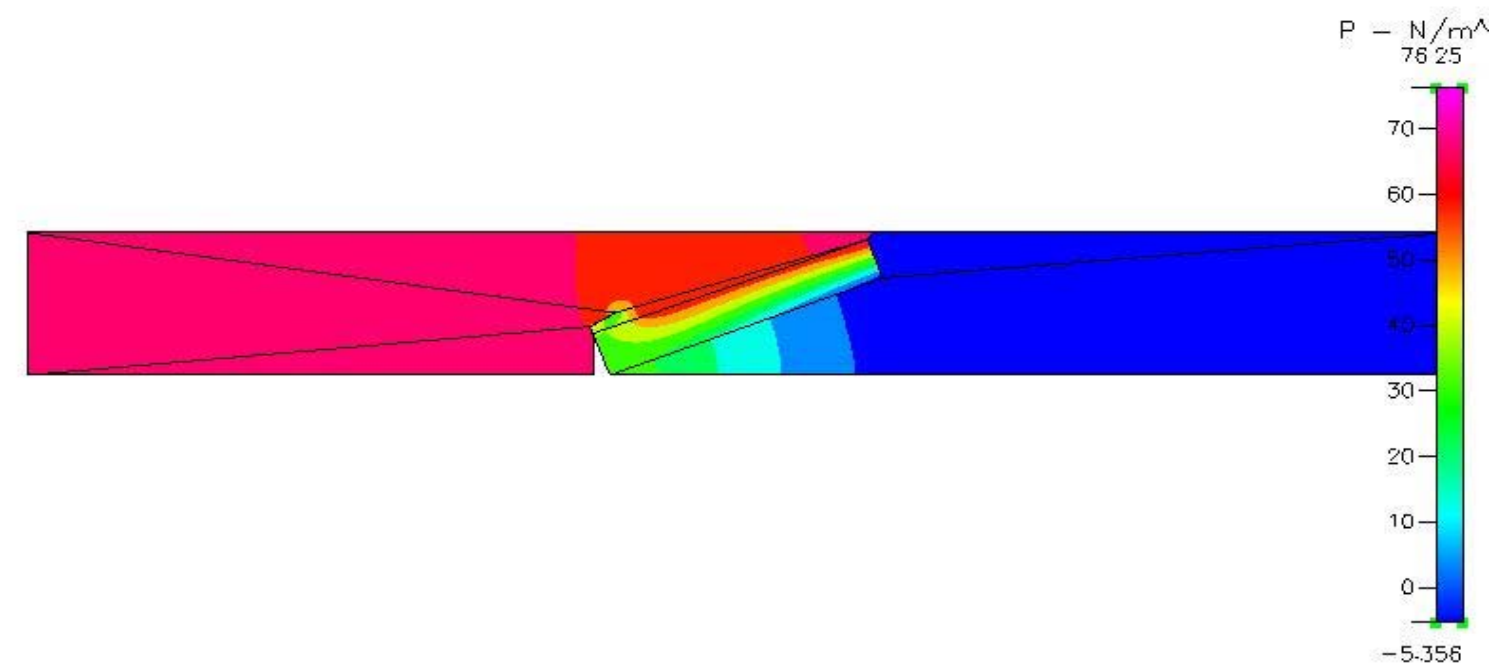

Figure 6.3.4 Pressure Profile for A-Shaped Coil

Our simulation results show that although most of the pressure drop occurs within the slab, there are significant contributions from two other the locations within the domain. The first location is where the condensate pan impacts the approaching flow; here the condensate pan blocks off almost half of the entire flow path forcing the flow to accelerate considerably, and then turn abruptly to approach the heat exchanger. The other location is at the heat exchanger exit. Here, since the angle between the heat exchanger and the duct is very small, the flow leaving the heat exchanger impacts the duct and turns towards the exit plane. Although these points reiterate the fact that our initial assumptions are not completely accurate, the solutions offered here are quite realistic. Although not perfect, this simulation provides us with a wealth of information about this flow field, and shows that the simulated velocity profile agrees well with the measured profile.

In order to provide a much more accurate simulation in the future, a better method would be to calculate the momentum resistance coefficients from laboratory data taken using the heat exchanger slab positioned at $90^{\circ}$ to the flow (as was done with the first coil in this study). Again, however, for the purposes of this study, the solution provided by coefficients that were calculated from overall pressure drop matched the measured data.

Figure 6.3.5 shows a series of velocity distribution patterns as determined by the CFD simulation. This figure well illustrates the complexity of this problem. The first velocity distribution pattern shown upstream of the heat exchanger is a typical pattern found in unobstructed turbulent flow. As the flow approaches the second position in the sequence, the air begins to negotiate around the condensate pan, i.e. flow near the bottom decelerates and the flow near the top accelerates to compensate for the increased mass flow. At the third position, the velocity distribution gets quite interesting. Along this line, most of the locations realize forward moving flow; however, the region between the condensate pan and the heat exchanger slab realizes backwards flow. The $4^{\text {th }}$ and $5^{\text {th }}$ 
position show how the flow passes through the heat exchanger and then change course to flow towards the exit plane.

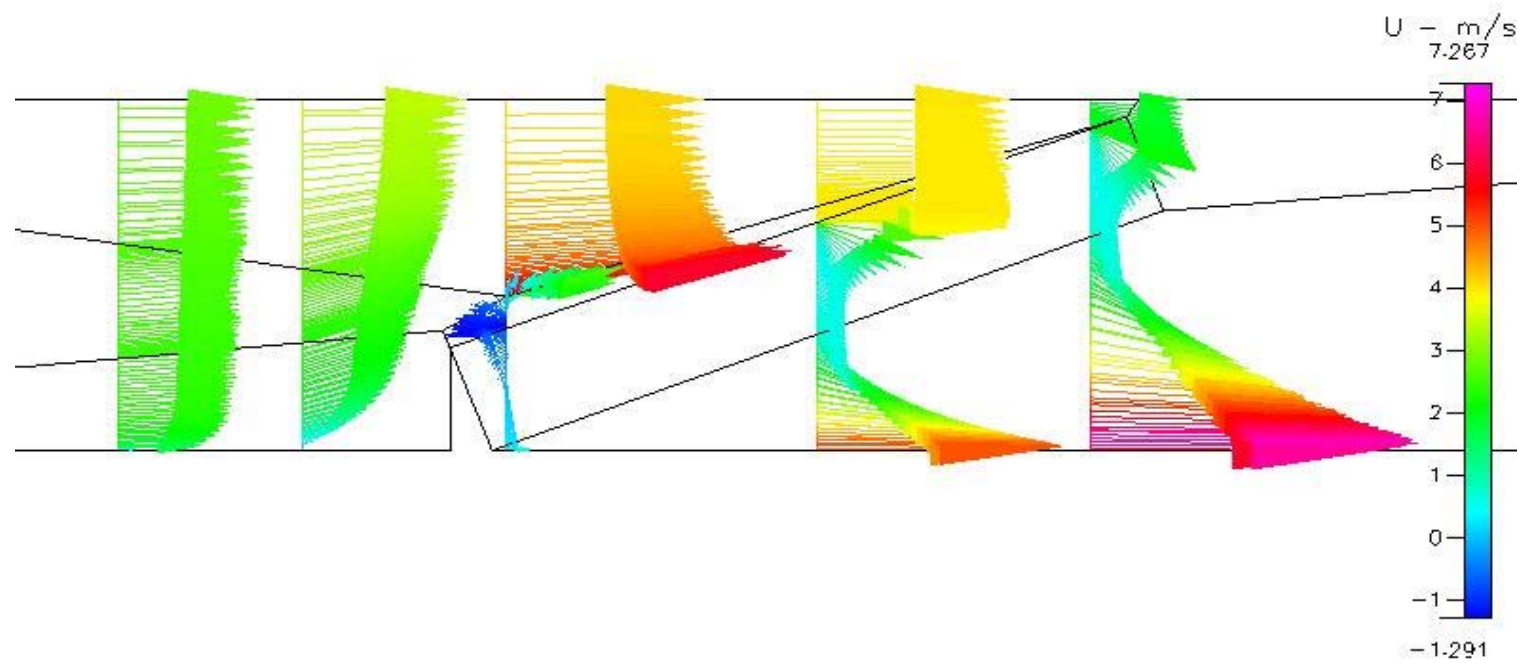

Figure 6.3.5 Vector Profile for A-Shaped Coil

Figure 6.3.6 shows the computed vector field located within the lower portion of subdomain IV. The results of this simulation predicted the recirculation zone seen during the PIV measurements. The presence, location, and magnitude of this recirculation zone agree with the information that we have from Figure 5.3.4 from the PIV measurements. The amount of information in Figure 5.3.4 is somewhat limited, though, since the laser sheet was obstructed by the condensate pan; but the simulation results agree very well with the measured data that we do have. 


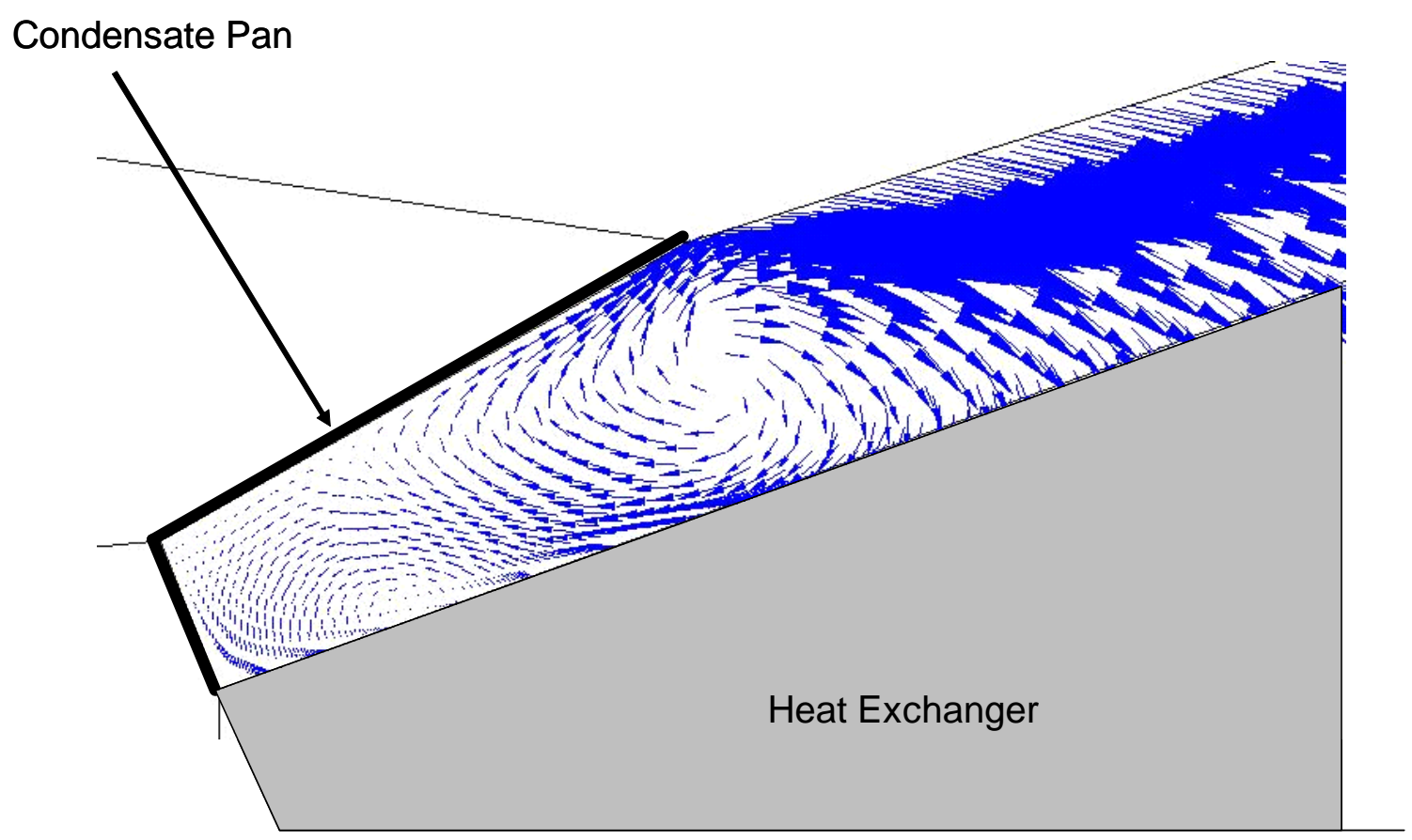

Figure 6.3.6 CFD Resolution of Recirculation Zone

The important information from this simulation is the air velocity profile as it enters the heat exchanger. Since we have computationally solved the entire flow domain, we can readily extract the velocity at any point within the domain, unlike with the PIV measurements where we are limited by line-of-sight. Figure 6.3.7 shows an enlarged picture of the computational domain used for the simulation. In this figure, the heat exchanger slab is shown in grey, with its inlet surface shown by the red line AD. The edge of the condensate pan is shown by the black lines connecting points $\mathrm{A}$ and $\mathrm{B}$. The blue line connected by points B and $\mathrm{C}$ represent the bottom edge of the line-of-sight plane used during the PIV measurements; therefore the PIV measurements used for comparison from this point onward are taken along B-C-D.

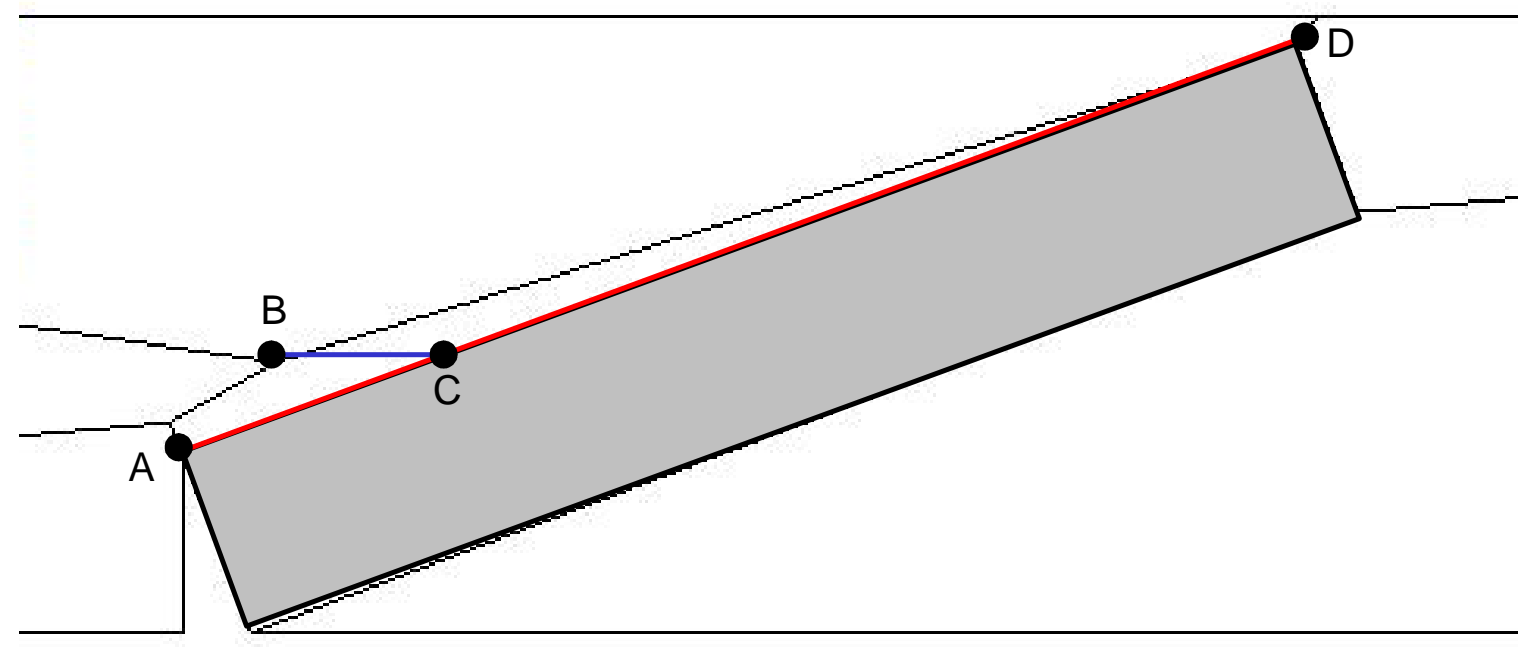

Figure 6.3.7 Computational Domain Sections 
Figure 6.3.8 shows the perpendicular component of the velocity field entering the lower slab of the heat exchanger, as computed by the CFD simulation. The data set shows the inlet velocity profile as realized by the heat exchanger along the line connecting points A and D from Figure 6.3.7.

This simulation shows that there exists a very large inefficient portion of this heat exchanger. There is a very small amount of air entering the coil along the very bottommost portion of the heat exchanger (between $0 \mathrm{~mm}$ and $21 \mathrm{~mm}$ from the edge). Then, between $21 \mathrm{~mm}$ and $80 \mathrm{~mm}$, the air flow is actually moving away from the coil. After about $80 \mathrm{~mm}$, a somewhat normal positive air flow pattern is established. This positivenegative-positive pattern indicates a recirculation zone. As a direct result of this recirculation zone a large portion of the heat exchanger receives very little or no air flow at all.

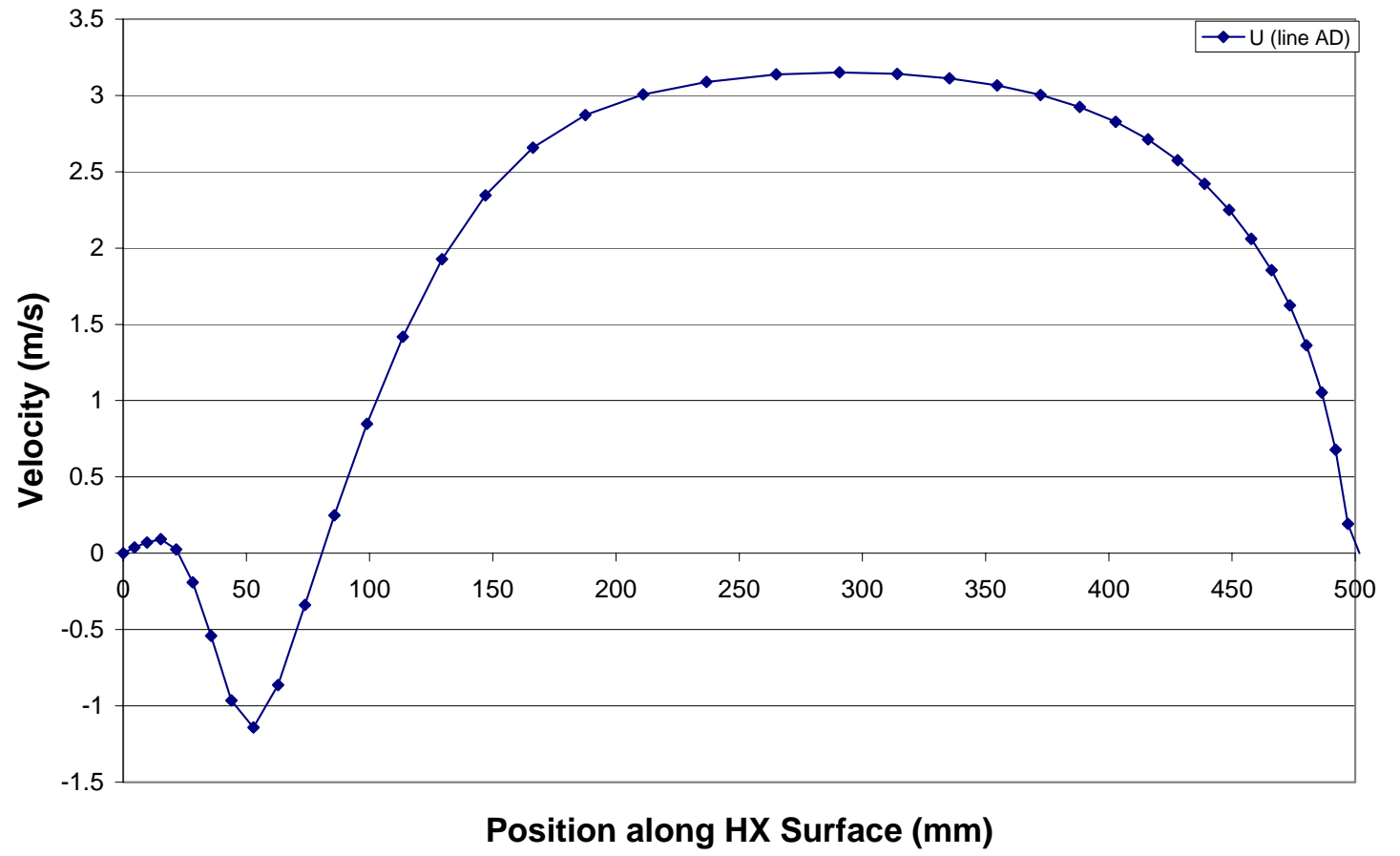

Figure 6.3.8 CFD Velocity Profile at A-Shaped Coil Inlet

We can compare the simulation results to the PIV measurements. Figure 6.3.9 shows the two data sets overlaid onto the same plot. In a few areas the computed velocity field differs from the measured velocity field; however, these differences can be explained. 


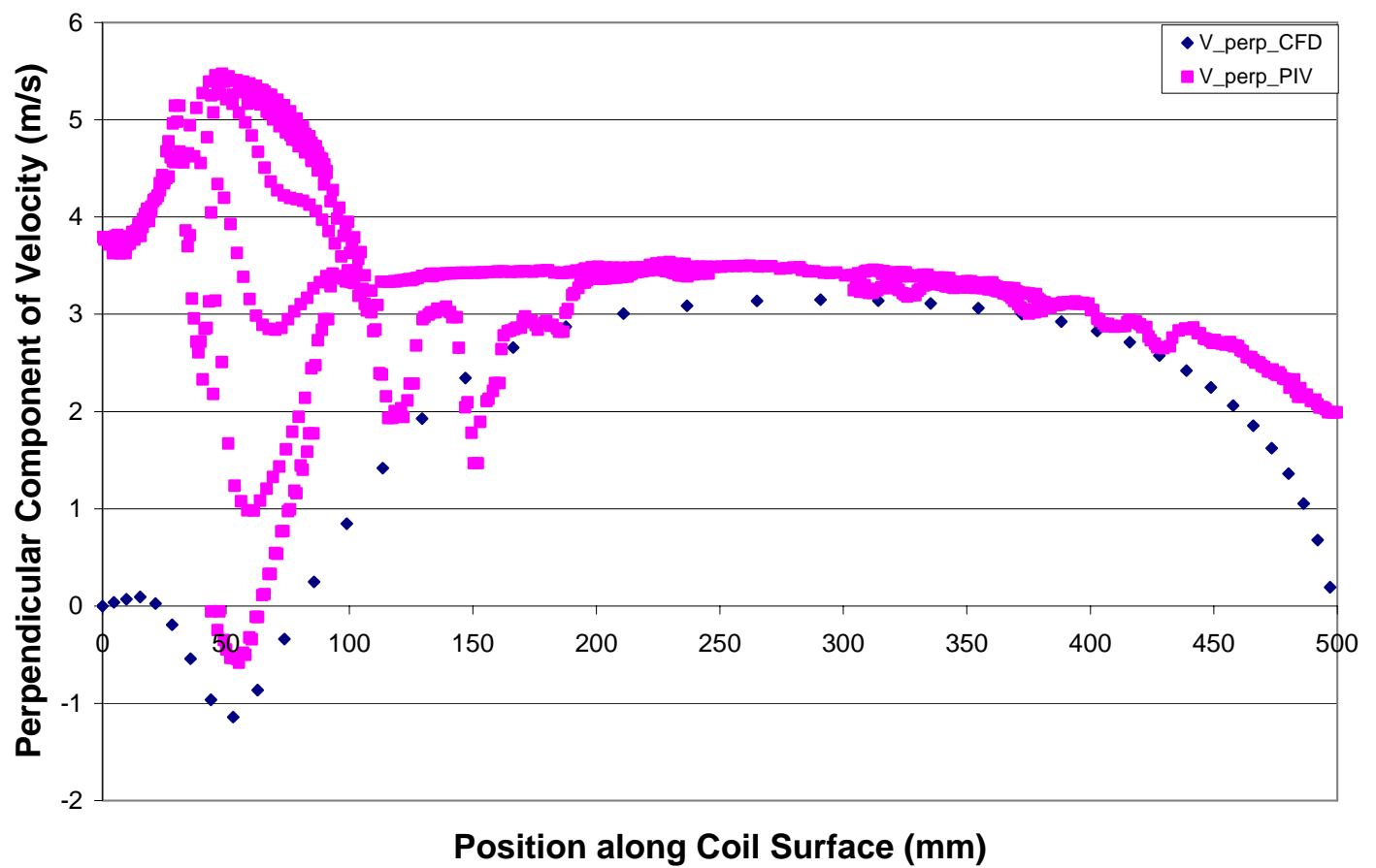

Figure 6.3.9 Comparison of PIV Data with CFD Coil Inlet Data for A-Shaped Coil

The CFD data plotted in Figure 6.3.9 shows the perpendicular component of velocity right at the heat exchanger interface; whereas the PIV data was measured at points that are slightly upstream from the heat exchanger interface. As was seen in the previous example, the simulation shows that the air flow decelerates at the interface, therefore, points slightly upstream show velocities that are a little higher than those at the interface. Figure 6.3.10 shows the measured PIV data overlaid with the perpendicular component of velocity for entire computational sub-domain IV. This figure shows that the simulated data does, in fact, agree very well with the measured data. This indicates that it is important to measure the velocity with PIV as close to the heat exchanger surface as allowed by line-of-sight because of the very large velocity gradients in this region. 


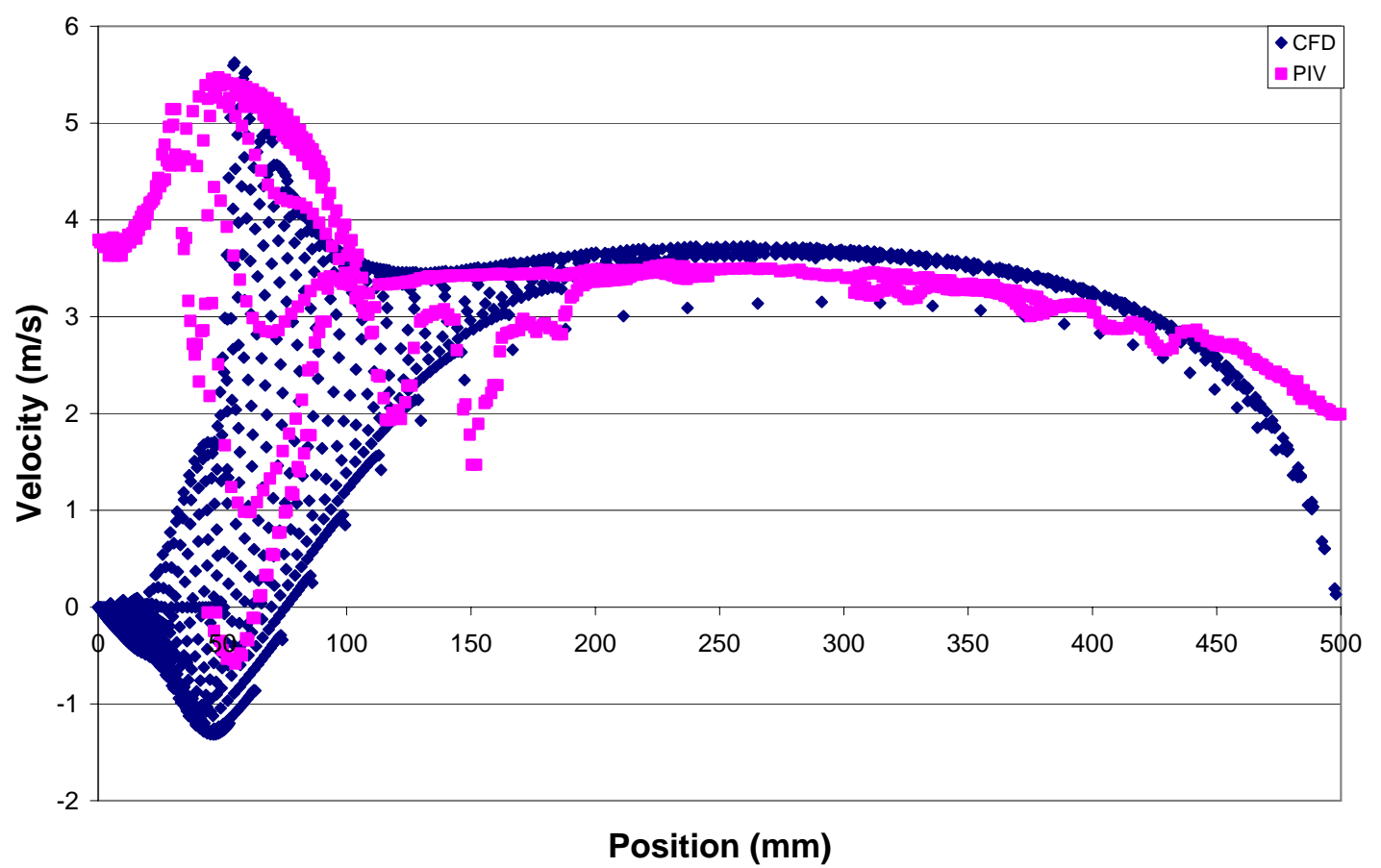

Figure 6.3.10 Comparison of PIV Data with all Data from CFD Computational SubDomain IV for A-Shaped Coil

Throughout the simulations of the more complicated installation configurations, some of the governing assumptions for the momentum resistance models were not strictly followed, but the consequences were minimal. The momentum resistance models are lumped parameter models that were used to impede the flow within a specific domain, and as such we assigned quadratic and linear impedance terms to a given domain. In our analysis, we used pressure differential information that was measured from the approach and discharge of the heat exchangers, and these regions included features outside of the heat exchanger that also reduce the static pressure and alter the local velocity. By taking this approach, the effects of the condensate pans, mounting brackets, etc. were doubly accounted for in the simulations because they were included in the momentum resistance coefficients and then simulated outside of the resistive domain. By taking this approach, we avoided the substantial burden of determining the momentum resistance coefficients through detailed simulation or additional laboratory experimentation; however, the velocity profiles found in simulation (the main intent of this study) were nearly identical to the measured ones. 


\section{7: Summary and Conclusions}

We studied the air side inlet velocity profiles of three common finned-tube heat exchanger installations. We measured the air velocity profile for each using Particle Image Velocimetry. We performed CFD simulations for the tested setups and replicated the measured air flow velocity distribution patterns.

Our measurements showed that the velocity distribution is strongly influenced by features within the duct and the orientation of the heat exchanger; therefore it is generally not uniform. Features, such as mounting brackets and condensate collection pans, greatly alter the local flow direction.

We also saw for the tested configurations that the air velocity profiles had very little variation in the lateral direction. This enabled us to accurately describe the air side velocity distribution with a simple two dimensional model. The test apparatus used in this study, however, maintained the flow by using a blower module that was located far downstream from the test section. It is therefore possible that this observation may not hold true for cases with the blower attached directly to the heat exchanger, where their three dimensional effects may be present in the duct upstream of the heat exchanger. This point requires further investigation.

The information documented in this report is very important for the design of finned-tube heat exchangers because the air distribution has a profound impact on the performance of such heat exchangers. Finned-tube heat exchangers can, in essence, be thought of as a network of single-tube cross flow heat exchangers, where the performance of the heat exchanger as a whole is dependent on the performance of each tube. If every tube in the heat exchanger is subject to a different amount of air flow, with different tube side and air side thermodynamic properties, each tube will perform differently. Ideally, the amount and thermodynamic state of refrigerant flowing through each tube should be well matched to the air side properties and velocity distribution so that the performance of the heat exchanger as a whole is maximized. Tubes which are included in the heat exchanger and receive very little or no air flow (which were located through the course of this study) reduce the overall performance of the coil. A design engineer armed with information about the air flow distribution can use it to incorporate features that minimize the losses associated with its pattern. 


\section{References:}

Adrian, R. J. Particle-Imaging Techniques for Experimental Fluid-Mechanics, Annual Review of Fluid Mechanics, no. 23, pp 261-304, 1991.

ASHRAE 1998. ANSI/ASHRAE Standard 37. Methods of testing for rating unitary air conditioning and heat pump equipment. American Society of Heating, Refrigerating and Air-Conditioning Engineers. Atlanta, GA.

Bryant, R. A., Particle Image Velocimetry Measurements of Buoyancy Induced Flow Through a Doorway, NISTIR 7252, National Institute of Standards and Technology, Gaithersburg, MD (2005).

Chwalowski, M., Didion, D. A., and Domanski, P. A. Verification of Evaporator Computer Models and Analysis of Performance of an Evaporator Coil, ASHRAE Transactions, Vol. 95, no. 1, 1987.

Domanski, P. A., Yashar, D. A., Kaufman, K. A. and Michalski, RK. An Optimized Design of Finned-Tube Evaporators Using the Learnable Evolution Model HVAC\&R Research April 01, 2004.

Domanski, P.A., 2007, EVAP-COND - Simulation models for finned-tube heat exchangers, Version 2.2, National Institute of Standards and Technology, Gaithersburg, MD, USA. http://www2.bfrl.nist.gov/software/evap-cond/

Durst, F., Melling, A. and Whitelaw, J.H., Principles and Practice of Laser Doppler Anemometry, Academic Press Inc., New York, NY, 1976.

ESI Group, Guidelines for Specification of Turbulence at Inflow Boundaries, ESI Group CFD Customer Portal, http://support.esi-cfd.com/esi-users/turb_parameters/, March 2007.

ESI Group, Momentum Resistance or Source, CFD-ACE+ V2006 User Manual, pp 133138, 2005.

IEC 60825-1, Safety of Laser Products - Part I: Equipment Classification and Requirements. International Electrotechnical Commission, Geneva, Switzerland (2007).

Lemmon, E.W., Huber, M.L., McLinden, M.O. NIST Standard Reference Database 23:

Reference Fluid Thermodynamic and Transport Properties-REFPROP, Version 8.0, National Institute of Standards and Technology, Standard Reference Data Program, Gaithersburg, 2007.

Payne, W. V. and Domanski, P. A. Potential Benefits of Smart Refrigerant Distributors (ARTI-21CR/605-200-50-01; 196 p.) January 01, 2003.

Seitzman, J. M.; Hanson, R. K. (1993). Planar Fluorescence Imaging in Gases, in Taylor, A. M. K. P.: Instrumentation for Flows with Combustion. Academic Press, pp. 405-466.

Taylor, B. N. and Kuyatt, C. E. Guidelines for Evaluating and Expressing the Uncertainty of NIST Measurement Results, NIST Technical Note 1297, NIST, Gaithersburg, MD, (1994). 


\section{Appendix A: Pressure Drop Data for Flow Resistance Coefficients}

Table A.1. Data used to Determine Momentum Resistance Coefficients for Vertical Coil

\begin{tabular}{|c|c|c|c|}
\hline $\begin{array}{c}\text { Flow Rate } \\
{\left[\mathrm{m}^{3} / \mathrm{s}\right]}\end{array}$ & $\begin{array}{c}\text { Pressure Drop } \\
{[\mathrm{Pa}]}\end{array}$ & $\begin{array}{c}\text { Average Velocity } \\
{[\mathrm{m} / \mathrm{s}]}\end{array}$ & $\begin{array}{c}\text { Pressure Gradient } \\
{[\mathrm{Pa} / \mathrm{m}]}\end{array}$ \\
\hline 0.3658 & 49.569 & 1.767 & 780.609 \\
\hline 0.2799 & 32.382 & 1.352 & 509.946 \\
\hline 0.1652 & 15.942 & 0.798 & 251.050 \\
\hline 0.4200 & 63.019 & 2.029 & 992.433 \\
\hline 0.3011 & 37.363 & 1.454 & 588.399 \\
\hline 0.3384 & 44.836 & 1.635 & 706.079 \\
\hline 0.1935 & 21.422 & 0.935 & 337.349 \\
\hline 0.2270 & 25.158 & 1.097 & 396.189 \\
\hline 0.4672 & 71.239 & 2.257 & 1121.881 \\
\hline 0.2454 & 27.898 & 1.185 & 439.338 \\
\hline
\end{tabular}

Table A.2. Data used to Determine Momentum Resistance Coefficients for Slant Coil

\begin{tabular}{|c|c|c|c|}
\hline $\begin{array}{c}\text { Flow Rate } \\
{\left[\mathrm{m}^{3} / \mathrm{s}\right]}\end{array}$ & $\begin{array}{c}\text { Pressure Drop } \\
{[\mathrm{Pa}]}\end{array}$ & $\begin{array}{c}\text { Average Velocity } \\
{[\mathrm{m} / \mathrm{s}]}\end{array}$ & $\begin{array}{c}\text { Pressure Gradient } \\
{[\mathrm{Pa} / \mathrm{m}]}\end{array}$ \\
\hline 0.6183 & 123.466 & 3.1032 & 1899.475 \\
\hline 0.2549 & 31.883 & 1.279182 & 490.5135 \\
\hline 0.2973 & 40.426 & 1.492379 & 626.5544 \\
\hline 0.3681 & 54.725 & 1.847707 & 841.9205 \\
\hline 0.5239 & 101.529 & 2.629429 & 1561.979 \\
\hline 0.1652 & 16.684 & 0.829099 & 256.6765 \\
\hline 0.4366 & 70.273 & 2.191191 & 1081.123 \\
\hline 0.5663 & 112.090 & 2.842626 & 1724.462 \\
\hline 0.3351 & 47.833 & 1.681887 & 735.8853 \\
\hline 0.2737 & 35.084 & 1.373936 & 539.7565 \\
\hline
\end{tabular}


Table A.3. Data used to Determine Momentum Resistance Coefficients for A-Shaped Coil

\begin{tabular}{|c|c|c|c|}
\hline $\begin{array}{c}\text { Flow Rate } \\
{\left[\mathrm{m}^{3} / \mathrm{s}\right]}\end{array}$ & $\begin{array}{c}\text { Pressure Drop } \\
{[\mathrm{Pa}]}\end{array}$ & $\begin{array}{c}\text { Average Velocity } \\
{[\mathrm{m} / \mathrm{s}]}\end{array}$ & $\begin{array}{c}\text { Pressure Gradient } \\
{[\mathrm{Pa} / \mathrm{m}]}\end{array}$ \\
\hline 0.4776 & 28.583 & 1.1572 & 409.22 \\
\hline 0.6612 & 51.853 & 1.6017 & 742.34 \\
\hline 0.3511 & 16.300 & 0.8504 & 233.37 \\
\hline 0.1506 & 3.579 & 0.3646 & 51.26 \\
\hline 0.4012 & 20.806 & 0.9715 & 297.89 \\
\hline 0.4460 & 24.971 & 1.0805 & 357.50 \\
\hline 0.2855 & 11.807 & 0.6921 & 169.04 \\
\hline 0.2313 & 7.687 & 0.5598 & 110.04 \\
\hline 0.5394 & 36.198 & 1.3060 & 518.23 \\
\hline 0.6088 & 45.850 & 1.4739 & 656.39 \\
\hline
\end{tabular}




\section{Appendix B. Uncertainty Analysis}

The uncertainty analysis of the PIV based measurements is presented in this appendix. This analysis is based on the guidelines adopted by NIST [Taylor and Kuyatt, 1994]; whereas two components of uncertainty are presented, statistically based Type A uncertainty and judgment based Type B uncertainty.

\section{B.1 Type A Uncertainty}

Type A uncertainty is based on the variation of repeated measurement results. In this study, we obtained the steady-state components of the flow velocity by capturing many instantaneous measurements within a turbulent flow field and averaging the resultant vector fields.

We acquired 100 image pairs for each data point so that the transient effects of turbulent flow would be dampened out and would not influence the data. We used each pair of images to compute a vector field representative of the instantaneous flow velocity distribution. We then computed the average of the 100 vectors at each location within the vector field. Therefore, each computed steady-state vector within each data file was computed by averaging 100 vectors that were captured through independent measurements. Therefore, the measurement uncertainty of each vector obtained through this method is equal to the standard deviation of the measured values of that vector, $\sigma$, divided by the square root of the number of samples, 10 .

Each data set consists of 100 data files and each data file consists of several hundred or in some cases several thousand vectors, therefore it is not feasible to include the uncertainty for each individual vector. Therefore, tables B.1.1 through B.1.3 show the average Type A uncertainty calculated for each data file from the results within each data set. The $\mathrm{x}$ and y- component values and standard deviations are shown, but the uncertainty is calculated for the vector lengths. Since the y- component of velocity is generally much smaller than the x-component due to the layout of the test apparatus, the y-component uncertainty is much greater compared to the measured values, but this is not very significant to the overall result. Overall, the type A uncertainty was small, typically in the range of $0.1 \%$. 
Table B.1.1 Type A Uncertainty for Vertical Coil

\begin{tabular}{|c|c|c|c|c|c|c|c|c|}
\hline & \multicolumn{2}{|c|}{$\mathrm{x}$-component } & \multicolumn{2}{|c|}{ y-component } & \multicolumn{4}{|c|}{ Vector length } \\
\hline $\begin{array}{c}\text { File } \\
\text { name }\end{array}$ & $\begin{array}{c}\text { Average } \\
{[\mathrm{m} / \mathrm{s}]}\end{array}$ & $\begin{array}{c}\text { Standard } \\
\text { Deviation } \\
{[\mathrm{m} / \mathrm{s}]} \\
\end{array}$ & $\begin{array}{c}\text { Average } \\
{[\mathrm{m} / \mathrm{s}]}\end{array}$ & $\begin{array}{c}\text { Standard } \\
\text { Deviation } \\
{[\mathrm{m} / \mathrm{s}]} \\
\end{array}$ & $\begin{array}{c}\text { Average } \\
{[\mathrm{m} / \mathrm{s}]}\end{array}$ & $\begin{array}{c}\text { Standard } \\
\text { Deviation } \\
{[\mathrm{m} / \mathrm{s}]} \\
\end{array}$ & $\begin{array}{c}\text { Vector } \\
\text { Length } \\
\text { Uncertainty } \\
{[\mathrm{m} / \mathrm{s}]} \\
\end{array}$ & $\begin{array}{c}\text { Vector } \\
\text { Length } \\
\text { Uncertainty } \\
{[\%]} \\
\end{array}$ \\
\hline 230-I & 1.3929 & 0.1151 & 0.0818 & 0.1758 & 1.4070 & 0.1128 & 0.0011 & 0.0802 \\
\hline 230-II & 1.1561 & 0.1776 & 0.1438 & 0.1908 & 1.2289 & 0.1700 & 0.0017 & 0.1384 \\
\hline 230-III & 1.1016 & 0.1272 & 0.1053 & 0.1755 & 1.1502 & 0.1132 & 0.0011 & 0.0984 \\
\hline 230-IV & 1.1560 & 0.1649 & 0.0515 & 0.1872 & 1.2010 & 0.1365 & 0.0014 & 0.1137 \\
\hline $300-\mathrm{I}$ & 1.3968 & 0.1790 & 0.1577 & 0.1673 & 1.4164 & 0.1773 & 0.0018 & 0.1252 \\
\hline $300-$ II & 1.3111 & 0.1675 & 0.1469 & 0.1865 & 1.3111 & 0.1675 & 0.0017 & 0.1278 \\
\hline 300-III & 1.2838 & 0.1405 & 0.1080 & 0.2202 & 1.3131 & 0.1342 & 0.0013 & 0.1022 \\
\hline 300-IV & 0.8757 & 0.2021 & 0.0356 & 0.1469 & 0.9494 & 0.1859 & 0.0019 & 0.1958 \\
\hline $360-\mathrm{I}$ & 1.3897 & 0.1967 & 0.1813 & 0.1922 & 1.4150 & 0.2006 & 0.0020 & 0.1418 \\
\hline 360-II & 1.3177 & 0.1796 & 0.2538 & 0.2412 & 1.3656 & 0.1768 & 0.0018 & 0.1294 \\
\hline 360-III & 1.3211 & 0.1117 & 0.2181 & 0.2510 & 1.3631 & 0.1151 & 0.0012 & 0.0844 \\
\hline 360-IV & 1.2723 & 0.1245 & 0.1742 & 0.1628 & 1.2962 & 0.1262 & 0.0013 & 0.0974 \\
\hline 405-I & 1.3223 & 0.1589 & 0.1345 & 0.1791 & 1.3420 & 0.1578 & 0.0016 & 0.1176 \\
\hline 405-II & 1.2634 & 0.1313 & 0.2850 & 0.2163 & 1.3122 & 0.1458 & 0.0015 & 0.1111 \\
\hline 405-III & 1.2861 & 0.1318 & 0.3020 & 0.2927 & 1.3519 & 0.1505 & 0.0015 & 0.1113 \\
\hline 405-IV & 1.2464 & 0.1440 & 0.1972 & 0.2192 & 1.2821 & 0.1434 & 0.0014 & 0.1119 \\
\hline $450-\mathrm{I}$ & 1.0156 & 0.2313 & 0.0169 & 0.1788 & 1.0488 & 0.1862 & 0.0019 & 0.1776 \\
\hline $450-$ II & 1.0613 & 0.1469 & 0.3730 & 0.2103 & 1.1424 & 0.1699 & 0.0017 & 0.1487 \\
\hline 450-III & 1.1136 & 0.1577 & 0.4667 & 0.2652 & 1.2349 & 0.1754 & 0.0018 & 0.1420 \\
\hline 450-IV & 1.0247 & 0.1652 & 0.3018 & 0.2263 & 1.0927 & 0.1784 & 0.0018 & 0.1633 \\
\hline
\end{tabular}


Table B.2 Type A Uncertainty for Slant Coil

\begin{tabular}{|c|c|c|c|c|c|c|c|c|}
\hline & \multicolumn{2}{|c|}{$\mathrm{x}$-component } & \multicolumn{2}{|c|}{ y-component } & \multicolumn{4}{|c|}{ Vector length } \\
\hline $\begin{array}{c}\text { File } \\
\text { name }\end{array}$ & $\begin{array}{c}\text { Average } \\
{[\mathrm{m} / \mathrm{s}]}\end{array}$ & $\begin{array}{c}\text { Standard } \\
\text { Deviation } \\
{[\mathrm{m} / \mathrm{s}]}\end{array}$ & $\begin{array}{c}\text { Average } \\
{[\mathrm{m} / \mathrm{s}]}\end{array}$ & $\begin{array}{c}\text { Standard } \\
\text { Deviation } \\
{[\mathrm{m} / \mathrm{s}]}\end{array}$ & $\begin{array}{c}\text { Average } \\
{[\mathrm{m} / \mathrm{s}]}\end{array}$ & $\begin{array}{c}\text { Standard } \\
\text { Deviation } \\
{[\mathrm{m} / \mathrm{s}]}\end{array}$ & $\begin{array}{c}\text { Vector } \\
\text { Length } \\
\text { Uncertainty } \\
{[\mathrm{m} / \mathrm{s}]}\end{array}$ & $\begin{array}{c}\text { Vector } \\
\text { Length } \\
\text { Uncertainty } \\
{[\%]} \\
\end{array}$ \\
\hline 215-I & 1.9411 & 0.1407 & 0.0497 & 0.1582 & 1.9518 & 0.1435 & 0.0014 & 0.0735 \\
\hline 215-II & 1.9369 & 0.1275 & -0.0225 & 0.1806 & 1.9479 & 0.1252 & 0.0013 & 0.0643 \\
\hline 215-III & 1.8006 & 0.1358 & -0.0713 & 0.2212 & 1.8187 & 0.1314 & 0.0013 & 0.0722 \\
\hline 215-IV & 1.6783 & 0.1395 & -0.2678 & 0.1984 & 1.7151 & 0.1227 & 0.0012 & 0.0715 \\
\hline 280-I & 2.0045 & 0.1658 & 0.2800 & 0.1587 & 2.0322 & 0.1760 & 0.0018 & 0.0866 \\
\hline 280-II & 1.9052 & 0.1397 & 0.1375 & 0.2215 & 1.9254 & 0.1457 & 0.0015 & 0.0757 \\
\hline 280-III & 1.7559 & 0.1809 & 0.0032 & 0.2117 & 1.7711 & 0.1792 & 0.0018 & 0.1012 \\
\hline 280-IV & 1.1442 & 0.0994 & -0.1671 & 0.1486 & 1.1683 & 0.0855 & 0.0009 & 0.0731 \\
\hline $340-\mathrm{I}$ & 1.8991 & 0.1614 & 0.1642 & 0.1871 & 1.9168 & 0.1716 & 0.0017 & 0.0895 \\
\hline 340-II & 1.9604 & 0.1561 & 0.1999 & 0.2874 & 1.9917 & 0.1706 & 0.0017 & 0.0857 \\
\hline 340-III & 1.7211 & 0.1995 & 0.0289 & 0.3129 & 1.7545 & 0.1966 & 0.0020 & 0.1121 \\
\hline 340-IV & 1.6491 & 0.1284 & -0.1095 & 0.1830 & 1.6654 & 0.1225 & 0.0012 & 0.0735 \\
\hline 380-I & 1.8613 & 0.1399 & 0.1906 & 0.1801 & 1.8817 & 0.1468 & 0.0015 & 0.0780 \\
\hline 380-II & 1.9874 & 0.1725 & 0.2419 & 0.2423 & 2.0181 & 0.1849 & 0.0018 & 0.0916 \\
\hline 380-III & 1.8932 & 0.1251 & 0.2017 & 0.2417 & 1.9197 & 0.1401 & 0.0014 & 0.0730 \\
\hline 380-IV & 1.6154 & 0.2155 & 0.0738 & 0.1956 & 1.6388 & 0.2053 & 0.0021 & 0.1253 \\
\hline 420-I & 1.6699 & 0.1639 & 0.1768 & 0.2109 & 1.6955 & 0.1676 & 0.0017 & 0.0989 \\
\hline 420-II & 1.7761 & 0.2024 & 0.1900 & 0.3671 & 1.8289 & 0.2134 & 0.0021 & 0.1167 \\
\hline $420-$ III & 1.7634 & 0.1717 & 0.3102 & 0.3024 & 1.8192 & 0.1994 & 0.0020 & 0.1096 \\
\hline 420-IV & 1.0610 & 0.1415 & 0.0690 & 0.1685 & 1.1219 & 0.1459 & 0.0015 & 0.1301 \\
\hline
\end{tabular}

Table B.3 Type A Uncertainty for A-Shaped Coil

\begin{tabular}{|c|c|c|c|c|c|c|c|c|}
\hline & \multicolumn{2}{|c|}{$\mathrm{x}$-component } & \multicolumn{2}{|c|}{$\mathrm{y}$-component } & \multicolumn{4}{|c|}{ Vector length } \\
\hline $\begin{array}{c}\text { File } \\
\text { name }\end{array}$ & $\begin{array}{c}\text { Average } \\
{[\mathrm{m} / \mathrm{s}]}\end{array}$ & $\begin{array}{c}\text { Standard } \\
\text { Deviation } \\
{[\mathrm{m} / \mathrm{s}]}\end{array}$ & $\begin{array}{c}\text { Average } \\
{[\mathrm{m} / \mathrm{s}]}\end{array}$ & $\begin{array}{c}\text { Standard } \\
\text { Deviation } \\
{[\mathrm{m} / \mathrm{s}]}\end{array}$ & $\begin{array}{c}\text { Average } \\
{[\mathrm{m} / \mathrm{s}]}\end{array}$ & $\begin{array}{c}\text { Standard } \\
\text { Deviation } \\
{[\mathrm{m} / \mathrm{s}]}\end{array}$ & $\begin{array}{c}\text { Vector } \\
\text { Length } \\
\text { Uncertainty } \\
{[\mathrm{m} / \mathrm{s}]}\end{array}$ & $\begin{array}{c}\text { Vector } \\
\text { Length } \\
\text { Uncertainty } \\
{[\%]} \\
\end{array}$ \\
\hline 270-I & 5.2304 & 0.1400 & -0.0681 & 0.1910 & 5.2615 & 0.1381 & 0.0014 & 0.0262 \\
\hline 270-II & 4.8501 & 0.2144 & -0.0500 & 0.2765 & 4.8586 & 0.2136 & 0.0021 & 0.0440 \\
\hline 270-III & 4.2874 & 0.1656 & -0.1538 & 0.1373 & 4.2963 & 0.1634 & 0.0016 & 0.0380 \\
\hline $340-\mathrm{I}$ & 4.9038 & 0.2278 & -0.2294 & 0.1968 & 4.9213 & 0.2227 & 0.0022 & 0.0452 \\
\hline 340-II & 4.7701 & 0.2739 & -0.0870 & 0.2831 & 4.7819 & 0.2711 & 0.0027 & 0.0567 \\
\hline 340-III & 3.8374 & 0.1737 & -0.1007 & 0.1201 & 3.8488 & 0.1705 & 0.0017 & 0.0443 \\
\hline $400-\mathrm{I}$ & 5.6473 & 0.2687 & -0.2317 & 0.2364 & 5.6865 & 0.2631 & 0.0026 & 0.0463 \\
\hline 400-II & 4.1773 & 0.3210 & -0.2296 & 0.2720 & 4.2112 & 0.3213 & 0.0032 & 0.0763 \\
\hline 400-III & 4.2832 & 0.2603 & -0.0292 & 0.2017 & 4.2925 & 0.2582 & 0.0026 & 0.0602 \\
\hline $420-\mathrm{I}$ & 5.6321 & 0.2969 & -0.2062 & 0.2944 & 5.6752 & 0.2899 & 0.0029 & 0.0511 \\
\hline $420-$ II & 3.9877 & 0.3056 & -0.0643 & 0.2193 & 4.0187 & 0.3037 & 0.0030 & 0.0756 \\
\hline 420-III & 2.3433 & 0.3143 & 0.0776 & 0.1443 & 2.3622 & 0.3175 & 0.0032 & 0.1344 \\
\hline
\end{tabular}




\section{B.2 Type B Uncertainty}

Type B uncertainty is based on scientific judgment of factors such as knowledge of the materials and instruments used for the measurements. There are a number of factors in these measurements that introduce some uncertainty under this category. The measurement uncertainty due to the pixel resolution is the only significant contributor. For this reason, we tabulated the type B uncertainty in tables B.2.1 through B.2.3 below based on the pixel resolution induced measurement uncertainty. The quoted accuracy of the pixel displacement measurement was $1 / 10$ of a pixel; therefore our uncertainty is based on the pixel size and the time difference between image pulses for each data set.

The type B uncertainty is much larger than the type A. The type B uncertainty was generally better than $2 \%$, except for the A-shaped coil which is better than $3.5 \%$; due to the very short time between measurement pulses. The combined uncertainty is calculated from the type A and type B uncertainty by taking the square root of the sum of the squares of both elements. Since the type B uncertainty is typically on the order of 20 times larger than the type A, it may be regarded as the combined uncertainty for the PIV measurements.

Table B.2.1 Type B Uncertainty for Vertical Coil

\begin{tabular}{|c|c|c|c|c|c|}
\hline File name & Pixel size $[\mu \mathrm{m}]$ & $\Delta \mathrm{t}[\mu \mathrm{s}]$ & Uncertainty [m/s] & Average Velocity [m/s] & Uncertainty [\%] \\
\hline 230-I & 144.0070 & 600.0000 & 0.0240 & 1.4070 & 1.7059 \\
\hline 230-II & 142.5820 & 600.0000 & 0.0238 & 1.2289 & 1.9337 \\
\hline 230-III & 143.5070 & 600.0000 & 0.0239 & 1.1502 & 2.0794 \\
\hline 230-IV & 144.4690 & 600.0000 & 0.0241 & 1.2010 & 2.0049 \\
\hline $300-I$ & 133.5240 & 600.0000 & 0.0223 & 1.4164 & 1.5712 \\
\hline 300-II & 133.8830 & 600.0000 & 0.0223 & 1.3111 & 1.7020 \\
\hline 300-III & 134.8860 & 600.0000 & 0.0225 & 1.3131 & 1.7120 \\
\hline 300-IV & 133.7570 & 600.0000 & 0.0223 & 0.9494 & 2.3482 \\
\hline 360-I & 124.8390 & 600.0000 & 0.0208 & 1.4150 & 1.4704 \\
\hline 360-II & 125.0060 & 600.0000 & 0.0208 & 1.3656 & 1.5256 \\
\hline 360-III & 125.9380 & 600.0000 & 0.0210 & 1.3631 & 1.5398 \\
\hline 360-IV & 126.1230 & 600.0000 & 0.0210 & 1.2962 & 1.6218 \\
\hline 405-I & 118.4470 & 600.0000 & 0.0197 & 1.3420 & 1.4710 \\
\hline 405-II & 118.1370 & 600.0000 & 0.0197 & 1.3122 & 1.5005 \\
\hline 405-III & 119.7800 & 600.0000 & 0.0200 & 1.3519 & 1.4767 \\
\hline 405-IV & 119.4940 & 600.0000 & 0.0199 & 1.2821 & 1.5534 \\
\hline $450-\mathrm{I}$ & 111.4030 & 600.0000 & 0.0186 & 1.0488 & 1.7703 \\
\hline $450-\mathrm{II}$ & 111.9020 & 600.0000 & 0.0187 & 1.1424 & 1.6326 \\
\hline 450-III & 112.1290 & 600.0000 & 0.0187 & 1.2349 & 1.5133 \\
\hline $450-I V$ & 112.9860 & 600.0000 & 0.0188 & 1.0927 & 1.7233 \\
\hline
\end{tabular}


Table B.2.2 Type B Uncertainty for Slant Coil

\begin{tabular}{|c|c|c|c|c|c|}
\hline File name & Pixel size $[\mu \mathrm{m}]$ & $\Delta \mathrm{t}[\mu \mathrm{s}]$ & Uncertainty [m/s] & Average Velocity [m/s] & Uncertainty [\%] \\
\hline 215-I & 140.7780 & 380.0000 & 0.0370 & 1.9518 & 1.8981 \\
\hline 215-II & 141.2010 & 380.0000 & 0.0372 & 1.9479 & 1.9076 \\
\hline 215-III & 140.8150 & 380.0000 & 0.0371 & 1.8187 & 2.0376 \\
\hline 215-IV & 141.5020 & 380.0000 & 0.0372 & 1.7151 & 2.1711 \\
\hline 280-I & 130.6460 & 380.0000 & 0.0344 & 2.0322 & 1.6918 \\
\hline 280-II & 131.0110 & 380.0000 & 0.0345 & 1.9254 & 1.7907 \\
\hline 280-III & 130.9060 & 380.0000 & 0.0344 & 1.7711 & 1.9451 \\
\hline 280-IV & 131.4700 & 380.0000 & 0.0346 & 1.1683 & 2.9612 \\
\hline $340-\mathrm{I}$ & 123.3160 & 380.0000 & 0.0325 & 1.9168 & 1.6930 \\
\hline 340-II & 124.1210 & 380.0000 & 0.0327 & 1.9917 & 1.6399 \\
\hline 340-III & 123.8820 & 380.0000 & 0.0326 & 1.7545 & 1.8581 \\
\hline 340-IV & 122.9480 & 380.0000 & 0.0324 & 1.6654 & 1.9428 \\
\hline $380-\mathrm{I}$ & 117.6620 & 380.0000 & 0.0310 & 1.8817 & 1.6455 \\
\hline 380-II & 116.7120 & 380.0000 & 0.0307 & 2.0181 & 1.5219 \\
\hline 380-III & 117.0930 & 380.0000 & 0.0308 & 1.9197 & 1.6051 \\
\hline 380-IV & 117.2730 & 380.0000 & 0.0309 & 1.6388 & 1.8832 \\
\hline $420-\mathrm{I}$ & 111.0150 & 380.0000 & 0.0292 & 1.6955 & 1.7230 \\
\hline $420-\mathrm{II}$ & 112.1460 & 380.0000 & 0.0295 & 1.8289 & 1.6137 \\
\hline 420-III & 112.2220 & 380.0000 & 0.0295 & 1.8192 & 1.6234 \\
\hline 420-IV & 111.8570 & 380.0000 & 0.0294 & 1.1219 & 2.6239 \\
\hline
\end{tabular}

Table B.2.3 Type B Uncertainty for A-Shaped Coil

\begin{tabular}{|c|c|c|c|c|c|}
\hline File name & Pixel size $[\mu \mathrm{m}]$ & $\Delta \mathrm{t}[\mu \mathrm{s}]$ & Uncertainty $[\mathrm{m} / \mathrm{s}]$ & Average Velocity $[\mathrm{m} / \mathrm{s}]$ & Uncertainty [\%] \\
\hline 270-I & 150.2650 & 100.0000 & 0.1503 & 5.2615 & 2.8559 \\
\hline $270-$ II & 152.4970 & 100.0000 & 0.1525 & 4.8586 & 3.1387 \\
\hline 270-III & 150.2250 & 100.0000 & 0.1502 & 4.2963 & 3.4966 \\
\hline $340-\mathrm{I}$ & 141.0440 & 100.0000 & 0.1410 & 4.9213 & 2.8660 \\
\hline $340-\mathrm{II}$ & 139.4970 & 100.0000 & 0.1395 & 4.7819 & 2.9172 \\
\hline 340-III & 140.7580 & 100.0000 & 0.1408 & 3.8488 & 3.6572 \\
\hline $400-\mathrm{I}$ & 133.4910 & 100.0000 & 0.1335 & 5.6865 & 2.3475 \\
\hline $400-\mathrm{II}$ & 131.6150 & 100.0000 & 0.1316 & 4.2112 & 3.1254 \\
\hline $400-\mathrm{III}$ & 132.1700 & 100.0000 & 0.1322 & 4.2925 & 2.0791 \\
\hline $420-\mathrm{I}$ & 130.0240 & 100.0000 & 0.1300 & 5.6752 & 3.2444 \\
\hline $420-\mathrm{II}$ & 130.3810 & 100.0000 & 0.1304 & 4.0187 & 5.4870 \\
\hline $420-\mathrm{III}$ & 129.6110 & 100.0000 & 0.1296 & 2.3622 & \\
\hline
\end{tabular}

